Illinois State University

ISU ReD: Research and eData

Theses and Dissertations

2-27-2018

\title{
Learning And Behavior In Hatchling Trachemys Scripta Exposed To Bisphenol-A During Embryonic Development
}

Justin E. Dillard

Illinois State University, jdillar@ilstu.edu

Follow this and additional works at: https://ir.library.illinoisstate.edu/etd

Part of the Biology Commons

\section{Recommended Citation}

Dillard, Justin E., "Learning And Behavior In Hatchling Trachemys Scripta Exposed To Bisphenol-A During Embryonic Development" (2018). Theses and Dissertations. 851.

https://ir.library.illinoisstate.edu/etd/851

This Thesis is brought to you for free and open access by ISU ReD: Research and eData. It has been accepted for inclusion in Theses and Dissertations by an authorized administrator of ISU ReD: Research and eData. For more information, please contact ISUReD@ilstu.edu. 


\title{
LEARNING AND BEHAVIOR IN HATCHLING TRACHEMYS SCRIPTA EXPOSED TO BISPHENOL-A DURING EMBRYONIC DEVELOPMENT
}

\author{
Justin E. Dillard
}

\section{Pages}

Steroids play an integral role in orchestrating embryonic development, and can affect a suite of phenotypic traits, including learning and memory. Endocrine disrupting compounds (EDCs) can mimic the effects of steroids and can affect the same suites of phenotypic traits during embryonic development. Bisphenol-A (BPA) is an EDC that mimics the action of estrogen, and recent work is beginning to implicate BPA in effects on learning and behavior similar to those caused by estrogen treatment studies. Red-eared slider turtles (Trachemys scripta) are a good system to investigate the effects of BPA on learning and behavior, both because the molecular underpinnings of the mechanistic action of BPA endocrine disruption are generally understood, and because maternal estrogens are limited to egg components allowing for controlled, intra-clutch treatment groups. We exposed T. scripta eggs to BPA during embryonic development, and tested hatchlings for effects on learning and behavior in modified T-mazes. Innate biases in arm choice during the training phase of the experiment limited our ability to assess learning. Time of day and day of experiment both had significant effects on behaviors we investigated, and we found no BPA treatment effects on behaviors. However, we found that hatchling turtles were highly individually repeatable in their behaviors. These repeatable behaviors varied between individual hatchlings, suggesting that there are discrete 
behavioral types in $T$. scripta hatchlings. The highly repetitive nature of behaviors might explain the innate biases that prevented us from examining learning with our experimental design.

KEYWORDS: Behavior; BPA; Learning; Turtle; Visualization 


\title{
LEARNING AND BEHAVIOR IN HATCHLING TRACHEMYS SCRIPTA EXPOSED TO BISPHENOL-A DURING EMBRYONIC DEVELOPMENT
}

\author{
JUSTIN E. DILLARD
}

A Thesis Submitted in Partial Fulfillment of the Requirements for the Degree of

\section{MASTER OF SCIENCE}

School of Biological Sciences

\section{ILLINOIS STATE UNIVERSITY}


(C) 2018 Justin E. Dillard 
LEARNING AND BEHAVIOR IN HATCHLING TRACHEMYS SCRIPTA EXPOSED TO BISPHENOL-A DURING EMBRYONIC DEVELOPMENT

\author{
JUSTIN E. DILLARD
}

COMMITTEE MEMBERS:

Rachel M. Bowden, Chair

Scott K. Sakaluk

Joseph M. Casto 


\section{ACKNOWLEDGMENTS}

I have many people to thank for my time at Illinois State. First, I would like to thank my committee chair, Dr. Rachel Bowden, for her mentorship, expertise, grant support, summer employment, and laboratory opportunities. I am also grateful to Dr. Scott Sakaluk and Dr. Joseph Casto for their advisory input, mentorship, and friendly camaraderie serving on my thesis advisory committee.

Next, I am thankful to the members of the Bowden laboratory whose time and efforts contributed to completion of my research and degree requirements. Dr. Amanda Carter and Dr. Ryan Paitz were both instrumental in my project: for statistical analysis, repeated mechanism explanations, mentorship, and countless revisions. Sarah Palackdharry, M.S., and Lisa Triedel, M.S., were both extremely helpful in the field components of our laboratory research, and in the coursework side of my master's program. I am indebted to the wonderful Bowden lab undergraduate assistants Haley Nichols and Dani Short for their tireless efforts in assisting in video scoring.

I would be remiss to neglect mentioning my close friends and family, whose love and support made this undertaking possible. Whether it be moral support in times of stress, or casually unwinding over beers; there are too many to name here, but I am forever thankful for your time and accompaniment.

Last and certainly not least, I would never have been able to finish this program without the tireless support of my loving wife Caitlin. Facing parenthood for this first time with you, within the constraints of starting a master's degree, was a daunting, rewarding, and strengthening experience for me, and your support was paramount.

J. E. D. 


\section{CONTENTS}

Page

ACKNOWLEDGMENTS

$\begin{array}{ll}\text { CONTENTS } & \text { ii }\end{array}$

TABLES

FIGURES

CHAPTER I: INTRODUCTION 1

Endocrine Disrupting Compounds $\quad 1$

Bisphenol-A 2

Bisphenol-A acts as an Exogenous Estrogen 3

Bisphenol-A Exposure and Behavior $\quad 4$

Bisphenol-A Exposure and Learning 5

$\begin{array}{ll}\text { Trachemys scripta } & 7\end{array}$

Maternal Estrogens and Trachemys scripta $\quad 7$

Behavior in Trachemys scripta $\quad 8$

Learning in Trachemys scripta 9

CHAPTER II: LEARNING AND BEHAVIOR IN HATCHLING TRACHEMYS SCRIPTA

EXPOSED TO BISPHENOL-A DURING EMBRYONIC DEVELOPMENT 13

$\begin{array}{ll}\text { Abstract } & 13\end{array}$

$\begin{array}{ll}\text { Introduction } & 14\end{array}$

$\begin{array}{ll}\text { Methods } & 18\end{array}$

$\begin{array}{ll}\text { Egg Collection, Dosing, and Incubation } & 18\end{array}$

Behavioral Arenas 19 
$\begin{array}{ll}\text { Pilot Reward Stimulus Study } & 19\end{array}$

$\begin{array}{ll}\text { Experimental Procedures } & 20\end{array}$

$\begin{array}{ll}\text { Training Period } & 20\end{array}$

$\begin{array}{ll}\text { Learning Period } & 21\end{array}$

Arm Choice and Quantification of Activity-related Behaviors 21

Data Visualization in Python® 22

Learning Analyses $\quad 22$

Analysis of Treatment and Time Effects on Behavior 22

Analysis of Trial of Day and Treatment on the Probability of Activity 23

$\begin{array}{ll}\text { Cluster Analysis of Behaviors } & 24\end{array}$

$\begin{array}{ll}\text { Results } & 24\end{array}$

$\begin{array}{ll}\text { Learning Experiment } & 24\end{array}$

Treatment and Time Effects on Behavior across Days of the Experiment 25

Treatment and Time Effects on Behavior across Trials within Day 25

Frequency of Inactivity $\quad 26$

Behavioral Cluster Analysis $\quad 26$

$\begin{array}{ll}\text { Discussion } & 26\end{array}$

$\begin{array}{ll}\text { REFERENCES } & 31\end{array}$

APPENDIX A: BEHAVIORAL DATA VISUALITAZION PLOTS 50

APPENDIX B: PILOT STUDY OF REWARD STIMULII 80 


\section{TABLES}

Table

Page

1. Favored Choices in the Training and Learning Periods of the Experiment

2. Time and Treatment Effects on Behavior across Days of the Experiment

3. Time and Treatment Effects on Behavior across Trials within Day

4. Treatment and Trial of the Day Effects on the Number of Inactive Turtles 


\section{FIGURES}

Figure $\quad$ Page

1. Modified T-maze Arena 43

2. Shelter Reward Stimulus within T-maze Arena 44

3. Post-hoc Comparisons for Effects of the Day of the Experiment on Behavior 45

4. Post-hoc Comparisons for Effects of the Trial of the Day on Behavior 46

5. Post-hoc Comparisons of the Probability of Inactivity for each Trial of the Day 47

6. Behavioral Cluster Designations 48

7. Average Behavioral Scores for each Cluster 49 


\section{CHAPTER I: INTRODUCTION}

\section{Endocrine Disrupting Compounds}

Endocrine disrupting compounds (EDCs) are chemicals that have been shown to adversely affect the endocrine environment of developing and adult organisms. There are many different families of EDCs that include, but are not limited to, polychlorinated biphenyls such as Aroclor (Safe, 1993), organochlorides such as DDT (Li et al. 2008), phthalates such as Camphor (Gray et al. 2000), dioxins such as polychlorinated dibenzo-p-dioxins (Safe, 1993), natural estrogens such as soybean phytoestrogens (Herman et al. 1995), and diphenylmethanes such as bisphenol-A (Norris \& Carr, 2005). These synthetic and natural EDCs are found in the environment and are referred to as environmental endocrine disruptors. Environmental endocrine disruptors are of increasing importance to study, because they can affect wildlife and human populations in ways that we do not yet fully understand.

Endocrine disrupting compounds generally disrupt normal endocrine function by mimicking natural hormones, with their primary mode of action being to bind to the respective receptors of the natural hormone(s) that the EDC mimics (Saili et al. 2012). This disruption of normal endocrine signaling can cause a wide array of effects, including infertility (Giwercman, 2011), brain feminization (Kuhl \& Brouwer, 2006), learning disabilities (Kim et al. 2011), and even social disorders such as autism (Miodovnik et al. 2011). Research on endocrine disruption has demonstrated a variety of effects, but it is important to note that any one endocrine disruptor can have different effects on various organisms, or even at different concentrations on the same organism (Segner et al. 2002, Welshons et al. 2006). 


\section{Bisphenol-A}

One environmental EDC that has been extensively studied is bisphenol-A (BPA). BPA was first synthesized in 1891 (Wolstenholme, 2011), and is currently used in the production of polycarbonate plastics (such as polyvinyl chloride), dental sealants, thermal printing paper for receipts, and epoxy. Roughly 1.7 billion pounds of BPA are synthesized each year in the USA alone (Vom Saal et al. 2007).

BPA is nearly ubiquitous in our world. It has been reported that over $92.6 \%$ of the U.S. population have BPA in their urine (Calafat et al. 2008), and BPA has even been documented in free-living polar bear tissues (Skaare, 2001), indicating that this compound is persistent in the environment and has great potential to disperse widely from its point of origin. Given the widespread distribution of BPA, it is concerning that we are only beginning to understand the implications of this compound.

The dose of BPA that wild animals or humans experience is another aspect of BPA research that deserves attention. Traditional toxicology studies typically look at lethal doses of contaminants, or glaringly obvious physiological malformations following high concentration exposure (Schwetz et al. 1973). Newer research on EDCs, however, is beginning to look at the non-lethal, long-term effects of exposure at low concentrations that are more similar to exposures experienced in the environment (Welshons et al. 2006).

These ecologically relevant doses are important to study to help us understand the effects that current environmental concentrations of BPA may be causing in humans and wildlife. With respect to conducting studies at ecologically relevant doses, research on BPA has determined the predicted safe dose to humans to be $50 \mu \mathrm{g} / \mathrm{kg} / \mathrm{day}$, which is calculated based on the reported lowest observed adverse effect level for BPA of $50 \mathrm{mg} / \mathrm{kg}$ (Morrissey et al. 1987, Palanza et al. 
2002). Studies that demonstrate effects following exposure to concentrations below these reference doses, but within ecologically relevant concentrations, raise questions about the validity of using the current lowest observed adverse effect level of BPA exposure as a metric for health and safety (Welshons et al. 2006).

\section{Bisphenol-A acts as an Exogenous Estrogen}

Bisphenol-A is a xenoestrogen, meaning it is an endocrine disrupting compound that specifically mimics estrogen. The estrogenic properties of BPA were accidentally discovered in 1993 when Krishnan et al. (1993) reported unexpected estrogenic secretions from Saccharomyces cerevisiae yeast. Upon further investigation, the authors discovered that these estrogenic properties were not coming from the S. cerevisiae, nor the medium in which the yeast samples were growing. Rather, the estrogenic action was coming from chemicals leached from the polycarbonate culture flasks during autoclaving. Upon further investigation, they reported that the exogenous BPA competed with $[3 \mathrm{H}]$ estradiol to bind to their experimental in vitro estrogen receptors (Krishnan et al. 1993).

This finding is in line with the proposed, although debated, mechanism of action of other xenoestrogens, which interact with the estrogen receptor (ER). Xenoestrogenic effects of other EDCs include infertility, reproductive organ malformations, and cancers in estrogenincorporated tissues (Gould et al. 1998). Bisphenol-A has been known to bind to one isoform of the estrogen receptor, ER- $\alpha$, which implies that the estrogenic effects of BPA exposure could be partially explained by BPA binding to the ER (Gould et al. 1998, Rajapakse et al. 2002). This is a complicated issue, however, because studies have also shown that estradiol has a 10,000 to 100,000-fold higher affinity to bind to ER- $\alpha$ than does BPA; yet we still see BPA eliciting 
adverse reproductive effects despite having a lower binding affinity for ER- $\alpha$ (Wolstenholme et al. 2011).

Work on the mechanistic actions of BPA suggests that xenoestrogens, including BPA, disrupt endocrine function by some additional mechanism other than strict ER agonism. Two alternatives could be either that BPA inhibits estradiol metabolism, or that BPA induces estradiol production. In a recent study, incubating Trachemys scripta eggs that werere dosed with exogenous BPA exhibited lower levels of estrone sulfate and higher levels of free estrogens than did eggs that were dosed with a control estradiol treatment, suggesting that estradiol was not being metabolized (Clairardin et al. 2013). This study demonstrated in ovo that BPA exposure resulted in the former of the two proposed alternatives of xenoestrogen activity - specifically, that BPA inhibits the metabolism of maternal estradiol into estrone sulfate (Clairardin et al. 2013).

\section{Bisphenol-A Exposure and Behavior}

Bisphenol-A has been shown to affect brain development in embryos (Ausó et al. 2004, Nakamura et al. 2006, Saili et al. 2012). These effects prompted the National Toxicology Program in 2008 to advise increased research efforts to explore the potential effects of BPA on brain development and behavior in children (Calafat et al. 2009). While it is important to understand the effects of BPA exposure on specific regions of the brain, this goal is ultimately outside the scope of this thesis. Equipped with the growing understanding that BPA exposure affects brain development, it follows that BPA could then have indirect effects on behavior, with significant impacts on survival and fitness of organisms. Indeed, there is a variety of research demonstrating the effects of BPA on behavior including maternal behaviors and hyperactivity. 
A recent study examined larval hyperactivity in zebrafish when treated with ecologically relevant concentrations of BPA. Increased larval hyperactivity in both BPA-treated and estrogen related receptor gamma (ERR $\gamma)$ agonist-treated zebrafish was reported (Saili et al. 2012). ERR $\gamma$ is important for brain development, and changes in larval behavior may be further evidence of BPA exposure affecting brain development and, indirectly, behavior. These results are consistent with other published results demonstrating increased anxiety and hyperactivity in rats and mice (Palanza et al. 2002, Nakamura et al. 2012).

\section{Bisphenol-A Exposure and Learning}

It is reasonable to conclude from the evidence of BPA affecting brain development that BPA exposure may also cause learning deficits, as it is known that estrogens are important for the development of regions of the brain required for learning such as the mammalian hippocampus and reptilian dorsal cortex (Blau \& Powers 1989, Kim et al. 2011). Much like other behavioral studies, studies that have examined learning in BPA treated individuals shed light on how BPA might disrupt of the endocrine environment. Initial studies have shown that effects on learning are present (Kim et al. 2011, Jašarević et al. 2013), although the role that BPA plays in impacting learning on a physiological level remains to be fully understood. Bisphenol-A has been proposed to interrupt neurogenesis within the hippocampus, a brain region involved in memory and spatial navigation. Thus the hippocampus might be a reasonable brain region to investigate learning deficits of the brain.

Adult mice were treated with up to $20 \mathrm{mg} / \mathrm{kg}$ BPA (within the "no observed adverse effect" limit) and subsequent histology was performed on their brains. The authoors report that BPA treated individuals showed decreased hippocampal neurogenesis, and impaired 
performance on a spatial memory task, the Morris water maze (Kim et al. 2011). All mice showed a decrease in maze completion times as trials progressed. However, there were significantly longer latencies to maze completion in BPA-treated mice compared to controls. Low dose BPA mice also swam farther distances before completing the maze. BPA treatments did not affect swim speed, suggesting that motor deficits were not the explanation for increased latencies, but instead that BPA was acting on the learning ability of the mice (Kim et al. 2011). Exploratory behaviors and spatial learning have also been assessed in wood mice, Peromyscus maniculatus bairdii, exposed to BPA. For spatial learning experiments the authors utilized a Barnes maze, which is a circular maze setup with 12 different escape holes, one of which led to the mouse's home cage. A visual cue in the form of a particular shape (circle, square, triangle, or star) was assigned to that mouse's home cage hole. The shape always indicated the correct hole, but all other aspects of the maze were altered between trials. Control (untreated) males were the quickest to learn the most efficient navigation strategy, where they navigate directly to their home cage. Males given low and high doses of BPA exhibited significantly worse maze learning. Female mice in this study showed no differences in maze learning between treatments, although the authors propose a possible explanation is that they used gonadally-intact females that were also experiencing cycles in ovarian hormone concentrations (Jašarević et al. 2013).

Learning to navigate a T-maze has also been assessed in adult zebrafish that were exposed to BPA as larvae. If a fish chose the incorrect arm of the $\mathrm{T}$, it received a mild shock and the trial was reset. When compared to sex-matched control groups, both sexes of BPA treated fish required significantly more trials to meet the learning criterion of 3 consecutive correct arm choices (Saili et al. 2012). 
Collectively, evidence supports the hypothesis that exposure to ecologically-relevant BPA concentrations can impair learning in mammals and fishes. Further examination of learning and behavior following exposure to BPA in other clades of animals is needed to better understand the effects that exposure to BPA elicits on wildlife and humans.

\section{Trachemys scripta}

Trachemys scripta is a widespread North American turtle species that has been introduced to all continents other than Antarctica, and thus may serve as a bioindicator of EDC action worldwide (Matsumoto et al. 2014). T. scripta has three representative subspecies within the continental United States; T. s. scripta (the yellow-bellied slider), T.s. troostii (the Cumberland slider), and T.s. elegans (the red-eared slider) (Ernst \& Lovich 2009). T. scripta has temperature-dependent sex determination (TSD), where incubation temperatures experienced during a critical window of development (the temperature-sensitive period, or TSP) determine offspring sex.

\section{Maternal Estrogens and Trachemys scripta}

The role that maternal estrogens play during embryonic development of $T$. scripta embryos is an important foundation to understanding the action, and implications, of EDCs in $T$. scripta embryos. We know that early in embryonic development, prior to the TSP, T. scripta eggs have relatively high levels of maternal estradiol in the yolk, and relatively low levels of estrone sulfate (a metabolic product of estradiol) in the embryo (Paitz et al. 2012). As embryonic development progresses through the TSP (roughly the middle third of development), levels of maternal estradiol in the yolk decrease, as levels of estrone sulfate in the embryo increase (Paitz 
et al. 2012). However, we also know that exposure to BPA during early development inhibits metabolism of maternal estrogens in the T. scripta embryo (Clairardin et al. 2013). By using $T$. scripta as a study organism, it allows us to simultaneously examine the effects of BPA on gonadal development due to the interactions between steroid hormone function and temperature, but also to examine effects of an estrogenic EDC on other aspects of the phenotype.

\section{Behavior in Trachemys scripta}

Trachemys scripta provide some unique benefits as subjects of behavioral studies in contrast to more conventional behavioral study species. First, as has been discussed above, the role of maternal estrogens in T. scripta embryonic development has been well-studied. This allows for studies of $T$. scripta to test for behavioral effects following endocrine manipulations in which the mechanism of endocrine action is understood, ultimately allowing for a clearer picture of the phenotypic implications of metabolic challenges in ovo. We also know that T. scripta has TSD, which adds another level of experimental control in behavioral studies, as any desired ratio of hatchlings from a clutch can be created by controlling incubation temperatures. We also know that the extent of maternal effects in T. scripta is limited to egg components and nest site location, as the females offer no further maternal care to their offspring. This is important in behavioral studies, as post-natal maternal effects have been shown to impact offspring behavior above and beyond prenatal effects (Carlier et al. 1983).

The most commonly studied behavior in T. scripta is the righting response, where a turtle is placed upside-down on their carapace and observed for various metrics, including the period of inactivity a turtle spends before beginning to right, and the amount of time from being overturned to righting (Ashe 1970). The righting response of T. scripta and other turtles is 
commonly used as an indirect measure of fitness, as righting is important for surviving dispersal from the natal nest (Delmas et al. 2007). Righting behavior is sensitive to various treatments, including exogenous steroids and incubation temperature (Freedberg et al. 2004, MicheliCampbell 2011). Righting behavior is also repeatable in T. scripta, where individual performance in one trial can help to predict performance in subsequent trials (Carter et al. 2016).

Other behaviors have also been assessed in T. scripta, including simulated nest dispersal, exploration within a laboratory arena, courtship and sexual behavior, basking, and locomotion (Cash \& Holberton 1999, Thomas et al. 1999, Cadi \& Joly 2003, Carter et al. 2016). There are two main points to gather from these studies for the purposes of this thesis. First, we know that T. scripta can be assessed in a laboratory setting for more "complex" behaviors than righting trials. Second, we know from recent work in our laboratory that T. scripta behavior is not only repeatable, but we also know that hatchlings exhibit behavioral types - whereby hatchlings show consistency in their behaviors across contexts and there is variation in the types of behaviors expressed (Carter et al. 2016).

\section{Learning in Trachemys scripta}

The capacity for learning has been demonstrated in various freshwater turtle species. The earliest report of this finding comes from R. M. Yerkes (1901), who investigated "labyrinth" (i.e. maze) trials in the spotted turtle, Clemmys guttata. He showed that over repeated trials the turtle $(n=1)$ improved the time it required to reach the end of the labyrinth (Yerkes 1901). Other laboratories have also tested cognition in several other freshwater turtle species, including $T$. scripta (Eskin \& Bitterman 1961, Murillo et al. 1961, Wise \& Gallagher, 1964, Pert \& Bitterman 1970, Morlock 1972, Cranney \& Powers 1983, Davis \& Burghardt 2007). 
Some of the visual projections of the reptilian brain ultimately terminate in a region of the telencephalon known as the dorsal cortex (Hall \& Ebner 1970), which prompted initial studies of this brain region to investigate visual perception in reptiles. In one of these studies, lesions of the dorsal cortex of $T$. scripta were conducted, and habituation to a looming stimulus (a ball swinging on a rope toward the turtle) was observed. Head retraction from turtles with lesions occurred more frequently, i.e. they habituated to the stimulus more slowly (Killackey et al. 1972). The authors reasoned that any perturbation of the visual system would likely decrease head retraction, and hypothesized that the dorsal cortex was involved in more than just visual processing. This study was important for identifying the brain region most responsible for learning and memory in reptiles, the dorsal cortex (Powers 1990).

Lesion studies of the dorsal cortex took a new direction, focusing on learning. The first of these studies examined spatial memory by utilizing a discrimination assay for a food reward, where turtles were trained to choose the correct "alley" of the apparatus, similar to a T-maze (Morlock 1972). Lesioned turtles met learning criterion of 9 correct alley choices in 10 trials after an average of 75.5 trials, whereas controls required an average of 60.5 trials. This was an initial, promising report for the importance of the reptilian dorsal cortex in learning and memory, although statistical analysis was not conducted on the discrimination data (Morlock 1972).

Further studies in dorsal cortex-ablated turtles were conducted to investigate the function of this brain region in reptilian cognition. One such study investigated pattern discrimination in Chrysemys picta, where the investigators trained C. picta pre-operatively to discriminate between horizontal and vertical patterns. On one wall of their trial arena two response keys were situated on either side of a revolving disc that served to produce a food reward for the turtles. Projectors produced images of the two patterns onto the response keys, so that one key was the 
horizontal stripes and the other displayed vertical stripes. Latency to a pre-operative criterion was recorded, and then lesions to the dorsal cortex were conducted. After lesions, all animals were re-evaluated on their latency to criterion. Interestingly, 6 of the 7 subjects retained information on how to complete the discrimination task (i.e. met criterion faster) (Reiner \& Powers 1983). These results suggest that the dorsal cortex is important to reptiles for learning, but not memory (retention).

The aforementioned ablation studies provide evidence that the dorsal cortex is responsible for learning visual discrimination in turtles, as damage to the dorsal cortex creates deficits in visual discrimination tasks. Spatial navigation has been investigated to see whether the dorsal cortex is also responsible for spatial learning. In this study, a T-maze was used to investigate spatial navigation in lesioned C. picta (Avigan \& Powers 1995). Prior to lesions, subjects were required to meet criterion of $2 / 3$ successful trials on 2 consecutive days. Once the pre-operational criterion was met, lesions were conducted, and latency to an identical criterion was recorded in a novel spatial navigation task, an X-maze. This was done in order to study lesions in animals that previously learned a spatial navigation task. Lesions caused individuals to take significantly longer to reach criterion in the new maze when compared to control animals (Avigan \& Powers, 1995).

The dorsal cortex is not the only area of the reptilian brain that has been found to be important for learning. The basal forebrain of reptiles contains cholinergic neurons that project to the cortex, indicating that the basal forebrain communicates with the cortex (Bruce \& Butler 1984). An alternative hypothesis that the previously observed learning impairments were perhaps due to damage to these cells (i.e. that the forebrain projections to the cortex were destroyed) was investigated. In this study, basal forebrain lesions were used to investigate the importance of the 
basal forebrain in turtle cognition. A similar pattern discrimination arena was used as in the Reiner \& Powers (1983) study. Following pre-operational criterion, ablations of either the dorsal cortex or the basal forebrain were conducted. As with the dorsal cortex, ablations to the basal forebrain lead to deficits in learning a pattern discrimination task (Grisham \& Powers 1989). While these studies are contradictory in suggesting the pertinent reptilian brain region for learning, both studies have demonstrated impairments to learning following ablation. Estrogen receptors have been demonstrated to be present in both of these regions of the turtle brain (Mak et al. 1982).

As has now been demonstrated in $T$. scripta and related species, turtles certainly have the capacity to learn both visual discrimination and spatial navigation tasks. The literature presented above also suggests that regions of the turtle brain with present ERs have been implicated in reptilian learning and memory. We know from our laboratory that developing T. scripta exposed to BPA will experience atypical levels of estrogens during embryonic development (Clairardin et al. 2013), so it is possible that these areas may be altered during development from embryonic exposure to BPA. Investigating learning in BPA exposed individuals may indicate that there is a permanent effect in the brain following just a single exposure during embryonic development. This would then warrant future investigation of reptilian brain region development following embryonic exposure to BPA and other EDCs. As we know, mammalian and fish brains are not identical to that of the reptile (Kesner 1990), so this information could also shed light on comparative brain development (e.g. by investigating learning) following endocrine disruption. In the present study, I sought to investigate the effects of embryonic exposure to BPA, by assessing learning and behavior in T. scripta hatchlings exposed to BPA in ovo. 


\title{
CHAPTER II: LEARNING AND BEHAVIOR IN HATCHLING TRACHEMYS SCRIPTA EXPOSED TO BISPHENOL-A DURING EMBRYONIC DEVELOPMENT
}

\begin{abstract}
Steroids play an integral role in orchestrating embryonic development, and can affect a suite of phenotypic traits, including learning and memory. Endocrine disrupting compounds (EDCs) can mimic the effects of steroids and can affect the same suites of phenotypic traits during embryonic development. Bisphenol-A (BPA) is an EDC that mimics the action of estrogen, and recent work is beginning to implicate BPA in effects on learning and behavior similar to those caused by estrogen treatment studies. Red-eared slider turtles (Trachemys scripta) are a good system to investigate the effects of BPA on learning and behavior, both because the molecular underpinnings of the mechanistic action of BPA endocrine disruption are generally understood, and because maternal estrogens are limited to egg components allowing for controlled, intra-clutch treatment groups. We exposed $T$. scripta eggs to BPA during embryonic development, and tested hatchlings for effects on learning and behavior in modified T-mazes. Innate biases in arm choice during the training phase of the experiment limited our ability to assess learning. Time of day and day of experiment both had significant effects on behaviors we investigated, and we found no BPA treatment effects on behaviors. However, we found that hatchling turtles were highly individually repeatable in their behaviors. These repeatable behaviors varied between individual hatchlings, suggesting that there are discrete behavioral types in $T$. scripta hatchlings. The highly repetitive nature of behaviors might explain the innate biases that prevented us from examining learning with our experimental design.
\end{abstract}




\section{Introduction}

Steroids play an integral role in orchestrating embryonic development (Guillette et al. 1995), and can elicit permanent phenotypic effects on a developing embryo, otherwise known as organizational effects (Phoenix et al. 1959). There are many important phenotypic traits subject to the organizing effects of steroids, including body condition, fertility, and behavior (Phoenix et al. 1959, Feder \& Whalen 1965, Matamoros et al. 1991, Mably et al. 1992, Lubahn et al. 1993, Guillette et al. 1995, Wilson 1999). One particularly important group of steroids during development are the estrogens. Estrogens influence the development of secondary sexual characteristics, behavior, sex determination in some species, brain development, and learning (Feder \& Whalen 1965, Dohanich 2002, Ryan \& Vandenbergh 2002, McCarthy 2008).

The ability to learn novel tasks can be impacted by exposure to estrogens during embryonic development (reviewed by Daniel 2006). There are two main bodies of evidence to support the importance of estrogens in learning. First, we know that treatment of embryos with estrogens alters the development of brain regions important for learning, including the mammalian hippocampus (Gould 1990). Second, it has been demonstrated that exposure to estrogens during embryonic development can lead to impairment or enhancement of spatial maze tasks (navigational tasks for acquisition of a reward stimulus or avoidance of a negative stimulus) when assessed later in life, highlighting the importance of embryonic estrogens for developing navigational behaviors (Dohanich 2002).

Organizational effects of estrogens on developing embryos are essential for development. Estrogens acting on the embryo can be derived from the mother (transported across the placenta in placental vertebrates, or via egg components in oviparous amniotes), or synthesized via the developing embryo in the gonad or brain (Holloway \& Clayton 2001, McCarthy 2008, Paitz et 
al. 2012). It is critical for developing embryos to regulate their exposure to maternal estrogens, because of the suite of developmental effects estrogens can elicit. Estrogens act on the developing embryo by binding to and activating estrogen receptors (ERs). The brain and gonad are particularly rich in ERs, and it follows that developmental effects mediated by the gonad and brain are sensitive to estrogens. The importance of estrogens for development has been well studied. For example, sex differences in the developing rat hypothalamus are mediated by estrogens (Rhoda \& Roffi, 1984). Estrogen receptor-knockout mice are impaired in their spatial learning when compared to wild-type littermates (Rissman et al. 2002). Topical estrogen treatment of eggs can override the temperature-dependent method of sex determination present in some reptiles, resulting in females at a temperature that would otherwise produce males (Crews et al. 1991).

In addition to the natural maternal estrogens that an embryo encounters during normal development, there are also a growing number of synthetic estrogens that can impact development by mimicking natural estrogens, known endocrine disrupting compounds (EDCs). Since EDCs mimic the action of steroids, they can impact the functioning of the endocrine system (Guillette et al. 1995). Bisphenol-A (BPA), an estrogenic EDC, has been particularly well-studied because of its potential effects on human health, including developmental effects (Crain et al. 2007, Hong et al. 2013). BPA is a plasticizer used in the production of various polycarbonate plastics and epoxy resins, and is one of the most commonly produced chemicals in the world (U.S. Department of Health and Human Services, 2008). BPA has been detected in a wide variety of sources, including pollution from production runoff, sewage effluent, and landfill leachate (Skaare et al. 2001, Huang et al. 2012). BPA has a chemical structure that is similar to estradiol (Kwon et al. 2007), and can bind to the ER (Wolstenholme et al. 2011). 
BPA, like natural estrogens, also has the capacity to permanently affect learning later in life when individuals are exposed to the chemical during development (Palanza et al. 2002, Ryan \& Vandenbergh 2006, Saili et al. 2012). It has been implicated in effects on behavior including learning when administered during embryonic and perinatal development in rodent and fish models (Kubo et al. 2003, Xu et al. 2010, Kim et al. 2011, Saili et al. 2012, Kuwahara 2013). While it is thought that most organisms have some level of exposure to BPA (Skaare, 2001), whether it has similar effects on behavior and learning on other groups, such as reptiles, is unknown.

For several reasons, turtles are a good study system for investigating the phenotypic effects (such as learning) of estrogenic endocrine disruptors during embryonic development (such as BPA). First, the opportunity for females to influence their offspring via maternal effects are limited to egg components, nest site selection, and epigenetics - there are no post-oviposition maternal effects to control for as can occur in other vertebrates. Secondly, many turtles possess temperature-dependent sex determination, which has been the subject of intense developmental research (Bull \& Vogt 1979, Crews et al. 1991, Ewert et al. 1994). From this research, we’ve learned that estrogens play an important role in the sex determination of these species, and as a result, we know quite a bit about the regulation of maternal estrogens in ovo in turtles. Red-eared slider turtle (Trachemys scripta) eggs have maternal estradiol within the yolk, and estrone sulfate (a metabolic product of estradiol) in the embryo (Paitz et al. 2012). As embryonic development progresses, levels of maternal estradiol in the yolk decrease, as levels of estrone sulfate in the embryo increase (Paitz et al. 2012). As a result of its estrogen-sensitive sex determination, $T$. scripta has also become a model for research on estrogenic EDCs, like BPA. Traditionally, it was thought that BPA elicits its endocrine disrupting effects by binding the ER (Wolstenholme et 
al. 2011). Recent work in our laboratory has shed light on another mechanism by which BPA can elicit its estrogenic effects on developing embryos. BPA inhibits the metabolism of estradiol in ovo (Clairardin et al. 2013). T. scripta eggs exposed to BPA have higher levels of estradiol and lower levels of estrone sulfate than control eggs that were not treated with BPA. Therefore, it appears that BPA inhibits the metabolism of maternal estradiol, thereby eliciting estrogenic effects in the embryo as free estradiol in the egg binds to and activates estrogen receptors.

Although not a classic model system, a number of studies have investigated behavior in turtles, including dispersal (Carter et al. 2016), basking (Hammond et al. 1988), righting response (Freedberg et al. 2004), and foraging (Bjorndal 1980). Learning in turtles has also been investigated, dating back to the early 1900's (Yerkes 1901). The red-eared slider turtle (Trachemys scripta) and the closely related painted turtle (Chrysemys picta) have been shown to have the capacity for various forms of learning, including visual discrimination (Blau \& Powers 1989, Davis \& Burghardt 2012), spatial navigation (Yerkes 1901, Morlock 1972, Cranney \& Powers, 1983, Manshack et al. 2016), and even visual observation of behaviors performed in other turtles (Davis \& Burghardt, 2011). We know that several genera of pond turtles are capable of navigational learning, and that estrogen-sensitive regions of the brain are important for learning in turtles (Avigan \& Powers, 1995). Recent work investigated whether learning performance is impaired following embryonic exposure to BPA, due to the estrogenic properties of BPA (Manshack et al. 2016). Monitoring learning in hatchlings, as opposed to adults, has several practical benefits (e.g. shorter durations between egg exposure and hatchling assessment and smaller housing and arena requirements), but there is also ecological relevance to understanding hatchling learning. For example, turtle hatchlings dispersing from the natal nest 
must perform visual navigation based on polarized light cues in order to find bodies of water (Iverson et al. 2009).

As we begin to understand the mechanism of action of BPA on T. scripta embryos, it is also important to understand the phenotypic implications of this altered estrogenic environment for the embryo. Equipped with our knowledge that BPA can inhibit estrogen metabolism in the T. scripta embryo, we sought to investigate learning and behavior in $T$. scripta hatchlings exposed to BPA in ovo. To assess temporal changes in learning and behavior, we monitored hatchling T. scripta during multiple daily trials for 14 consecutive days. We ultimately sought to answer the question of how the early developmental endocrine environment affects learning and other behaviors in hatchling $T$. scripta, by testing two separate hypotheses: first, that $T$. scripta hatchlings have the capacity to learn a spatial memory task, and second, that embryonic exposure to BPA will affect the learning and behavior of hatchlings.

\section{Methods}

\section{Egg Collection, Dosing, and Incubation}

We collected 10 clutches $(\mathrm{n}=110$ eggs) of freshly laid $T$. scripta eggs from gravid females at Banner Marsh Fish and Wildlife Reserve (Glasford, IL) in June 2015. Gravid females were collected from baited hoop traps, and returned to the lab for oviposition following an oxytocin induction (Les et al. 2007). Within 24 hours of oviposition, eggs were given a topical bolus of $5 \mu$ l ethanol + treatment, as has been previously done in reptile steroid manipulation studies (Stoker et al. 2003, Clairardin et al. 2013). Egg treatment groups included BPA only

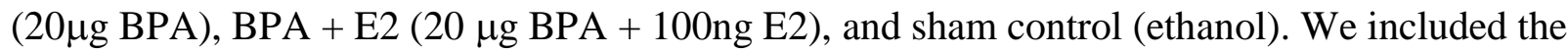
BPA + E2 group to test whether estradiol would affect behavior and learning. After treatment, 
eggs were incubated in boxes of moist vermiculite $(\sim-150 \mathrm{kPa})$ at a constant $28.5^{\circ} \mathrm{C}$ until hatching (Fisher Scientific, Hampton NH). Egg boxes were rotated within an incubator, and water was added weekly to maintain consistent hydric conditions. After hatching, all hatchlings $(\mathrm{n}=82)$ were kept in individual containers to preserve hatchling identification and to monitor feeding. Water was added to each individual container to prevent desiccation, and was changed at least weekly. Turtles were housed in a dark room separate from the room in which behavioral trials were conducted. The ambient temperatures of both rooms were between $23-26^{\circ} \mathrm{C}$ for the duration of the experiment. Studies were conducted following IACUC approved methods, and animals were collected under approval from the Illinois Department of Natural Resources.

\section{Behavioral Arenas}

To assess learning and behavior in hatchling turtles, we built modified T-mazes where an individual is placed in the starting well of the arena and tested for left or right arm choices. (Fig 1). Mazes were constructed with polyurethane to avoid additional BPA exposure, and were filled with water to encourage hatchling movement.

\section{Pilot Reward Stimulus Study}

We provided shelter as a reward stimulus in the form of a covered overhead end of one arm of the modified T-maze. Pilot data revealed that this shelter reward promoted hatchling movement better than various food reward stimuli (data not shown, but see Appendix B for more pilot study information). During pilot observations, we also found that 30-minute trial durations were sufficient for a majority of hatchlings to make an arm decision, and that 5 consecutive days of trials were sufficient to promote trial participation (i.e. movement) in a majority of the 
hatchlings used for this preliminary study. Based upon our initial findings, we constructed reduced size overhead shelters so that the shelter covered only a portion of the maze arm, and the shelter was not visible to the hatching until that arm was chosen (Fig 2). At the conclusion of the pilot study, we had 29 naïve hatchlings remaining for use in the experimental trials.

\section{Experimental Procedures}

We video recorded all hatchlings in the experimental group $(n=29)$ for ten 30-minute trials each day for 14 consecutive days. Behavioral arenas were filled with roughly $1 / 2 \mathrm{~cm}$ roomtemperature water. All trials were started in the same manner; hatchlings were moved from their individual containers into the starting arm and the trial began once they were released (Fig 1A). At the end of each trial, turtles were removed from the arenas and placed back into their individual containers for 5-10 minutes between trials. Trials were conducted between 8:00 and 17:00 each day, and hatchlings were tested in four 14-day cohorts between October 8, 2015 December 2, 2015.

\section{Training Period}

For the first five days (50 trials) of the experiment, a shelter reward was present in each arm of the arena for all hatchlings. This period of the experiment allowed turtles to habituate to the maze, to find the shelter reward at the end of the maze arms, to reduce inactivity before learning trials, and to assess any potential biases in arm choices in our post-hoc analysis. 


\section{Learning Period}

Upon completion of the training period, one shelter was removed at random for every hatchling such that each hatchling's arena had one arm containing a shelter (Fig 1B or Fig 1C) and one empty arm. The location of the shelter (right arm or left arm) was kept constant for that hatchling for the remainder of the experiment (nine days, 90 trials). This period of the experiment allowed us to test observed hatchling arm choices against our a priori learning criterion of 8 or more correct (i.e., shelter) arm choices for two consecutive days.

\section{Arm Choice and Quantification of Activity-related Behaviors}

All video files were scored with VLC media player (ver 2.2.1, VideoLAN) by individuals blind to treatment. Trial videos were first scored for decision data, where we recorded which arm a hatchling entered first for that trial, and the time of the trial at which this decision occurred. Training period trials were scored as right, left, or no decision (R, L, ND, respectively); learning period trials were scored as shelter, empty, or no decision (S, E, ND, respectively). Additional behavioral data was later scored from all trials. We recorded the time of the trial when each bout of activity started and ended, and whether the turtle ended the activity bout under a shelter or in an open area of the arena. For activity bout scoring, we defined 'activity' as movement about the arena, or attempted movement in cases such as climbing against the arena walls. Importantly, scoring these activity bouts and distinguishing the location where each bout ended allowed us to assess four behaviors: latency to first activity, activity, inactivity in the open arena (open), and time spent under the shelter (shelter). 


\section{Data Visualization in Python®}

In order to visualize within- and among-turtle temporal patterns of behavior, custom Python (ver 3.6) code was developed by G.D.O. to produce behavioral activity plots. All trials for each turtle were loaded into a NumPy (ver 1.11.1rc1) t x s dimensional array, where t was the total number of trials for that turtle, and s was the total number of seconds in each trial.

Matplotlib (ver 2.1.2) was used to process the NumPy array into behavioral activity plots. The color of each second in the plots corresponds to the turtles' current behavior, with yellow representing latency to first activity, red indicating activity, gray indicating open behavior, and blue denoting time spent under shelter, respectively (Appendix A). Behavioral data visualization plots were formatted for presentation with GIMP (ver 2.8.22).

\section{Learning Analyses}

Sums of right or left arm decisions across the training and learning periods were compared for designations of bias, and to compare favored arm choices between both periods (training and learning). Training period decisions were analyzed for side bias with a Chi square analysis, where we compared observed decisions against an expected equal distribution of right and left arm choices.

\section{Analysis of Treatment and Time Effects on Behavior}

When we conducted gross comparisons of the behavioral data visualization plots (Appendix A) for each turtle, we noticed patterns in behavior across the duration of the experiment, as well as within days of the experiment. To analyze these two temporal behavioral trends, we devised two separate time-average schemes to aggregate/condense our data, since we 
had significantly more samples per individual (560, i.e. 4 behaviors $* 140$ trials) than individual hatchlings (29). To summarize data across days of the experiment, we calculated the mean value of each behavior for each day of the experiment for each turtle. This day average allowed us to examine trends from the beginning to end of the 14 days of observation. Second, we summarized data across trials of the day, where we calculated the mean value of each behavior for the first trial of every day, the second trial of every day, and so on, for each turtle. This trial within day average allowed us to examine trends of behavior across the daily assay period of observation for each individual. All analyses were conducted in SAS (ver 9.4), and all tests were held to an $\alpha$ of 0.05. Where applicable, we transformed data to meet the assumptions of normality and homoscedasticity.

We tested for treatment and time effects on behavior with 8 separate repeated measures mixed model analyses of variance (PROC MIXED) for each combination of behaviors (latency to first activity, activity, inactivity in the open, and time spent under shelter) and time factor (day of the experiment or trial within day).we ran repeated measures ANOVAs, with treatment and time included as main effects, and clutch and individual ID nested within clutch as random effects. In all eight ANOVAs, the interaction of treatment and time was not significant and the F value was $<1$, and therefore removed from the model. Post-hoc comparisons were corrected with Tukey's HSD.

\section{Analysis of Trial of Day and Treatment on the Probability of Activity}

In order to assess whether there was a difference in the number of turtles that were active across the 10 trials within a day, we analyzed binary activity data $(0=$ inactive for that trial, $1=$ active for that trial) using a generalized linear mixed model (PROC GLIMMIX). The response 
variable was the number of active turtles/the number of turtles run in a trial (for example, if 21 turtles were active in a trial, a response variable of 21/29 was used for that trial). We included treatment, trial of the day, and their interaction in the model as well as the random effect of clutch. The model specified a logit link function and a binomial distribution. Post-hoc comparisons were conducted with Tukey's HSD.

\section{Cluster Analysis of Behaviors}

In order to describe similarities in behavior among turtles to examine potential behavioral types, we utilized a cluster analysis (PROC CLUSTER) with Wards minimum variance method. We only compared the average of each behavior (latency to first activity, activity, inactivity in the open, and time spent under shelter) during the training period, in order to avoid potential biases of shelter removal in the learning period. To estimate the appropriate number of clusters, we utilized cubic clustering criterion, Pseudo-F statistics, Pseudo-t statistics, and approximate expected R-square values.

\section{Results}

\section{Learning Experiment}

Although it was one of our initial goals, we were unable to assess learning because we detected strong, innate side biases in the hatchlings. We found that 9 of our experimental turtles had a significant arm bias across the training period when we tested observed R:L arm choice distributions to an expected 50:50 distribution (cases are denoted with an asterisk in Table 1). When comparing turtles by their most frequent choices in the training and learning periods

(Table 1$)$, we found that 11 of our experimental turtles $(\diamond$, Table 1$)$ maintained the same most 
frequent arm choice from the training period into the learning period. Further, we found that 6 of these hatchlings ( $\dagger$, Table 1$)$ favored the empty arm in the learning period. Simply put, hatchlings were meeting our a priori learning criteria of 8 or more correct arm choices in two days during the training period, which prohibited an assessment of learning for all turtles.

\section{Treatment and Time Effects on Behavior across Days of the Experiment}

Egg dosing treatments did not affect any hatchling behavior, when behavioral scores were averaged across the entire experiment by day (Table 2). All four behaviors varied significantly across days of the experiment (Table 2). On average, activity generally decreased as the experiment progressed (Fig 3A). As we predicted, shelter utilization (Fig 3B) increased through the training period (days 1-5). Open behavior generally increased as the experiment progressed (Fig 3C). As we also predicted, latency to first activity decreased through the training period (Fig 3D). We found that behaviors significantly varied among individuals, and that individual explained more of the variance than did clutch (Table 2, covariance parameters).

\section{Treatment and Time Effects on Behavior across Trials within Day}

Egg dose treatment did not affect any hatchling behavior, when averaged across trials within a day. Latency to first activity, shelter, and activity varied significantly across trials of the day (Table 3). Activity and shelter behaviors (Fig 4A, Fig 4B, respectively) were significantly lower in the middle of the day. Open behavior was statistically indistinguishable across trials of the day (Fig 4C). Latency to first activity (Fig 4D) was significantly higher in the middle of the day. As in the day of experiment analysis, behaviors significantly varied among individuals and individual explains more of the variance than does clutch (Table 3, covariance parameters). 


\section{Frequency of Inactivity}

The number of turtles that were inactive in a given trial within a day was not significantly affected by treatment and varied across trial (Table 4). Specifically, we found that more turtles were inactive in the middle trials of the day (Fig 5).

\section{Behavioral Cluster Analysis}

Estimates revealed four behavioral clusters based on average training period behaviors. When we plot the average latency to first activity against the average shelter score for each hatchling, the behavioral clusters can be visualized (Fig 6), however it is important to note that these behavioral clusters are based on the data from all four behaviors. After cluster designation, we averaged training period behavioral scores for each cluster (Fig 7). From these average training period behavioral scores, the suite of preferred behaviors for each cluster is apparent. Cluster 1 (Fig 7A) turtles demonstrated a combination of moderate latency to first activity and shelter utilization. Cluster 2 (Fig 7B) turtles demonstrated shelter behavior more frequently than any other behavior. Cluster 3 (Fig 7C) turtles displayed latency to first activity more frequently than any other behavior. Cluster 4 (Fig 7D) turtles did not demonstrate one behavior more frequently than any other, however this cluster demonstrated more open behavior than any other cluster.

\section{Discussion}

In this study we set out to examine learning and behavior in hatchling T. scripta exposed to BPA during embryonic development. We found no treatment effects on any of the behaviors 
we tested; however, we did find significant effects of time on behavior. We unexpectedly found that individual hatchlings were highly repeatable in their "preferred" behavioral repertoires, in that individual turtles behaved consistently throughout the experiment both in their individual behavioral repertoires and preferred arm choices. In fact, we found that hatchlings were so repeatable in their behaviors that we were not able to test learning as several hatchlings displayed strong, innate side biases that persisted throughout the training and learning trials. Several hatchlings conserved their favored arm choice through the learning period even in cases where that bias led them to an empty arm. While the innate biases in hatchling arm choices was unexpected and warrants further investigation, our experimental design that consisted of a large number of trials helped us to uncover this bias; running fewer trials in one day might have led us to conclude that more turtles had met an arm choice criterion, rather than that they had a side bias. Nonetheless, this eliminated us from assessing learning in this study, as individual hatchlings were more likely to follow their side bias than to follow the reward stimulus.

This study is the first to our knowledge to attempt to assess learning in turtles across a more rigorous trial schedule of multiple consecutive trials and days. Future studies of learning in turtles should take our results into account — as many learning studies assess performance in a single trial per day (Avigan \& Powers 1995, Manshack et al. 2016). Assessing learning across multiple trials per day and multiple consecutive days allows for a better understanding of changes in behavior, and also allows for a more conservative learning criterion.

We did not find any effect of BPA or estradiol on behavior, and this may have resulted from the metabolism of BPA and estradiol during during development. Our laboratory has recently demonstrated that BPA delays the metabolism of yolk estradiol (Clairardin et al. 2013) and estrone (Paitz \& Bowden, 2015). Although this inhibition of estrogen metabolism is present, 
perhaps the delayed metabolism of estrogens still does not result in enough maternal estrogens or BPA reaching the embryo to elicit organizational effects. In fact, our laboratory has demonstrated that turtle hatchling behavioral types are not affected by other developmental manipulations (Carter et al. 2016). Thus it appears that developing T. scripta embryos may be somewhat buffered from the effects of maternal steroids and environmental chemicals as it pertains to behavior and learning.

Contrary to the lack of treatment effects on behavior, we found significant effects of time of day and day of experiment on behavior. Across days of the experiment we found significant effects of time on each behavior. Latency to first activity decreased and shelter use increased, as the training period progressed. These results do suggest the hatchlings habituated, although our original learning criterion was not developed to investigate habituation apart from a strict correct/incorrect arm choice criterion.

Open behavior generally increased and activity generally decreased as the experiment progressed. These trends in open behavior and activity might be due to hatchlings becoming complacent in trial completion. Alternatively, the hatchlings may have simply become more comfortable in the apparatus after several "uneventful" trails.

Across trials of the day, we found significant effects of time of day on latency to first activity, activity, and shelter. Across trials of the day, there were no time effects on open behavior. Within a day, latency to first activity was highest in the middle trials of the day. Additionally, shelter use and activity were lowest during intermediate trials of the day. It is again important to highlight the value of assessing behaviors across multiple trials in one day, for multiple consecutive days. As is demonstrated here, behaviors change across a day, and across multiple days, suggesting that perhaps the time of the day that trials are conducted is important 
for behavior. For example, in our study there were more inactive turtles in the middle trials of the day. It appears that this pattern of inactivity drove the pattern of behavior across trials of the day, as average latency to first activity increased during the same trials that shelter and activity decreased. Further studies are needed to better understand this pattern of inactivity, and will perhaps elucidate whether time of day dictates activity.

Our cluster analysis of average training period behavioral scores produced clusters of hatchlings that behaved similarly to one another, and differently from other clusters of hatchlings. Individuals exhibiting consistent behavioral differences, otherwise known as a behavioral type, was an unexpected result. Our finding of behavioral types in the experimental hatchlings based on their training period behaviors corroborate previous assessments of behavioral types in turtle hatchlings (Carter et al. 2016) and in adults (Kashon \& Carlson 2018). In our study, treatment group did not correlate to behavioral type designation. While we did not have specific predictions about behavioral type in this study, our cluster analysis suggests there are four behavioral types based on behavioral scores in the training period. The strength of our dataset, stemming from the large volume of repeated trials per individual, further supplements our behavioral type analysis. The analysis of behavioral types in hatchling behavioral repertoires corroborates recent work that specifically demonstrates turtle hatchlings show persistent behavioral tendencies when reassessed at a different age/season (Carter et al. 2016). This potential for behavioral correlation across contexts, otherwise known as a behavioral syndrome, is a growing field of study in behavioral ecology (Sih et al. 2004). An individual's behavioral type has obvious fitness consequences, which further highlights the significance of this field of study. For example, an aggressive individual would be expected to be more successful in a 
context in which resources are limited. A 'shy' individual, in turn, might be more successful in a context in which predation is a more important factor than resource availability (Sih et al. 2004). In summary, we did not find any direct treatment effects on behaviors in our analysis of hatchling T. scripta exposed to BPA during embryonic development. We found consistent individual behaviors regardless of embryonic treatments. Further, we found patterns in hatchling behavior across and within days of the experiment. Together, these findings support the further use of turtle hatchlings in future behavioral assessments. 


\section{REFERENCES}

Ashe, V. M. (1970). The righting reflex in turtles: a description and comparison. Psychonomic Science, 20(3), 150-152.

Ausó, E., Lavado-Autric, R., Cuevas, E., del Rey, F. E., Morreale de Escobar, G., \& Berbel, P. (2004). A moderate and transient deficiency of maternal thyroid function at the beginning of fetal neocorticogenesis alters neuronal migration. Endocrinology, 145(9), 4037-4047.

Avigan, M. R., \& Powers, A. S. (1995). The effects of MK-801 injections and dorsal cortex lesions on maze learning in turtles (Chrysemys picta).Psychobiology, 23(1), 63-68.

Bjorndal, K. A. (1980). Nutrition and grazing behavior of the green turtle Chelonia mydas. Marine Biology, 56(2), 147-154.

Blau, A., \& Powers, A. S. (1989). Discrimination learning in turtles after lesions of the dorsal cortex or basal forebrain. Psychobiology, 17(4), 445-449.

Bruce, L. L., \& Butler, A. B. (1984). Telencephalic connections in lizards. I. Projections to cortex. Journal of Comparative Neurology, 229(4), 585-601.Cadi, A., \& Joly, P. (2003). Competition for basking places between the endangered European pond turtle (Emys orbicularis galloitalica) and the introduced red-eared slider (Trachemys scripta elegans). Canadian Journal of Zoology, 81(8), 1392-1398.

Bull, J. J., \& Vogt, R. C. (1979). Temperature-dependent sex determination in turtles. Science, 206(4423), 1186-1188.

Calafat, A. M., Ye, X., Wong, L. Y., Reidy, J. A., \& Needham, L. L. (2008). Exposure of the US population to bisphenol A and 4-tertiary-octylphenol: 2003-2004. Environmental health perspectives, 39-44.

Calafat, A. M., Weuve, J., Ye, X., Jia, L. T., Hu, H., Ringer, S., Huttner, K., \& Hauser, R. (2009). Exposure to bisphenol A and other phenols in neonatal intensive care unit premature infants. Environmental health perspectives, 117(4), 639.

Carlier, M., Roubertoux, P., \& Cohen-Salmon, C. (1983). Early development in mice: I. Genotype and post-natal maternal effects. Physiology \& behavior, 30(6), 837-844.

Carter, A. W., Paitz, R. T., McGhee, K. E., \& Bowden, R. M. (2016). Turtle hatchlings show behavioral types that are robust to developmental manipulations. Physiology \& behavior, $155,46-55$.

Cash, W. B., \& Holberton, R. L. (1999). Effects of exogenous corticosterone on locomotor activity in the red-eared slider turtle, Trachemys scripta elegans. The Journal of experimental zoology, 284(6), 637-644. 
Clairardin, S. G., Paitz, R. T., \& Bowden, R. M. (2013). In ovo inhibition of steroid metabolism by bisphenol-A as a potential mechanism of endocrine disruption. Proceedings of the Royal Society of London B: Biological Sciences, 280(1769), 20131773.

Crain, D. A., Eriksen, M., Iguchi, T., Jobling, S., Laufer, H., LeBlanc, G. A., \& Guillette, L. J. (2007). An ecological assessment of bisphenol-A: evidence from comparative biology. Reproductive toxicology, 24(2), 225-239.

Cranney, J., \& Powers, A. S. (1983). The effects of core nucleus and cortical lesions in turtles on reversal and dimensional shifting. Physiological Psychology, 11(2), 103-111.

Crews, D., Bull, J.J., Wibbels, T., 1991. Estrogen and sex reversal in turtles: a dose-dependent phenomenon. General and Comparative Endocrinology 81: 357-364

Daniel, J. M. (2006). Effects of oestrogen on cognition: what have we learned from basic research?. Journal of neuroendocrinology, 18(10), 787-795.

Davis, K. M., \& Burghardt, G. M. (2007). Training and long-term memory of a novel food acquisition task in a turtle (Pseudemys nelsoni). Behavioural processes, 75(2), 225-230.

Davis, K. M., \& Burghardt, G. M. (2011). Turtles (Pseudemys nelsoni) learn about visual cues indicating food from experienced turtles. Journal of Comparative Psychology, 125(4), 404.

Davis, K. M., \& Burghardt, G. M. (2012). Long-term retention of visual tasks by two species of emydid turtles, Pseudemys nelsoni and Trachemys scripta. Journal of Comparative Psychology, 126(3), 213.

Delmas, V., Baudry, E., Girondot, M., \& Prevot-Julliard, A. C. (2007). The righting response as a fitness index in freshwater turtles. Biological Journal of the Linnean Society, 91(1), 99109.

Dohanich, G. P. (2002). Gonadal steroids, learning and memory. Hormones, brain and behavior, $1,265-327$.

Ernst, C. H., \& Lovich, J. E. (2009). Turtles of the united states and Canada. JHU Press.

Eskin, R. M., \& Bitterman, M. E. (1961). Partial reinforcement in the turtle. Quarterly Journal of Experimental Psychology, 13(2), 112-116.

Ewert, M. A., Jackson, D. R., \& Nelson, C. E. (1994). Patterns of temperature-dependent sex determination in turtles. Journal of Experimental Zoology Part A: Ecological Genetics and Physiology, 270(1), 3-15.

Feder, H. H., \& Whalen, R. E. (1965). Feminine behavior in neonatally castrated and estrogentreated male rats. Science, 147(3655), 306-307. 
Freedberg, S., Stumpf, A. L., Ewert, M. A., \& Nelson, C. E. (2004). Developmental environment has long-lasting effects on behavioural performance in two turtles with environmental sex determination. Evolutionary Ecology Research, 6(5), 739-747.

Giwercman, A. (2011). Estrogens and phytoestrogens in male infertility. Current opinion in urology, 21(6), 519-526.

Gould, E., Woolley, C. S., Frankfurt, M., \& McEwen, B. S. (1990). Gonadal steroids regulate dendritic spine density in hippocampal pyramidal cells in adulthood. The Journal of Neuroscience, 10(4), 1286-1291.

Gould, J. C., Leonard, L. S., Maness, S. C., Wagner, B. L., Conner, K., Zacharewski, T., Safe, S., McDonnell, D.P., \& Gaido, K. W. (1998). Bisphenol A interacts with the estrogen receptor $\alpha$ in a distinct manner from estradiol. Molecular and cellular endocrinology, 142(1), 203-214.

Gray, L. E., Ostby, J., Furr, J., Price, M., Veeramachaneni, D. R., \& Parks, L. (2000). Perinatal exposure to the phthalates DEHP, BBP, and DINP, but not DEP, DMP, or DOTP, alters sexual differentiation of the male rat. Toxicological Sciences, 58(2), 350-365.

Grisham, W., \& Powers, A. S. (1989). Function of the dorsal and medial cortex of turtles in learning. Behavioral neuroscience, 103(5), 991.

Guillette Jr, L. J., Crain, D. A., Rooney, A. A., \& Pickford, D. B. (1995). Organization versus activation: the role of endocrine-disrupting contaminants (EDCs) during embryonic development in wildlife. Environmental health perspectives, 103(Suppl 7), 157.

Hall, W. C., \& Ebner, F. F. (1970). Thalamotelencephalic projections in the turtle (Pseudemys scripta). Journal of Comparative Neurology, 140(1), 101-122.

Hammond, K. A., Spotila, J. R., \& Standora, E. A. (1988). Basking behavior of the turtle Pseudemys scripta: effects of digestive state, acclimation temperature, sex, and season. Physiological Zoology, 61(1), 69-77.

Herman, C., Adlercreutz, T., Goldin, B. R., \& Gorbach, S. L. (1995). Soybean phytoestrogen intake and cancer risk. The Journal of nutrition, 125(3), 757S.

Holloway, C. C., \& Clayton, D. F. (2001). Estrogen synthesis in the male brain triggers development of the avian song control pathway in vitro. Nature neuroscience, 4(2), 170.

Hong, S. B., Hong, Y. C., Kim, J. W., Park, E. J., Shin, M. S., Kim, B. N., Yoo, H.J., Cho, I.H., Bhong, S.Y., \& Cho, S. C. (2013). Bisphenol A in relation to behavior and learning of school-age children. Journal of Child Psychology and Psychiatry, 54(8), 890-899. 
Huang, Y. Q., Wong, C. K. C., Zheng, J. S., Bouwman, H., Barra, R., Wahlström, B., Neretin, L., \& Wong, M. H. (2012). Bisphenol A (BPA) in China: a review of sources, environmental levels, and potential human health impacts. Environment international, 42, 91-99.

Iverson, J. B., Prosser, R. L., \& Dalton, E. N. (2009). Orientation in juveniles of a semiaquatic turtle, Kinosternon flavescens. Herpetologica, 65(3), 237-245.

Jašarević, E., Williams, S. A., Vandas, G. M., Ellersieck, M. R., Liao, C., Kannan, K., Roberts, R. M., Geary, D.C., \& Rosenfeld, C. S. (2013). Sex and dose-dependent effects of developmental exposure to bisphenol A on anxiety and spatial learning in deer mice (Peromyscus maniculatus bairdii) offspring. Hormones and behavior, 63(1), 180-189.

Kashon, E. F., \& Carlson, B. E. (2018). Consistently bolder turtles maintain higher body temperatures in the field but may experience greater predation risk. Behavioral Ecology and Sociobiology, 72(1), 9.

Kesner, R. P. (1990). Memory for frequency in rats: role of the hippocampus and medial prefrontal cortex. Behavioral and neural biology, 53(3), 402-410.

Killackey, H., Pellmar, T., \& Nilsson, G. (1972) The effects of general cortex ablation on habituation in the turtle. Federation Proceedings, 31, 819.

Kim, M. E., Park, H. R., Gong, E. J., Choi, S. Y., Kim, H. S., \& Lee, J. (2011). Exposure to bisphenol A appears to impair hippocampal neurogenesis and spatial learning and memory. Food and chemical toxicology, 49(12), 3383-3389.

Krishnan, A. V., Stathis, P., Permuth, S. F., Tokes, L., \& Feldman, D. (1993). Bisphenol-A: an estrogenic substance is released from polycarbonate flasks during autoclaving. Endocrinology, 132(6), 2279-2286.

Kubo, K., Arai, O., Omura, M., Watanabe, R., Ogata, R., \& Aou, S. (2003). Low dose effects of bisphenol $A$ on sexual differentiation of the brain and behavior in rats. Neuroscience research, 45(3), 345-356.

Kuhl, A. J., \& Brouwer, M. (2006). Antiestrogens inhibit xenoestrogen-induced brain aromatase activity but do not prevent xenoestrogen-induced feminization in Japanese medaka (Oryzias latipes). Environmental health perspectives, 500-506.

Kuwahara, R., Kawaguchi, S., Kohara, Y., Cui, H., \& Yamashita, K. (2013). Perinatal exposure to low-dose bisphenol A impairs spatial learning and memory in male rats. Journal of pharmacological sciences, 123(2), 132-139.

Kwon, J. H., Katz, L. E., \& Liljestrand, H. M. (2007). Modeling binding equilibrium in a competitive estrogen receptor binding assay. Chemosphere, 69(7), 1025-1031. 
Les, H. L., Paitz, R. T., \& Bowden, R. M. (2007). Experimental test of the effects of fluctuating incubation temperatures on hatchling phenotype. Journal of Experimental Zoology Part A: Ecological and Integrative Physiology, 307(5), 274-280.

Li, J., Li, N., Ma, M., Giesy, J. P., \& Wang, Z. (2008). In vitro profiling of the endocrine disrupting potency of organochlorine pesticides. Toxicology letters, 183(1), 65-71.

Lubahn, D. B., Moyer, J. S., Golding, T. S., Couse, J. F., Korach, K. S., \& Smithies, O. (1993). Alteration of reproductive function but not prenatal sexual development after insertional disruption of the mouse estrogen receptor gene. Proceedings of the National Academy of Sciences, 90(23), 11162-11166.

Mably, T. A., Moore, R. W., Goy, R. W., \& Peterson, R. E. (1992). In utero and lactational exposure of male rats to 2, 3, 7, 8-tetrachlorodibenzo-p-dioxin: 2. Effects on sexual behavior and the regulation of luteinizing hormone secretion in adulthood. Toxicology and applied pharmacology, 114(1), 108-117.

Mak, P., Ho, S. M., \& Callard, I. P. (1982). Estrogen receptors in the turtle brain. Brain research, 231(1), 63-74.

Manshack, L. K., Conard, C. M., Johnson, S. A., Alex, J. M., Bryan, S. J., Deem, S. L., Holliday, D.K., Ellersieck, M.R., \& Rosenfeld, C. S. (2016). Effects of developmental exposure to bisphenol A and ethinyl estradiol on spatial navigational learning and memory in painted turtles (Chrysemys picta). Hormones and Behavior, 85, 48-55.

Matamoros, I. A., Cox, N. M., \& Moore, A. B. (1991). Effects of exogenous insulin and body condition on metabolic hormones and gonadotropin-induced follicular development in prepuberal gilts. Journal of animal science, 69(5), 2081-2091.

Matsumoto, Y., Hannigan, B., \& Crews, D. (2014). Embryonic PCB exposure alters phenotypic, genetic, and epigenetic profiles in turtle sex determination, a biomarker of environmental contamination. Endocrinology, 155(11), 4168-4177.

McCarthy, M. M. (2008). Estradiol and the developing brain. Physiological reviews, 88(1), 91134.

Micheli-Campbell, M. A., Campbell, H. A., Cramp, R. L., Booth, D. T., \& Franklin, C. E. (2011). Staying cool, keeping strong: incubation temperature affects performance in a freshwater turtle. Journal of Zoology, 285(4), 266-273.

Miodovnik, A., Engel, S. M., Zhu, C., Ye, X., Soorya, L. V., Silva, M. J., Calafet, A.M., \& Wolff, M. S. (2011). Endocrine disruptors and childhood social impairment. Neurotoxicology, 32(2), 261-267.

Morlock, H. C. (1972). Behavior following ablation of the dorsal cortex of turtles. Brain, behavior and evolution, 5(2-3), 256-263. 
Morrissey, R. E., George, J. D., Price, C. J., Tyl, R. W., Marr, M. C., \& Kimmel, C. A. (1987). The developmental toxicity of bisphenol $\mathrm{A}$ in rats and mice. Fundamental and Applied Toxicology, 8(4), 571-582.

Murillo, N. R., Diercks, J. K., \& Capaldi, E. J. (1961). Performance of the turtle, Pseudemys scripta troostii, in a partial-reinforcement situation. Journal of comparative and physiological psychology, 54(2), 204.

Nakamura, K., Itoh, K., Yaoi, T., Fujiwara, Y., Sugimoto, T., \& Fushiki, S. (2006). Murine neocortical histogenesis is perturbed by prenatal exposure to low doses of bisphenol A. Journal of neuroscience research, 84(6), 1197-1205.

Nakamura, K., Itoh, K., Dai, H., Han, L., Wang, X., Kato, S., Sugimoto, T., \& Fushiki, S. (2012). Prenatal and lactational exposure to low-doses of bisphenol A alters adult mice behavior. Brain and Development, 34(1), 57-63.

Norris, D. O., \& Carr, J. A. (Eds.). (2005). Endocrine disruption: biological bases for health effects in wildlife and humans. Oxford University Press.

Paitz, R. T., Sawa, A. R., \& Bowden, R. M. (2012). Characterizing the metabolism and movement of yolk estradiol during embryonic development in the red-eared slider (Trachemys scripta). General and comparative endocrinology, 176(3), 507-512.

Paitz, R. T., \& Bowden, R. M. (2015). The in ovo conversion of oestrone to oestrone sulfate is rapid and subject to inhibition by Bisphenol A. Biology letters, 11(4), 20140946.

Palanza, P. L., Howdeshell, K. L., Parmigiani, S., \& vom Saal, F. S. (2002). Exposure to a low dose of bisphenol A during fetal life or in adulthood alters maternal behavior in mice. Environmental health perspectives, 110(Suppl 3), 415.

Pert, A., \& Bitterman, M. E. (1970). Reward and learning in the turtle. Learning and Motivation, $1(1), 121-128$.

Phoenix, C. H., Goy, R. W., Gerall, A. A., \& Young, W. C. (1959). Organizing action of prenatally administered testosterone propionate on the tissues mediating mating behavior in the female guinea pig 1. Endocrinology, 65(3), 369-382.

Powers, A. S., (1990). Chapter 6: Brain Mechanisms of Learning in Reptiles, within: Neurobiology of comparative cognition, Kesner, R.P., \& Olton, D.S., (1990). Hillsdale, N.J.: L. Erlbaum Associates.

Rajapakse, N., Silva, E., \& Kortenkamp, A. (2002). Combining xenoestrogens at levels below individual no-observed-effect concentrations dramatically enhances steroid hormone action. Environmental health perspectives, 110(9), 917. 
Reiner, A., \& Powers, A. S. (1983). The effects of lesions of telencephalic visual structures on visual discriminative performance in turtles (Chrysemyspicta picta). Journal of Comparative Neurology, 218(1), 1-24.

Rhoda, J., Corbier, P., \& Roffi, J. (1984). Gonadal steroid concentrations in serum and hypothalamus of the rat at birth: aromatization of testosterone to $17 \beta$-estradiol. Endocrinology, 114(5), 1754-1760.

Rissman, E. F., Heck, A. L., Leonard, J. E., Shupnik, M. A., \& Gustafsson, J. Å. (2002). Disruption of estrogen receptor $\beta$ gene impairs spatial learning in female mice. Proceedings of the National Academy of Sciences, 99(6), 3996-4001.

Ryan, B. C., \& Vandenbergh, J. G. (2006). Developmental exposure to environmental estrogens alters anxiety and spatial memory in female mice. Hormones and behavior, 50(1), 85-93.

Ryan, B. C., \& Vandenbergh, J. G. (2002). Intrauterine position effects. Neuroscience \& Biobehavioral Reviews, 26(6), 665-678.

Safe, S. (1993). Toxicology, structure-function relationship, and human and environmental health impacts of polychlorinated biphenyls: progress and problems. Environmental health perspectives, 100, 259.

Saili, K. S., Corvi, M. M., Weber, D. N., Patel, A. U., Das, S. R., Przybyla, J., Anderson, K., \& Tanguay, R. L. (2012). Neurodevelopmental low-dose bisphenol A exposure leads to early life-stage hyperactivity and learning deficits in adult zebrafish. Toxicology, 291(1), 83-92.

Schwetz, B. A., Norris, J. M., Sparschu, G. L., Rowe, V. K., Gehring, P. J., Emerson, J. L., \& Gerbig, C. G. (1973). Toxicology of chlorinated dibenzo-p-dioxins.

Segner, H., Caroll, K., Fenske, M., Janssen, C. R., Maack, G., Pascoe, D., Schäfers, C., Vandenbergh, G.F., Watts, M., \& Wenzel, A. (2003). Identification of endocrinedisrupting effects in aquatic vertebrates and invertebrates: report from the European IDEA project. Ecotoxicology and environmental safety, 54(3), 302-314.

Sih, A., Bell, A., \& Johnson, J. C. (2004). Behavioral syndromes: an ecological and evolutionary overview. Trends in ecology \& evolution, 19(7), 372-378.

Skaare, J. U., Bernhoft, A., Wiig, Ø., Norum, K. R., Haug, E., Eide, D. M., \& Derocher, A. E. (2001). Relationships between plasma levels of organochlorines, retinol and thyroid hormones from polar bears (Ursus maritimus) at Svalbard. Journal of Toxicology and Environmental Health Part A, 62(4), 227-241. 
Stoker, C., Rey, F., Rodriguez, H., Ramos, J. G., Sirosky, P., Larriera, A., Luque, E.H., \& Munoz-de-Toro, M. (2003). Sex reversal effects on Caiman latirostris exposed to environmentally relevant doses of the xenoestrogen bisphenol A. General and comparative endocrinology, 133(3), 287-296.

Thomas, R. B., Vogrin, N., \& Altig, R. (1999). Sexual and seasonal differences in behavior of Trachemys scripta (Testudines: Emydidae). Journal of Herpetology, 33(3), 511-515.

U.S. Department of Health and Human Services NTP-CERHR monograph on the potential human reproductive and developmental effects of bisphenol A. Center for the Evaluation of Risks to Human Reproduction, National Toxicology Program, U.S. Department of Health and Human Services. 2008.

Vom Saal, F. S., Akingbemi, B. T., Belcher, S. M., Birnbaum, L. S., Crain, D. A., Eriksen, M., Farabollini, F., Guillette, L., Hauser, R., Heindel, J., Ho, S., Hunt, P., Iguchi, T., Jobling, S., Kanno, J., Keri, R., Knudsen, K., Laufer, H., LeBlanc, G., Marcus, M., McLachlan, J., Myers, J., Nadal, A., Newbold, R., Olea, N., Prins, G., Richter, C., Rubin, B., Sonnenschein, C., Soto, A., Talsness, C., Vendenbergh, J., Walser-Kuntz, D., Watson, C., Welshons, W., Wetherill, Y., \& Zoeller, R. (2007). Chapel Hill bisphenol A expert panel consensus statement: integration of mechanisms, effects in animals and potential to impact human health at current levels of exposure. Reproductive toxicology (Elmsford, NY), 24(2), 131.

Welshons, W. V., Nagel, S. C., \& vom Saal, F. S. (2006). Large effects from small exposures. III. Endocrine mechanisms mediating effects of bisphenol A at levels of human exposure. Endocrinology, 147(6), s56-s69.

Wilson, J. D. (1999). The role of androgens in male gender role behavior. Endocrine reviews, 20(5), 726-737.

Wise, L. M., \& Gallagher, D. P. (1964). Partial reinforcement of a discriminative response in the turtle. Journal of comparative and physiological psychology, 57(2), 311.

Wolstenholme, J. T., Rissman, E. F., \& Connelly, J. J. (2011). The role of Bisphenol A in shaping the brain, epigenome and behavior. Hormones and behavior, 59(3), 296-305.

Xu, X. H., Zhang, J., Wang, Y. M., Ye, Y. P., \& Luo, Q. Q. (2010). Perinatal exposure to bisphenol-A impairs learning-memory by concomitant down-regulation of N-methyl-Daspartate receptors of hippocampus in male offspring mice. Hormones and behavior, 58(2), 326-333.

Yerkes, R. M. (1901). The formation of habits in the turtle. Popular Science Monthly. http://www.archive.org/stream/popularsciencemo58newy\#page/518/mode/2up 
Table 1

Favored Choices in the Training and Learning Periods of the Experiment

\begin{tabular}{|c|c|c|c|c|c|}
\hline Turtle & Treatment & $\begin{array}{c}\text { Favored choice in } \\
T P\end{array}$ & $\begin{array}{c}\text { Favored choice in } \\
L P\end{array}$ & $\begin{array}{l}\text { Favored arm } \\
\text { repeated in } L P\end{array}$ & $\begin{array}{l}\text { Favored arm repeated to } \\
\text { an empty arm in } L P\end{array}$ \\
\hline 1 & BPA & $\mathrm{R}^{*}$ & $\mathrm{R}$ & $\diamond$ & $\dagger$ \\
\hline 9 & BPA & $\mathrm{R}^{*}$ & $\mathrm{R}$ & $\diamond$ & $\dagger$ \\
\hline 19 & BPA & $\mathrm{L}$ & $\mathrm{L}$ & $\diamond$ & $\dagger$ \\
\hline 29 & BPA & ND & ND & & \\
\hline 6 & BPA & $\mathrm{R}^{*}$ & ND & & \\
\hline 10 & BPA & $\mathrm{R}$ & $\mathrm{L}$ & & \\
\hline 14 & BPA & $\mathrm{R}$ & $\mathrm{L}$ & & \\
\hline 17 & BPA & $\mathrm{R}$ & $\mathrm{L}$ & & \\
\hline 23 & BPA & $\mathrm{R}$ & $\mathrm{L}$ & & \\
\hline 25 & BPA & $\mathrm{R}$ & $\mathrm{L}$ & & \\
\hline 3 & $\mathrm{BPA}+\mathrm{E}_{2}$ & $\mathrm{R}^{*}$ & $\mathrm{R}$ & $\diamond$ & $\dagger$ \\
\hline 5 & $\mathrm{BPA}+\mathrm{E}_{2}$ & $\mathrm{~L}^{*}$ & $\mathrm{~L}$ & $\diamond$ & $\dagger$ \\
\hline 20 & $\mathrm{BPA}+\mathrm{E}_{2}$ & $\mathrm{~L}^{*}$ & $\mathrm{~L}$ & $\diamond$ & \\
\hline 22 & $\mathrm{BPA}+\mathrm{E}_{2}$ & $\mathrm{~L}$ & $\mathrm{~L}$ & $\diamond$ & \\
\hline 26 & $\mathrm{BPA}+\mathrm{E}_{2}$ & $\mathrm{~L}$ & $\mathrm{~L}$ & $\diamond$ & \\
\hline 7 & $\mathrm{BPA}+\mathrm{E}_{2}$ & ND & ND & & \\
\hline 15 & $\mathrm{BPA}+\mathrm{E}_{2}$ & $\mathrm{~L}^{*}$ & $\mathrm{R}$ & & \\
\hline 16 & $\mathrm{BPA}+\mathrm{E}_{2}$ & $\mathrm{R}$ & ND & & \\
\hline 28 & $\mathrm{BPA}+\mathrm{E}_{2}$ & $\mathrm{~L}$ & $\mathrm{R}$ & & \\
\hline 11 & $\mathrm{BPA}+\mathrm{E}_{2}$ & - & $\mathrm{L}$ & & \\
\hline 12 & Control & $\mathrm{L}$ & $\mathrm{L}$ & $\diamond$ & $\dagger$ \\
\hline 8 & Control & $\mathrm{L}$ & $\mathrm{L}$ & $\diamond$ & \\
\hline 18 & Control & $\mathrm{L}$ & $\mathrm{L}$ & $\diamond$ & \\
\hline 21 & Control & ND* & ND & & \\
\hline 27 & Control & ND* & ND & & \\
\hline 2 & Control & $\mathrm{R}$ & $\mathrm{L}$ & & \\
\hline 13 & Control & $\mathrm{R}$ & $\mathrm{L}$ & & \\
\hline 24 & Control & $\mathrm{L}$ & $\mathrm{R}$ & & \\
\hline 4 & Control & - & ND & & \\
\hline
\end{tabular}

Notes: TP and LP are shorthand for the training period and learning period, respectively.

* denotes cases where one arm was chosen significantly more than an expected even distribution of R:L arm choices.

$\checkmark$ denotes cases of a hatchling repeating their favored choice in both periods of the experiment. $\dagger$ denotes cases where a hatchling favored the empty arm in the learning period.

$\mathrm{R}$ denotes right arm choices are the more frequent choice for that hatchling.

L denotes left arm choices are the more frequent choice for that hatchling.

ND denotes no decision was the most frequent choice for that hatchling. 
Table 2

Time and Treatment Effects on Behavior across Days of the Experiment

\begin{tabular}{|c|c|c|c|c|c|c|c|c|c|}
\hline Behavior & Effect & Num $d f$, Den $d f$ & F-value & $P$-value & Parameter & Estimate & S.E. & Z-value & $P$-value \\
\hline \multicolumn{10}{|c|}{ A) Activity } \\
\hline & Treatment & $2,17.3$ & 0.03 & 0.97 & Individual & 3.82 & 1.38 & 2.76 & 0.003 \\
\hline & Day & 13,354 & 8.51 & $<0.0001$ & Clutch & 0.31 & 0.94 & 0.33 & 0.37 \\
\hline \multicolumn{10}{|l|}{ B) Shelter } \\
\hline & Treatment & $2,17.4$ & 0.59 & 0.56 & Individual & 20.82 & 7.49 & 2.78 & 0.003 \\
\hline & Day & 13,354 & 5.48 & $<0.0001$ & Clutch & 11.10 & 9.06 & 1.21 & 0.11 \\
\hline \multicolumn{10}{|l|}{ C) Open } \\
\hline & Treatment & $2,17.5$ & 1.42 & 0.27 & Individual & 14.16 & 5.04 & 2.81 & 0.003 \\
\hline & Day & 13,354 & 6.51 & $<0.0001$ & Clutch & 4.51 & 4.81 & 0.94 & 0.17 \\
\hline \multicolumn{10}{|c|}{ D) Latency } \\
\hline & Treatment & $2,17.7$ & 0.32 & 0.73 & Individual & 40.71 & 14.19 & 2.87 & 0.003 \\
\hline & Day & 13,354 & 5.63 & $<0.0001$ & Clutch & 12.76 & 13.42 & 0.95 & 0.17 \\
\hline
\end{tabular}

Notes: "Latency" is the latency to first activity. The random effect of clutch was tested as individual nested within clutch in the model. 
Table 3

Time and Treatment Effects on Behavior across Trials within Day

\begin{tabular}{|c|c|c|c|c|c|c|c|c|c|}
\hline Behavior & Effect & Num $d f$, Den $d f$ & F-value & $P$-value & Parameter & Estimate & S.E. & Z-value & $P$-value \\
\hline \multicolumn{10}{|c|}{ A) Activity } \\
\hline & Treatment & $2,17.3$ & 0.03 & 0.97 & Individual & 3.8141 & 1.35 & 2.82 & 0.002 \\
\hline & Trial & 9,252 & 12.1 & $<0.0001$ & Clutch & 0.4035 & 0.96 & 0.42 & 0.34 \\
\hline \multicolumn{10}{|l|}{ B) Shelter } \\
\hline & Treatment & $2,17.3$ & 0.58 & 0.57 & Individual & 21.027 & 7.47 & 2.81 & 0.003 \\
\hline & Trial & 9,252 & 9.93 & $<0.0001$ & Clutch & 11.1582 & 9.17 & 1.22 & 0.11 \\
\hline \multicolumn{10}{|l|}{ C) Open } \\
\hline & Treatment & $2,17.5$ & 1.51 & 0.25 & Individual & 14.6646 & 5.08 & 2.88 & 0.002 \\
\hline & Trial & 9,252 & 0.75 & 0.6603 & Clutch & 4.4449 & 4.81 & 0.92 & 0.18 \\
\hline \multicolumn{10}{|c|}{ D) Latency } \\
\hline & Treatment & $2,17.6$ & 0.33 & 0.72 & Individual & 40.6051 & 14.14 & 2.87 & 0.002 \\
\hline & Trial & 9,252 & 11.21 & $<0.0001$ & Clutch & 12.8866 & 13.45 & 0.96 & 0.17 \\
\hline
\end{tabular}

Notes: "Latency" is the latency to first activity. The random effect of individual was tested as individual nested within clutch in the model. 
Table 4

Treatment and Trial of the Day Effects on the Number of Inactive Turtles

\begin{tabular}{llll}
\hline Effect & Num df, Den $d f$ & F-value & P-value \\
\hline Treatment & 2,260 & 0.74 & 0.4777 \\
Trial of the day & 9,260 & 10.6 & $<\mathbf{0 . 0 0 0 1}$ \\
Trial of the day * Treatment & 18,260 & 1.44 & 0.1114 \\
\hline
\end{tabular}




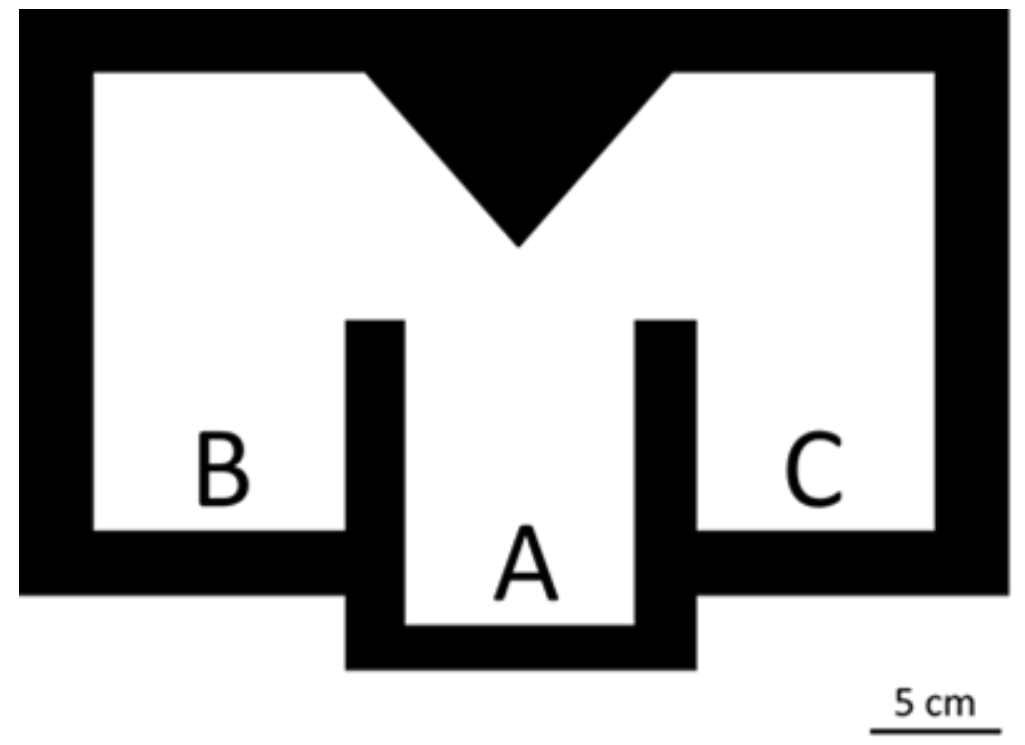

Figure 1. Modified T-maze arena. Turtles were placed into the starting well (A) and tested for their arm (B, C) choices. Reward stimuli were placed at the ends of arms (B \& C labels) so that an arm decision was made without the turtle seeing what the arm contained. 


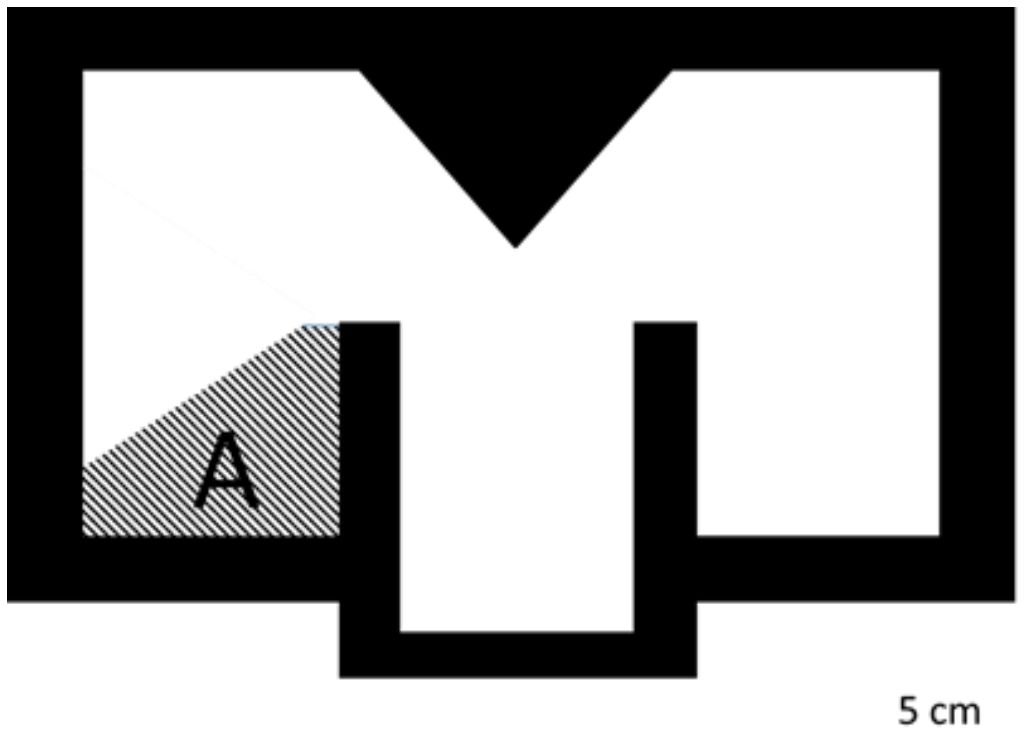

Figure 2. Shelter reward stimulus within T-maze arena. We modified overhead shelters (A) such that a turtle could not see that an arm contained a shelter before choosing it. 


\section{A. Activity}

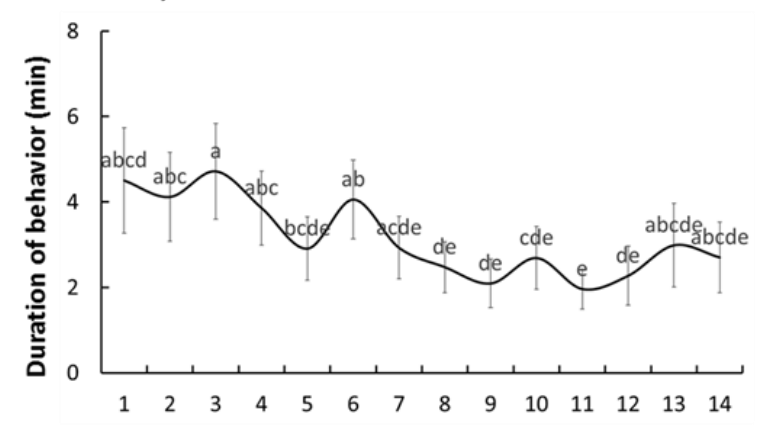

C. Open

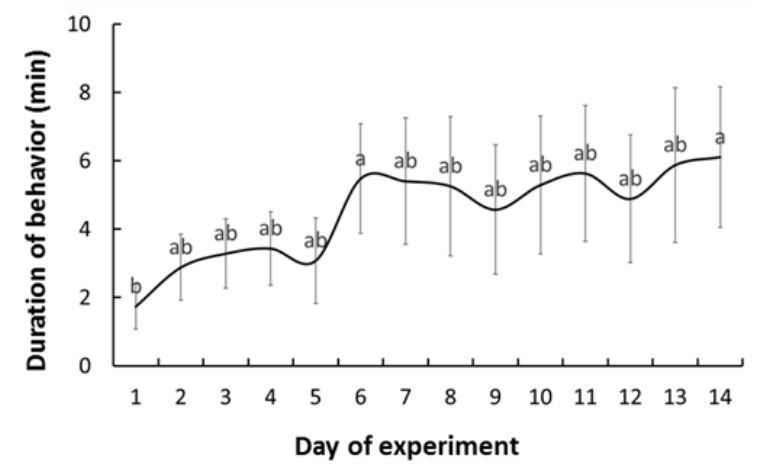

B. Shelter

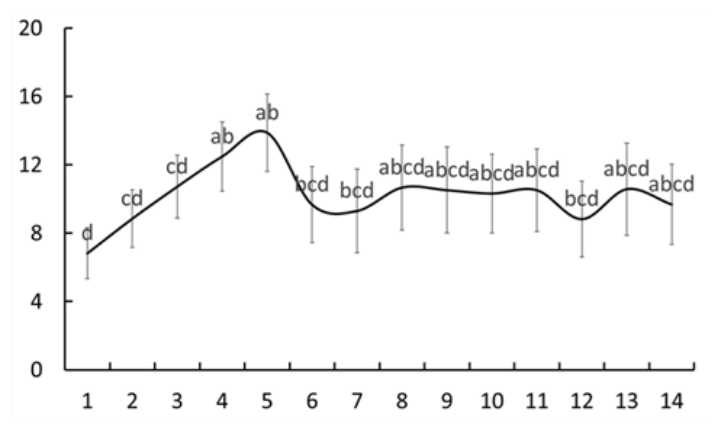

D. Latency to first activity

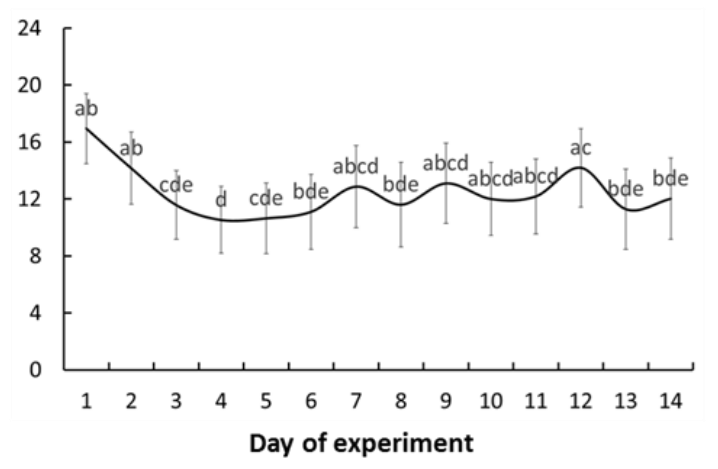

Figure 3. Post-hoc comparisons for effects of the day of the experiment on behavior. For all behaviors, there were no treatment effects on the day averages of behavior, therefore all plots are average daily behavioral scores for all experimental turtles. For each behavior (A-D), days with the same letter grouping are not statistically different. Error bars are the standard error for the average behavior for that day. Note that the scale of the y-axis varies for each behavior. 
A. Activity

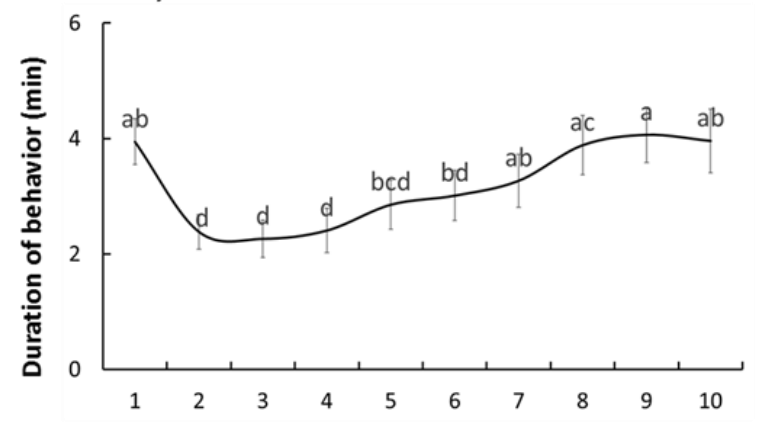

C. Open

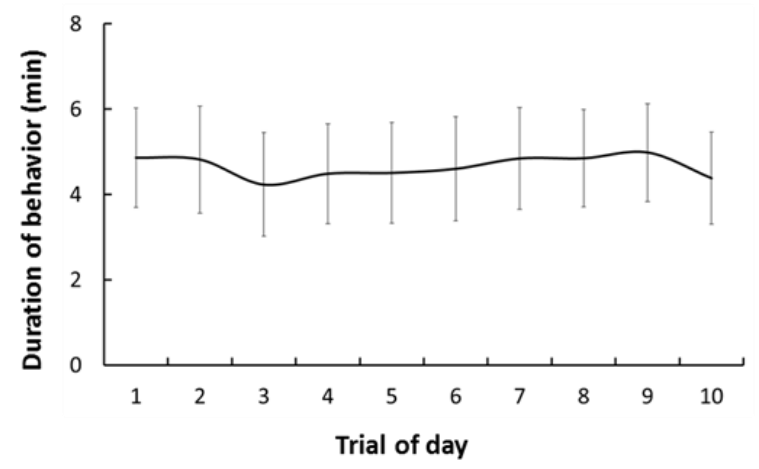

B. Shelter

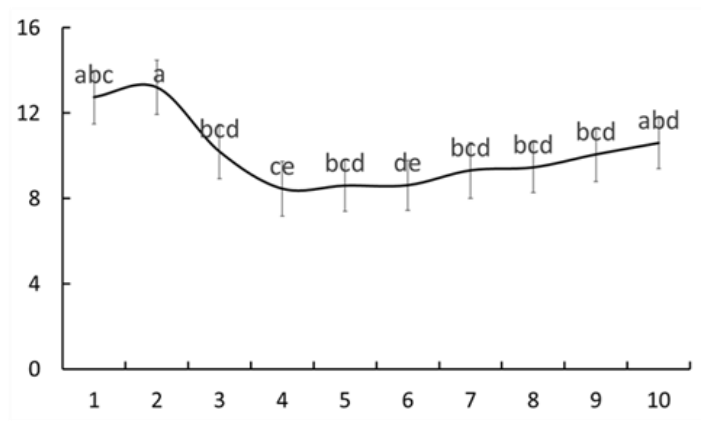

D. Latency to first activity

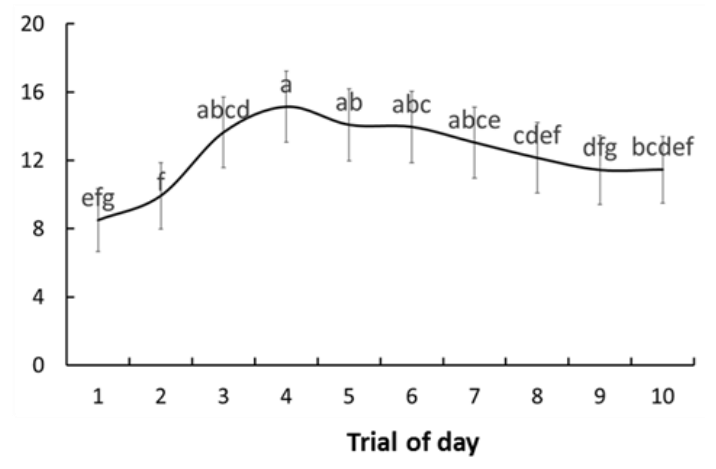

Figure 4. Post-hoc comparisons for effects of the trial of the day on behavior. For all behaviors, there were no treatment effects on the day averages of behavior, therefore all plots are trial of day average behavioral scores for all experimental turtles. For each behavior (A-D), days with the same letter grouping are not statistically different. Error bars are the standard error for the average behavior for that day. Note that the scale of the y-axis varies for each behavior. 


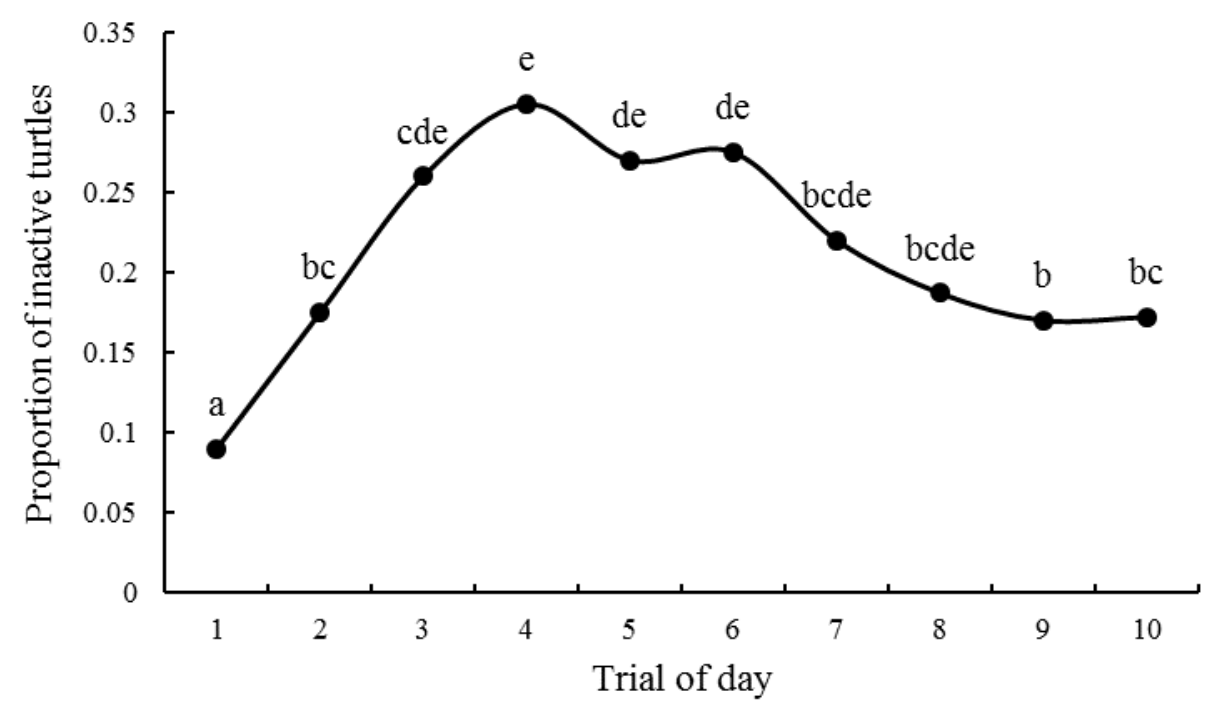

Figure 5. Post-hoc comparisons of the probability of inactivity for each trial of the day. Inactive trials are those where latency to first activity $=30$ minutes, and therefore no other behavior was observed. Trials with the same letter grouping are not statistically different. 


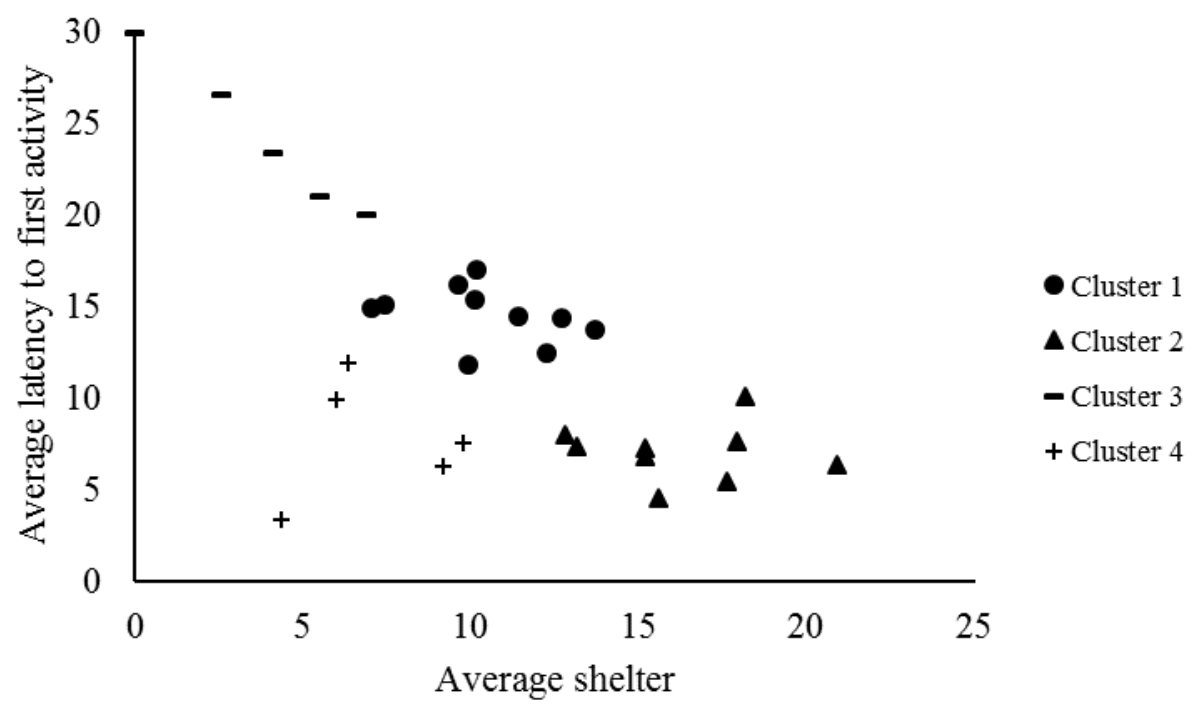

Figure 6. Behavioral cluster designations. Behavioral clusters are plotted by the average shelter and average latency to first activity within the training period for each experimental hatchling. 
A. Latency/Shelter (cluster 1)

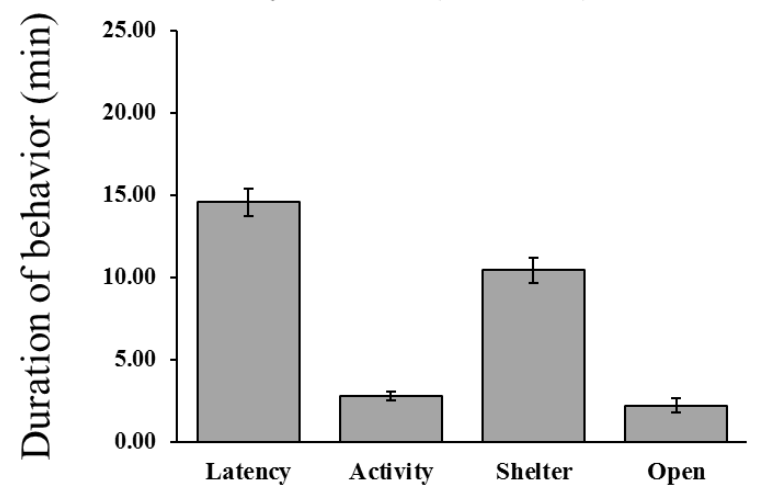

C. Latency (cluster 3)

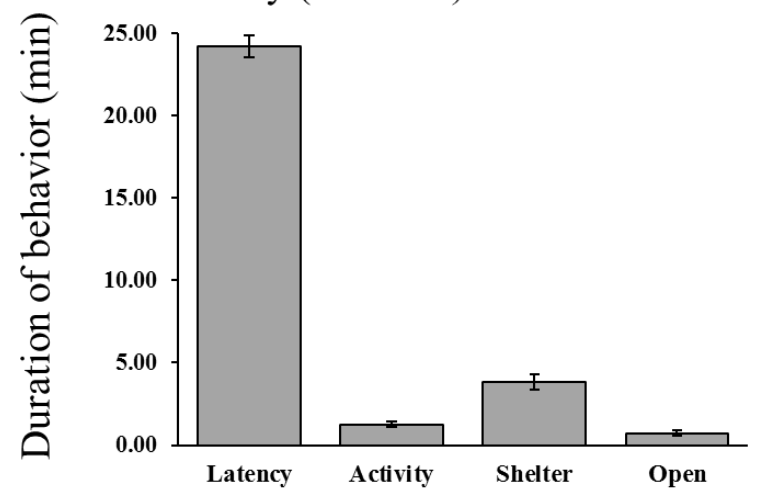

B. Shelter (cluster 2)

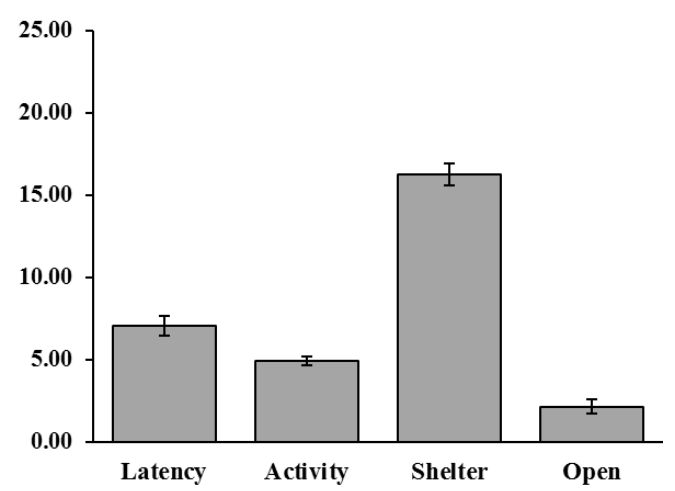

D. Open (cluster 4)

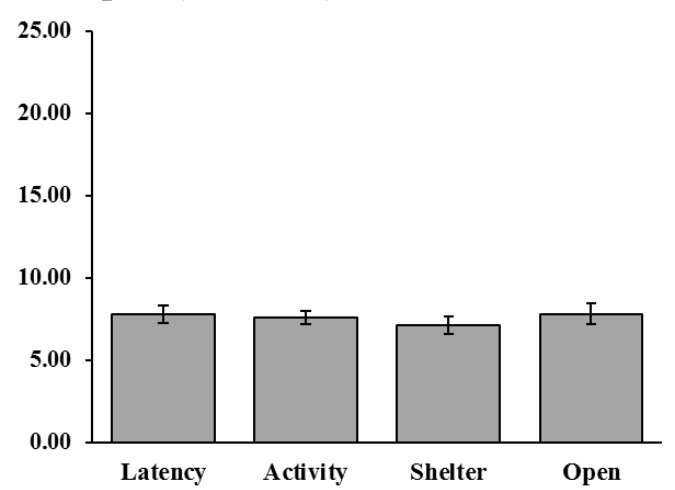

Figure 7. Average behavioral scores for each cluster. Data presented are the mean duration for each behavior for each hatchling within that behavioral cluster $+/$ - standard error. Note that the cluster numbers in parentheses refer to the cluster groupings in Fig 6. 


\section{APPENDIX A: BEHAVIORAL DATA VISUALITAZION PLOTS}

The following 29 pages of Appendix A are the behavioral data visualization plots for each individual hatchling. These plots show hatchling behavior at each second of any given trial, for all trials in the experiment that hatchling was assessed. Trials begin at 0 minutes on the left of the plot (i.e. time $=0, \mathrm{x}$ axis), and behaviors are visualized via color as the trial progresses from left to right across the plot. Trial one for any given hatchling is the top row of color visualization, and each subsequent trial is visualized below. Behaviors are labelled as follows:

Yellow: Latency to first activity

Red: Activity

Grey: Inactivity outside of shelter (“Open")

Blue: Shelter 
Turtle 1

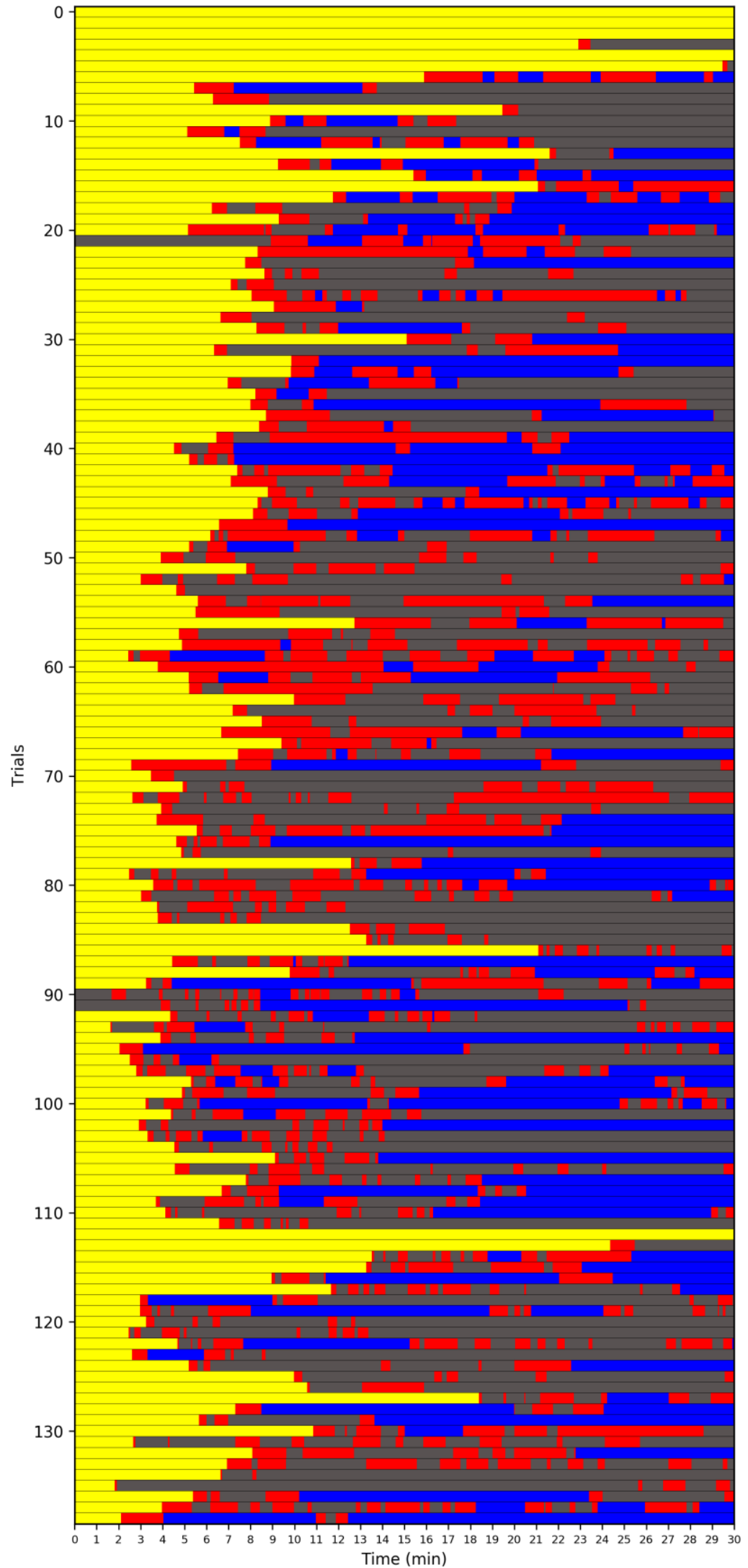


Turtle 2

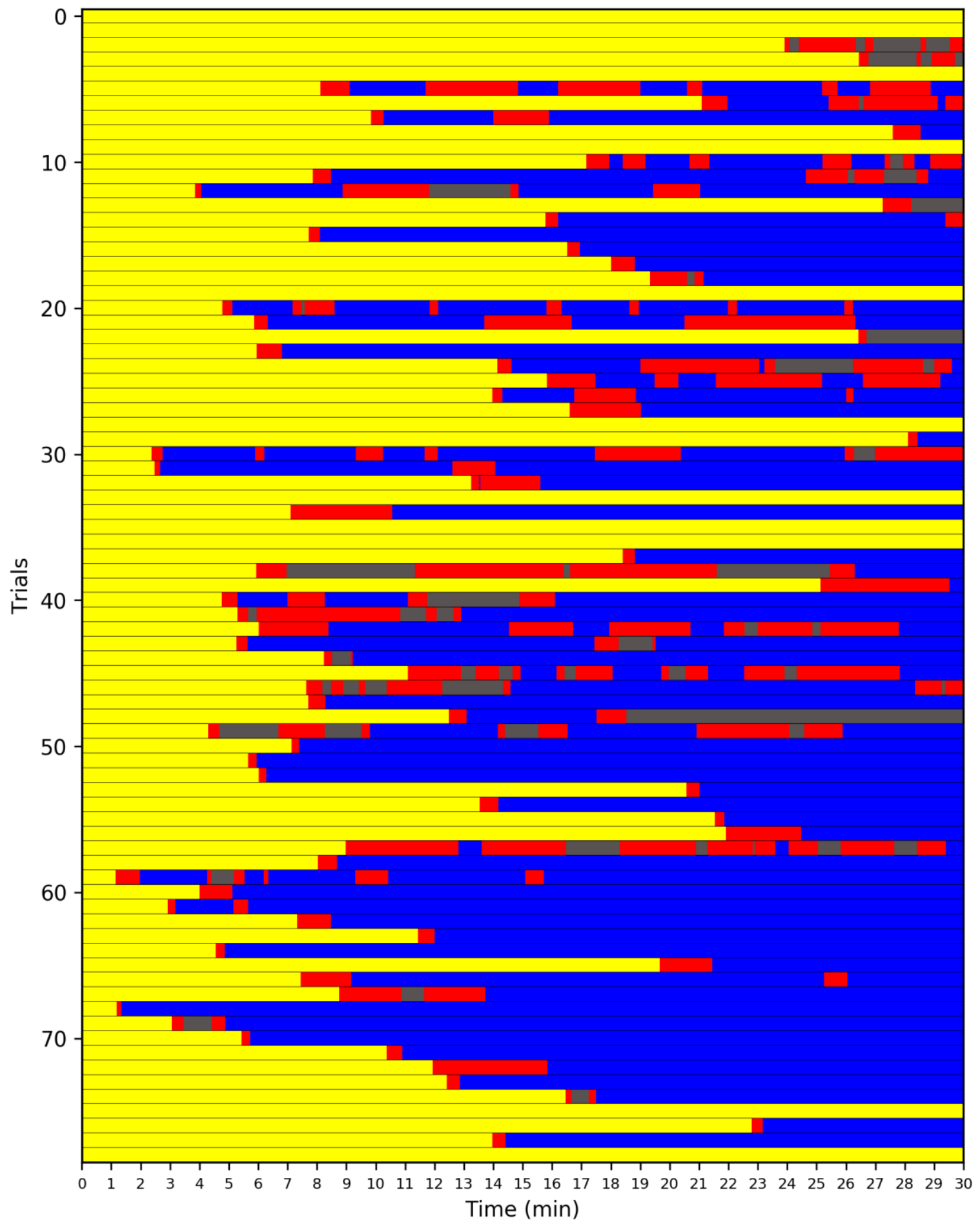


Turtle 3

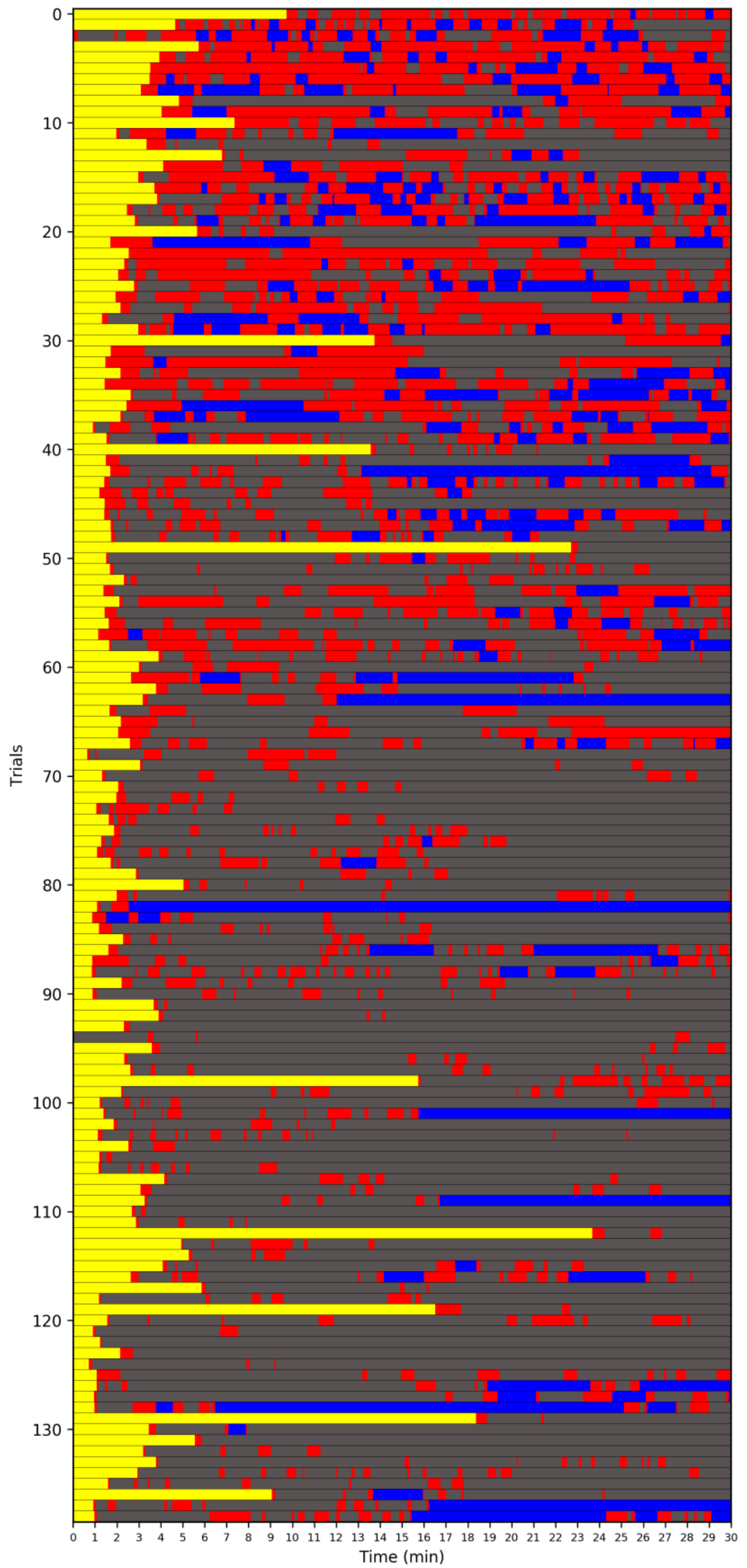


Turtle 4

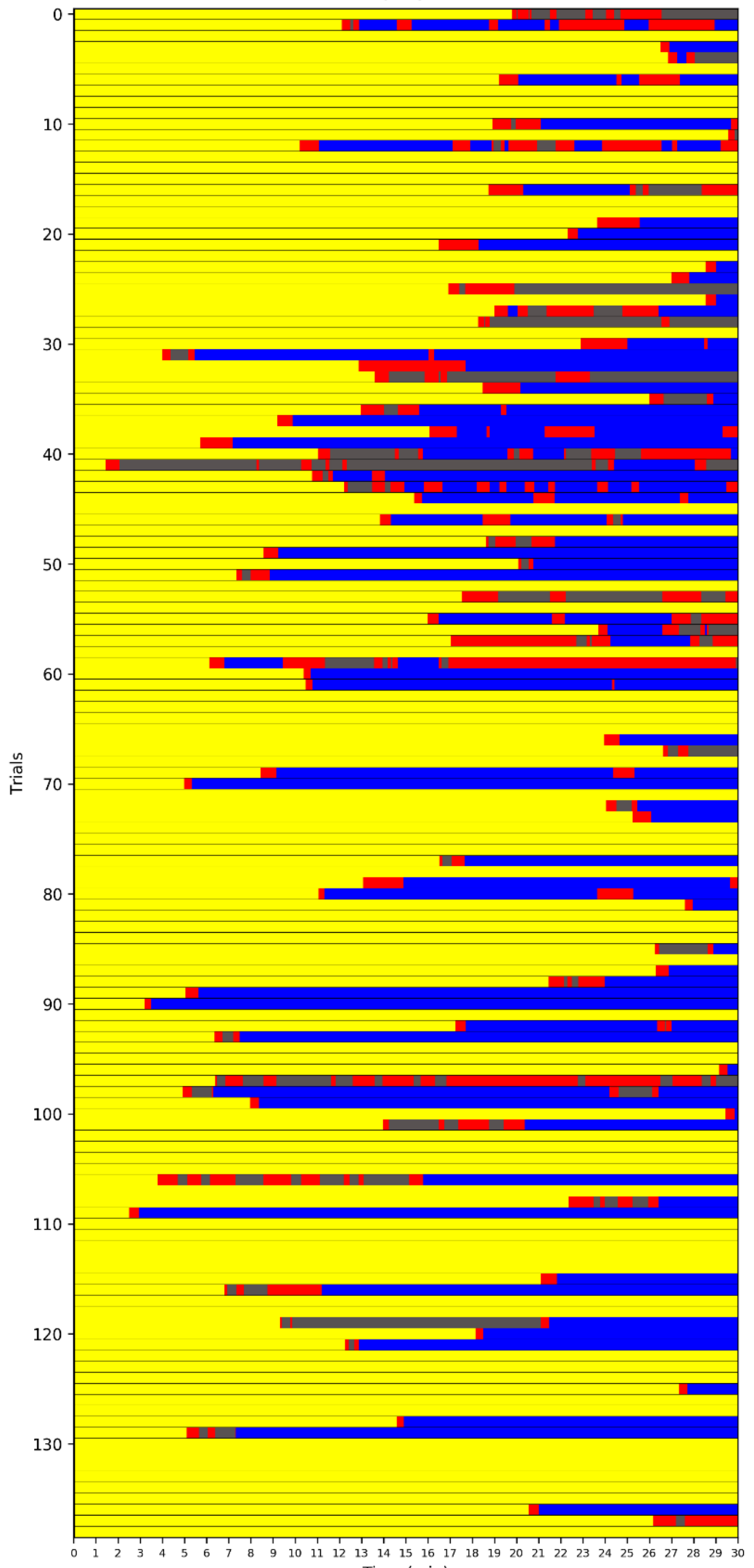

Time (min) 
Turtle 5

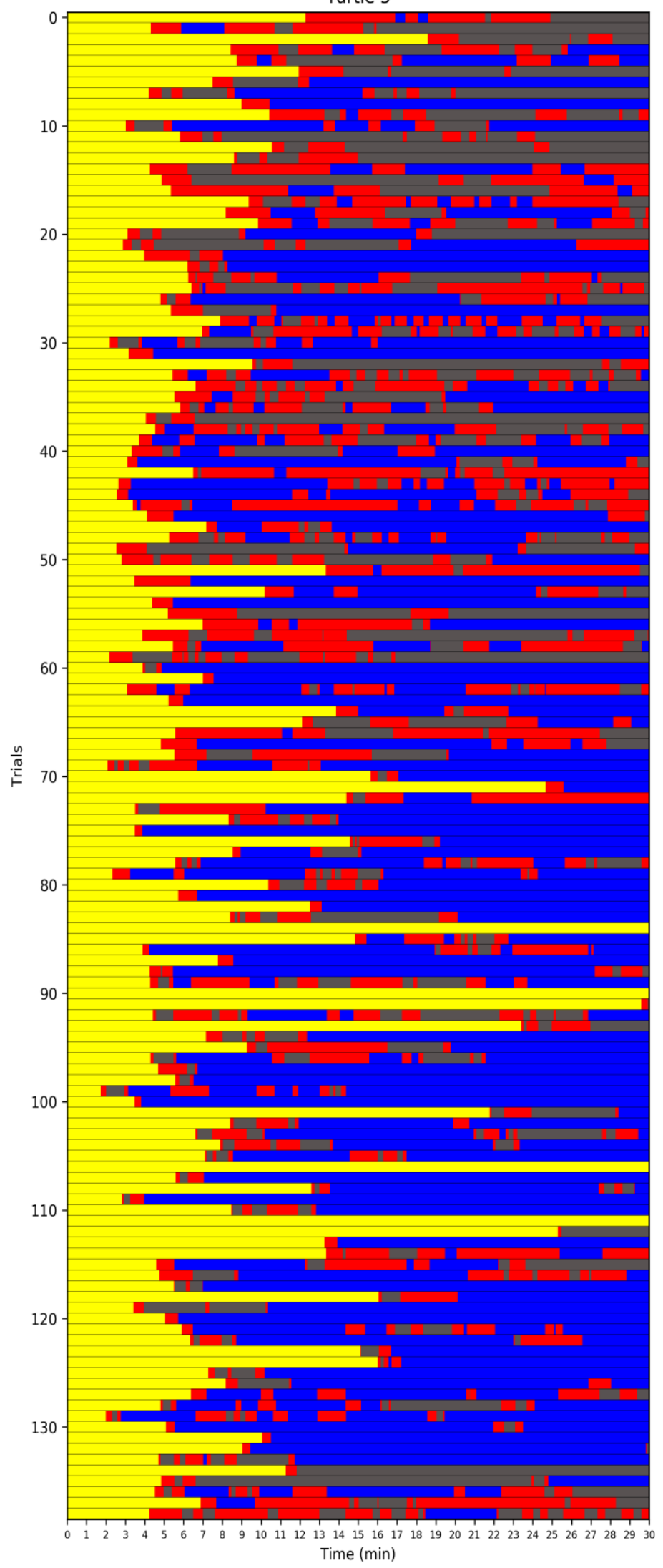


Turtle 6

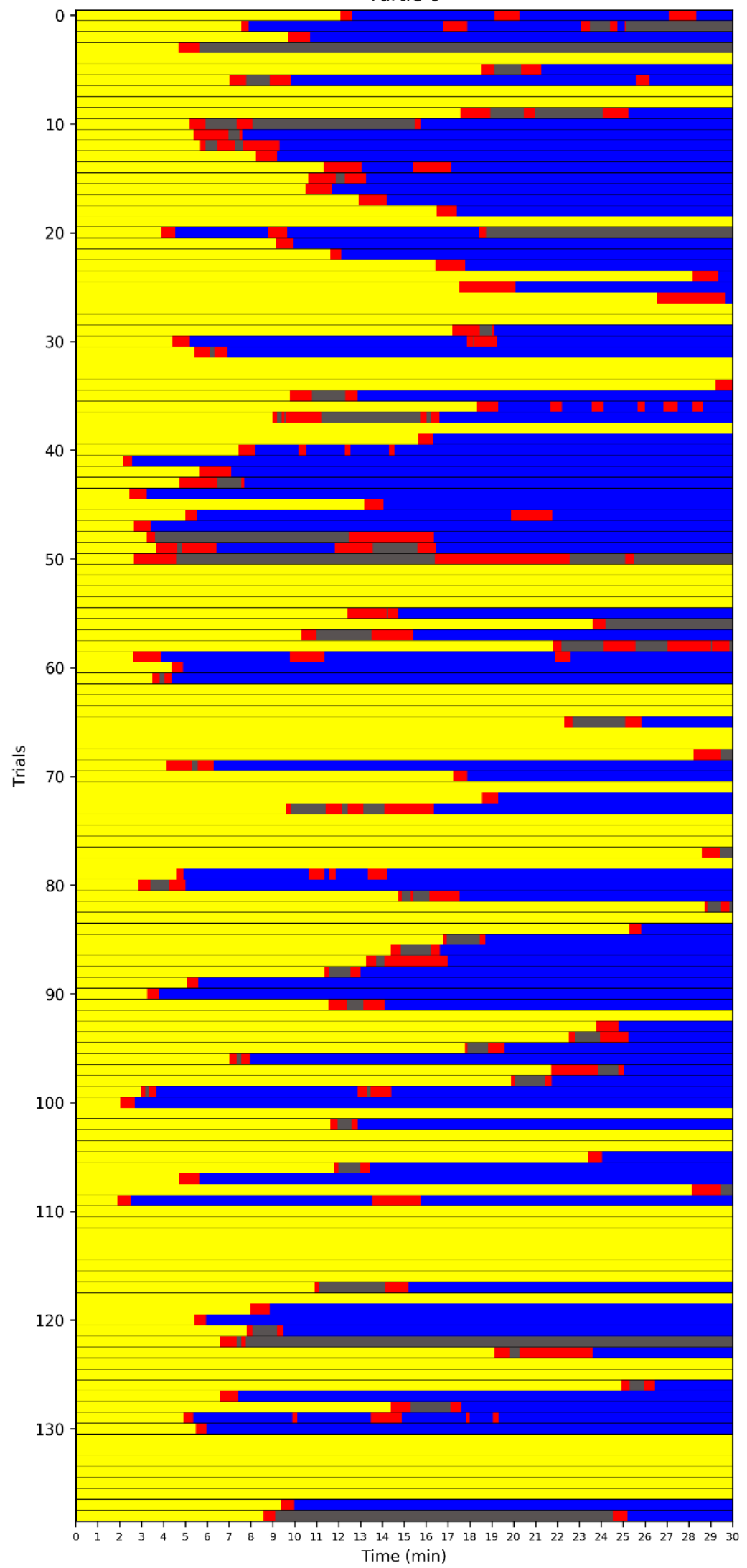


Turtle 7

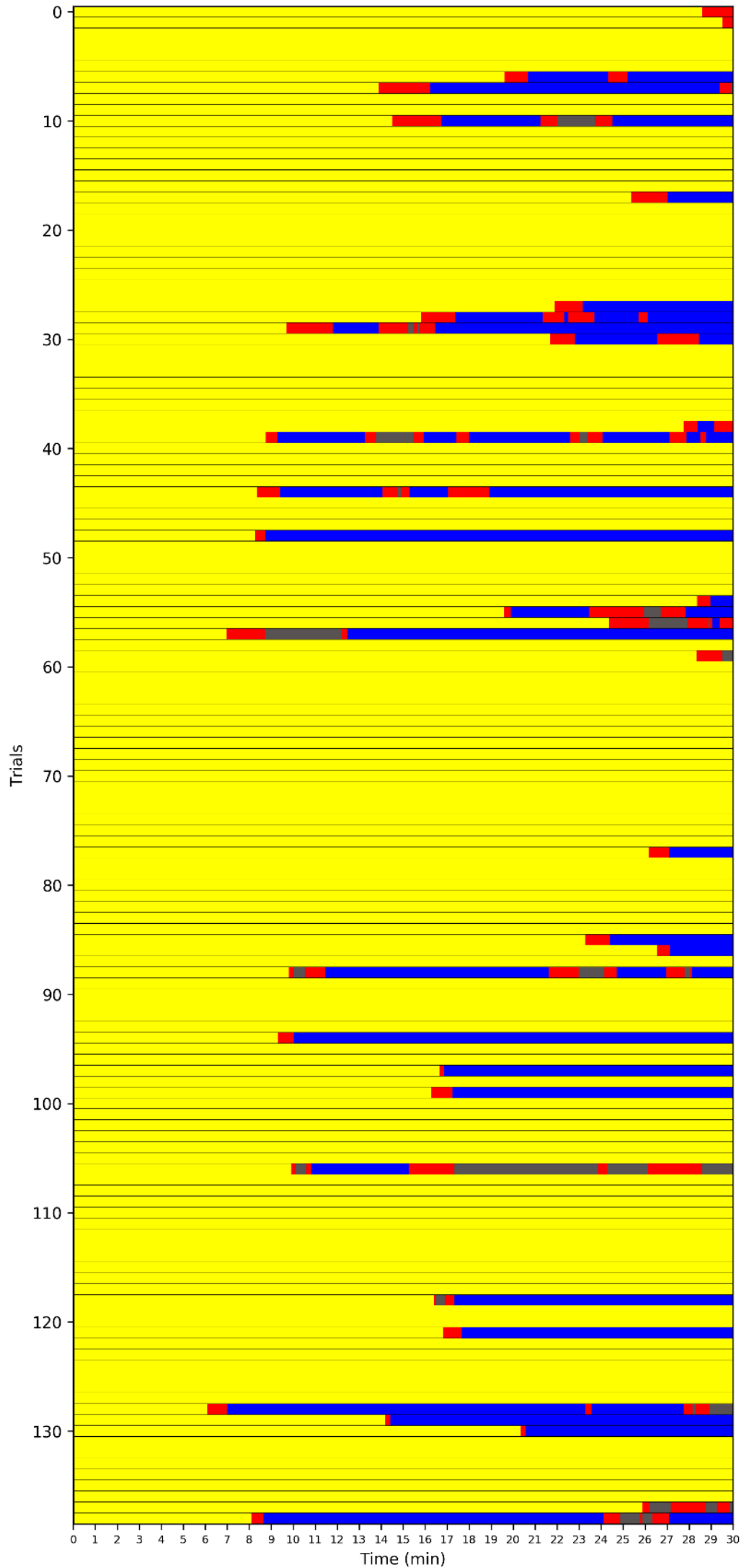

Time (min) 
Turtle 8

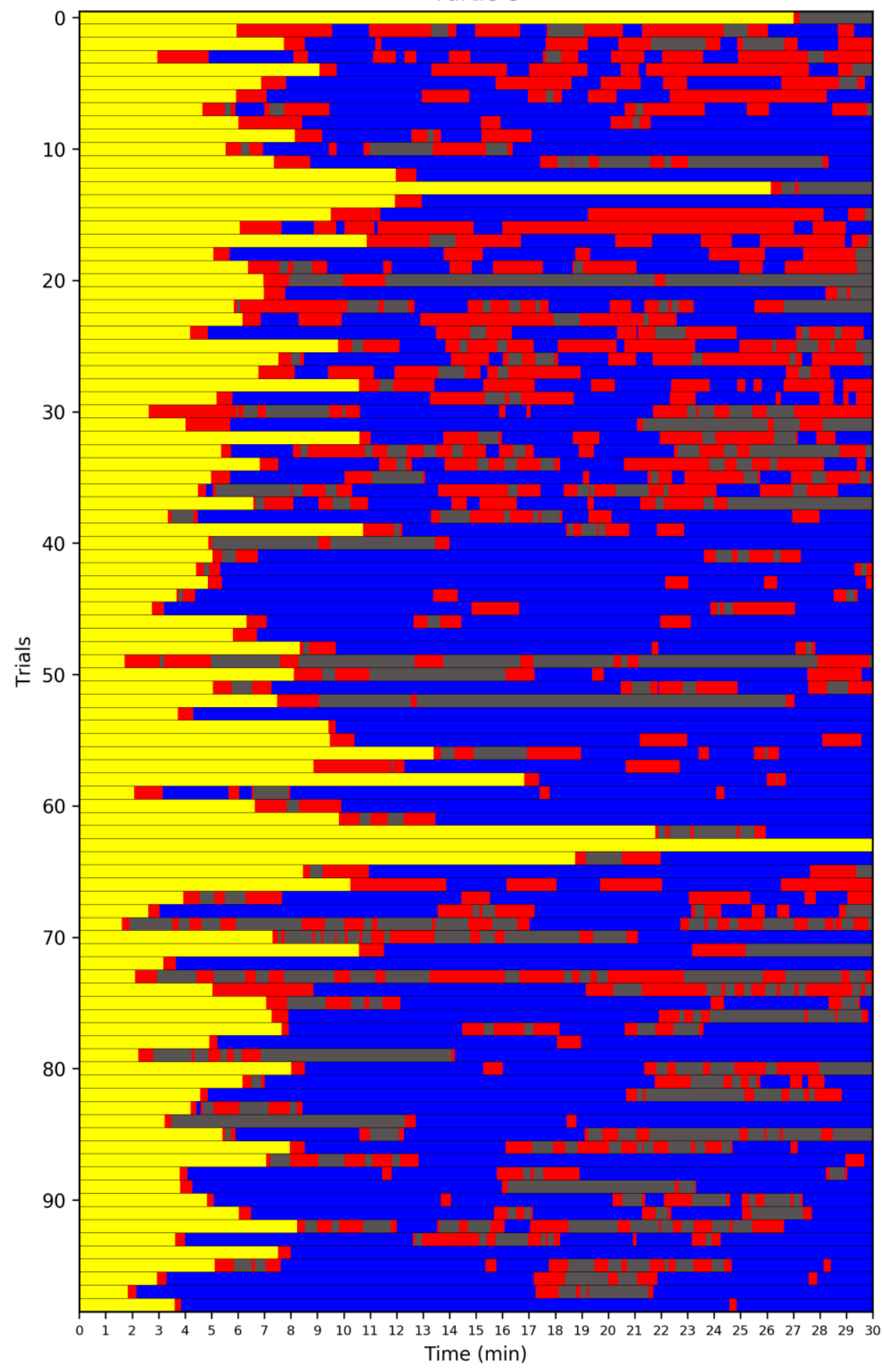


Turtle 9

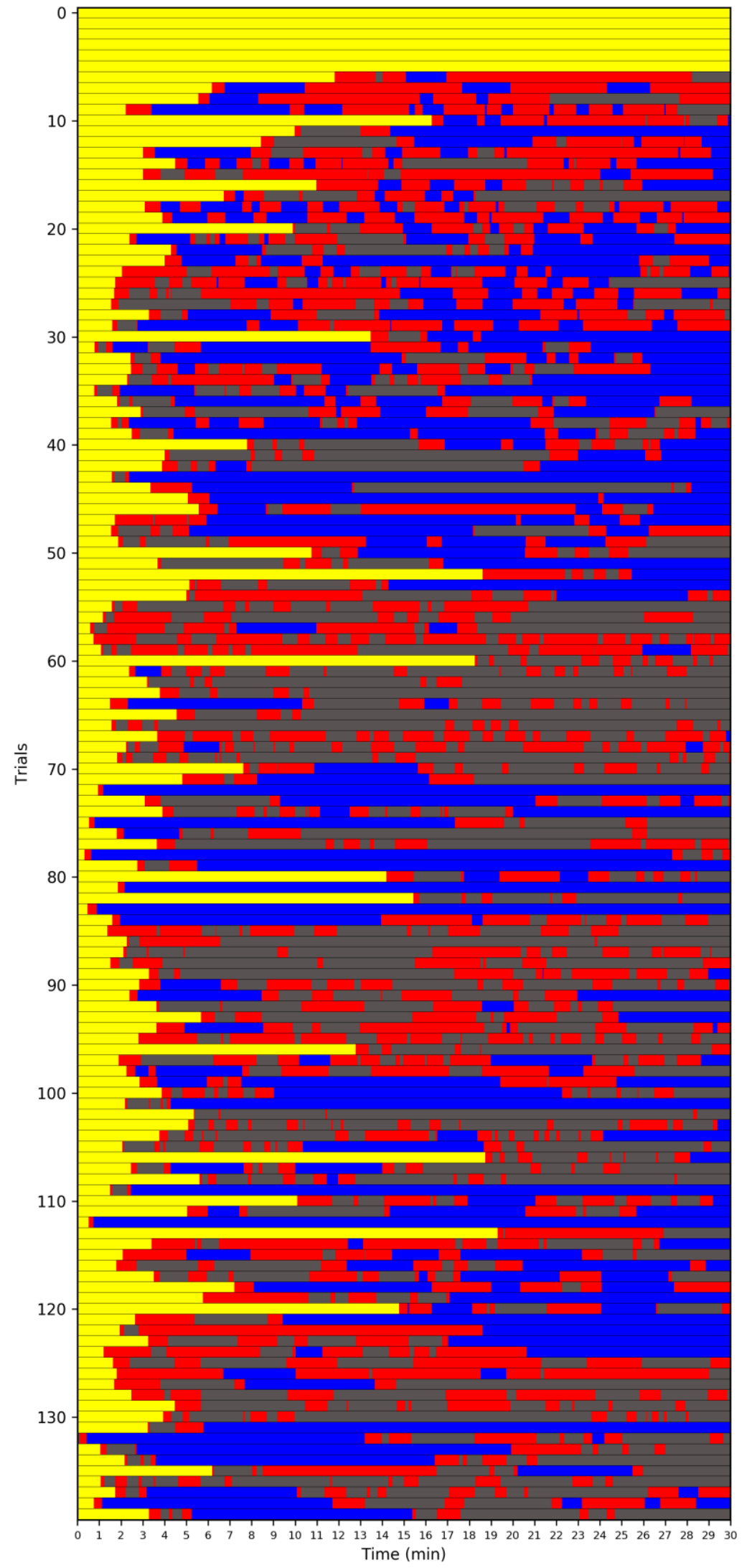


Turtle 10

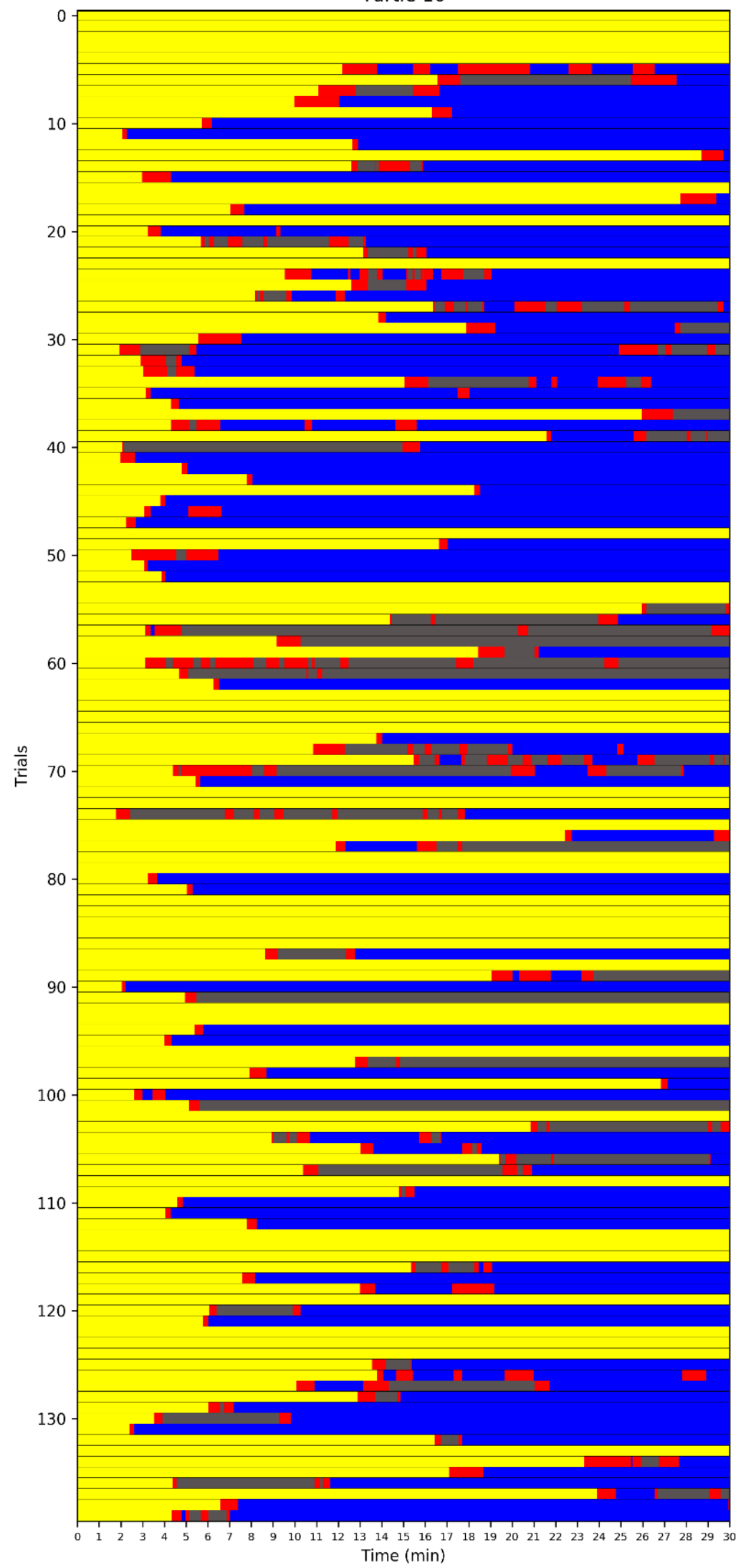


Turtle 11

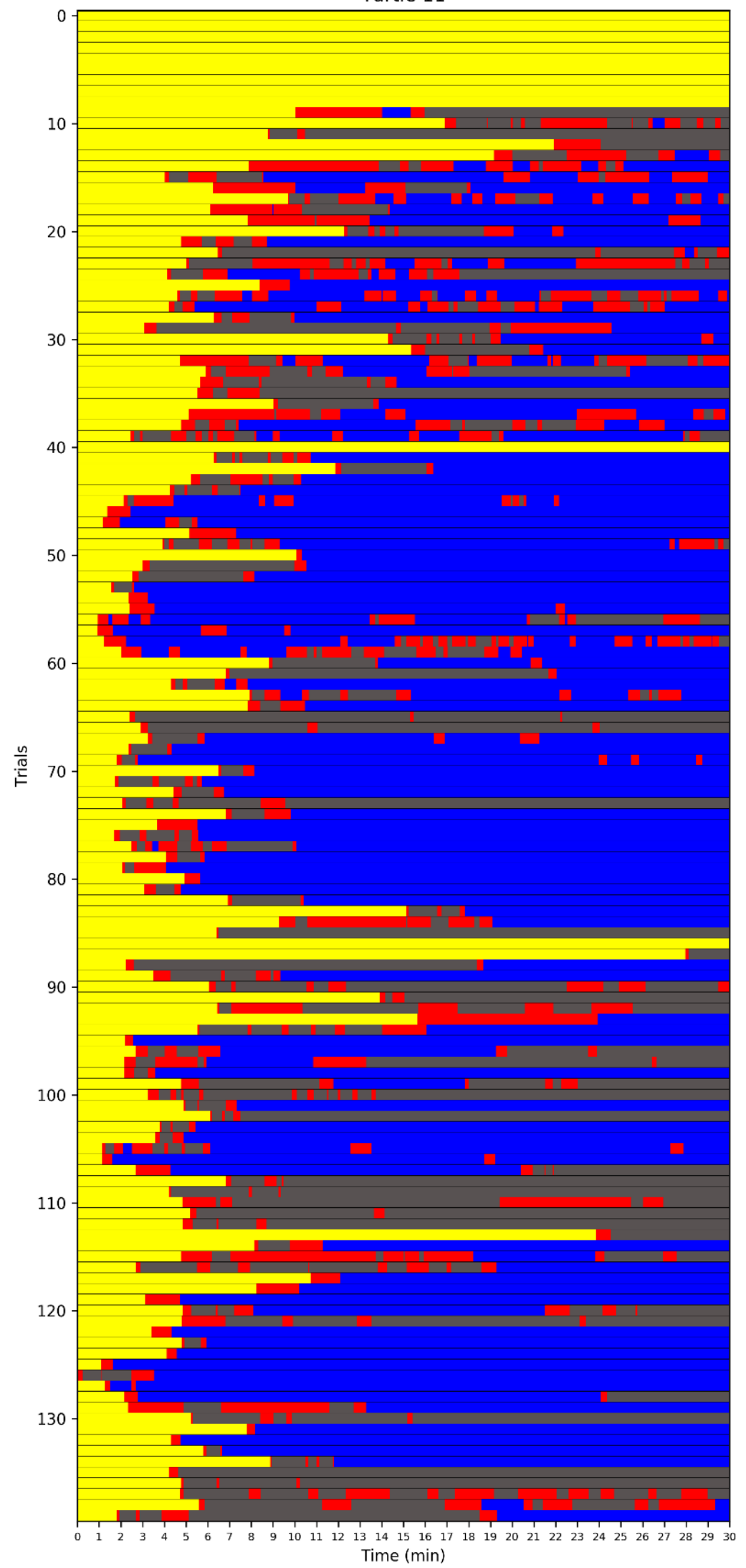


Turtle 12

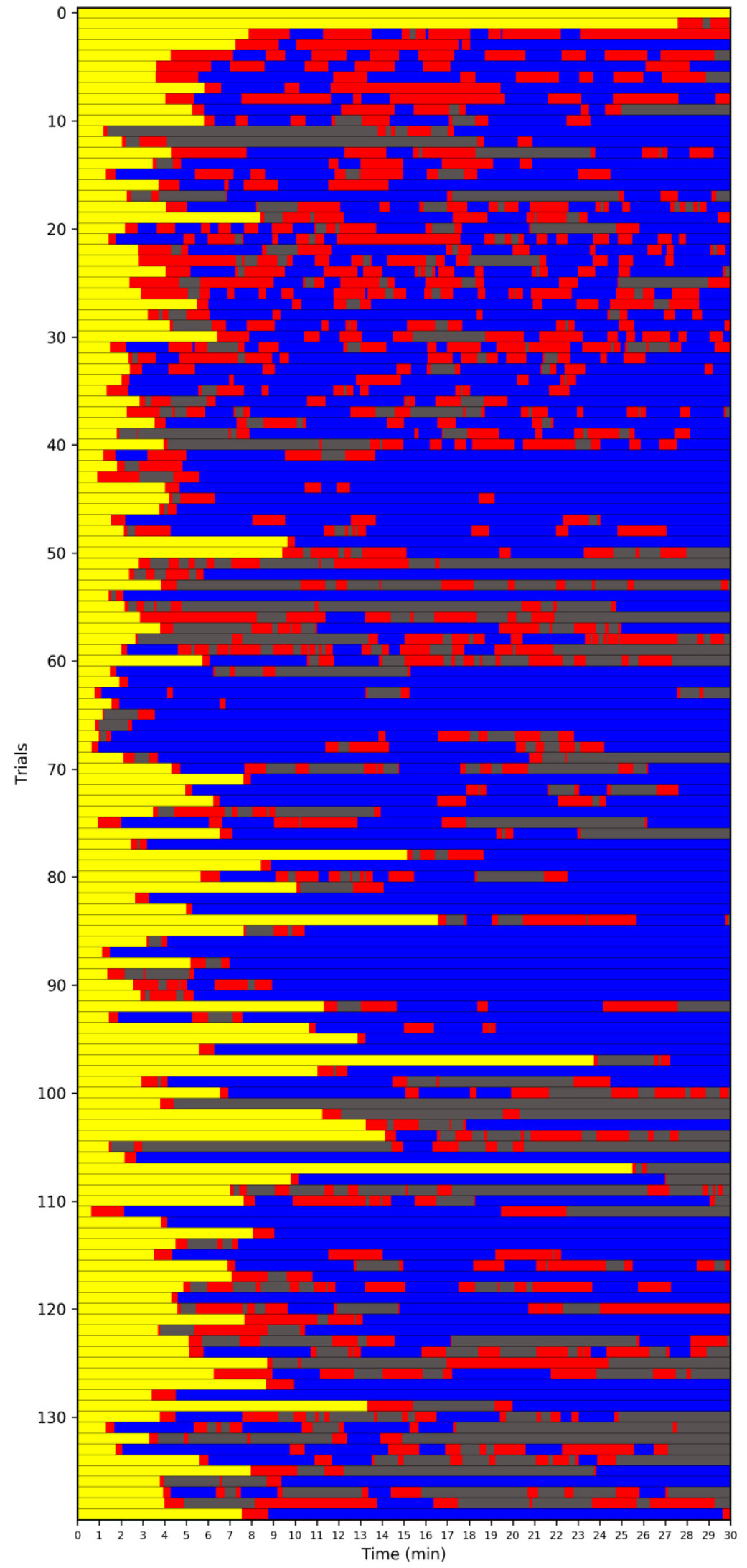


Turtle 13

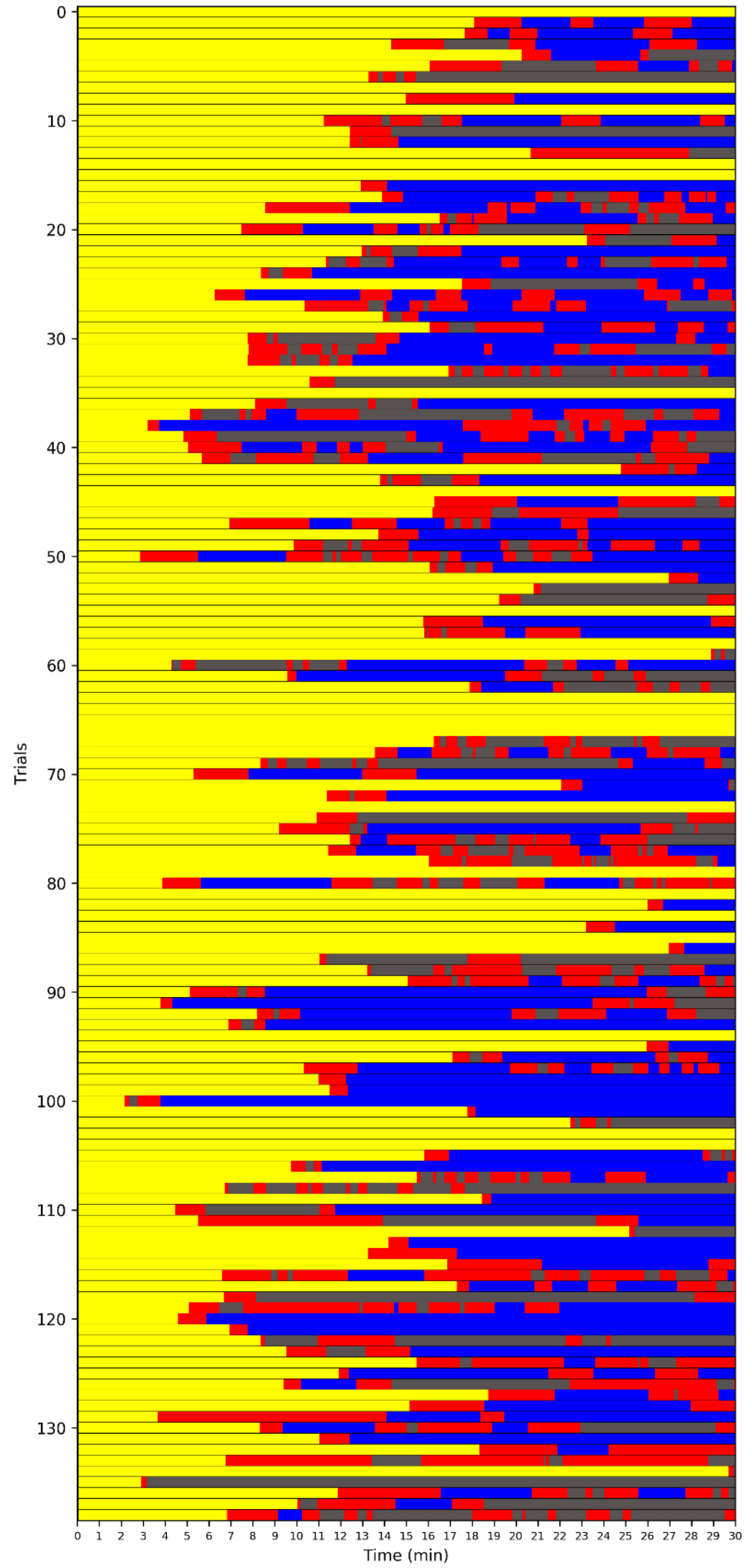


Turtle 14

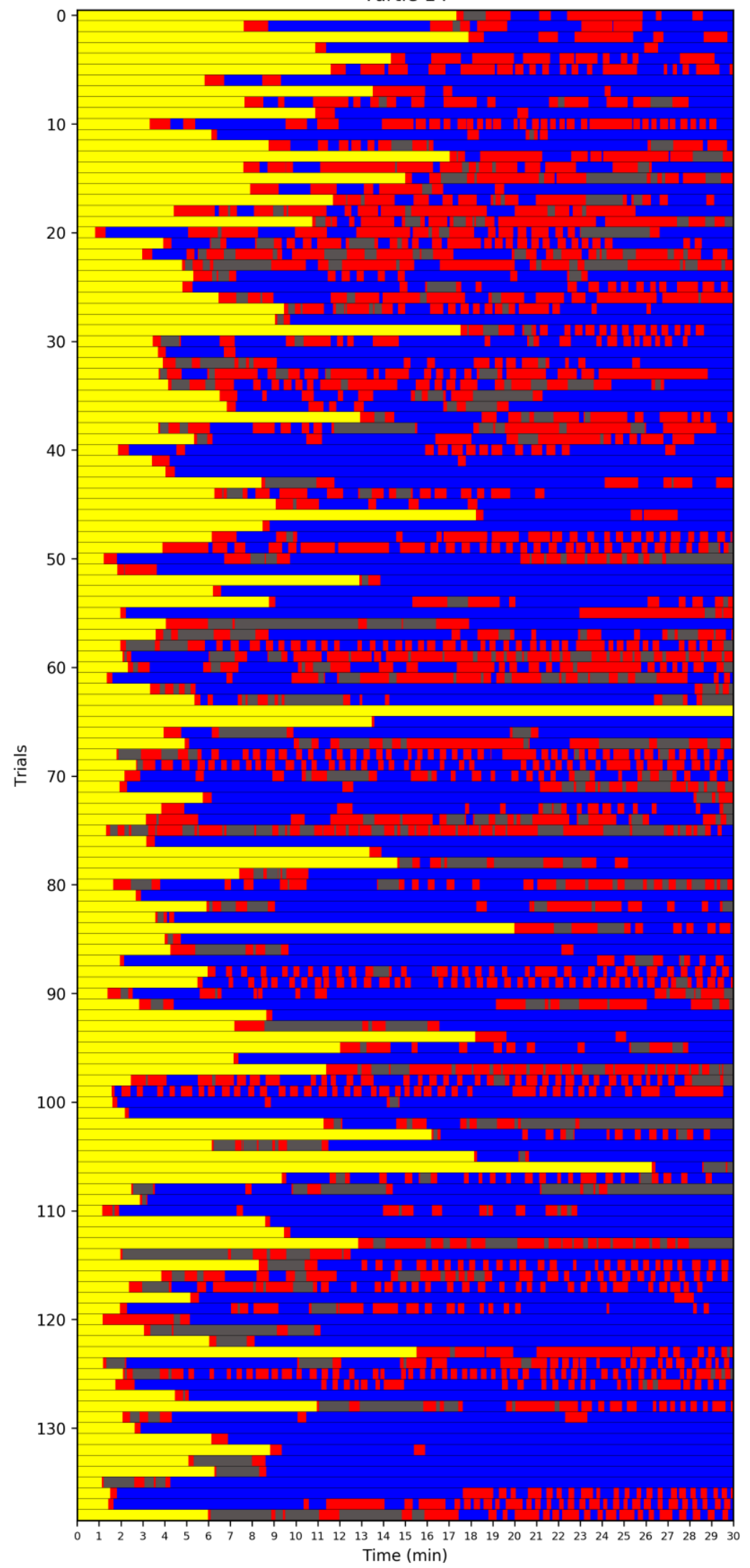




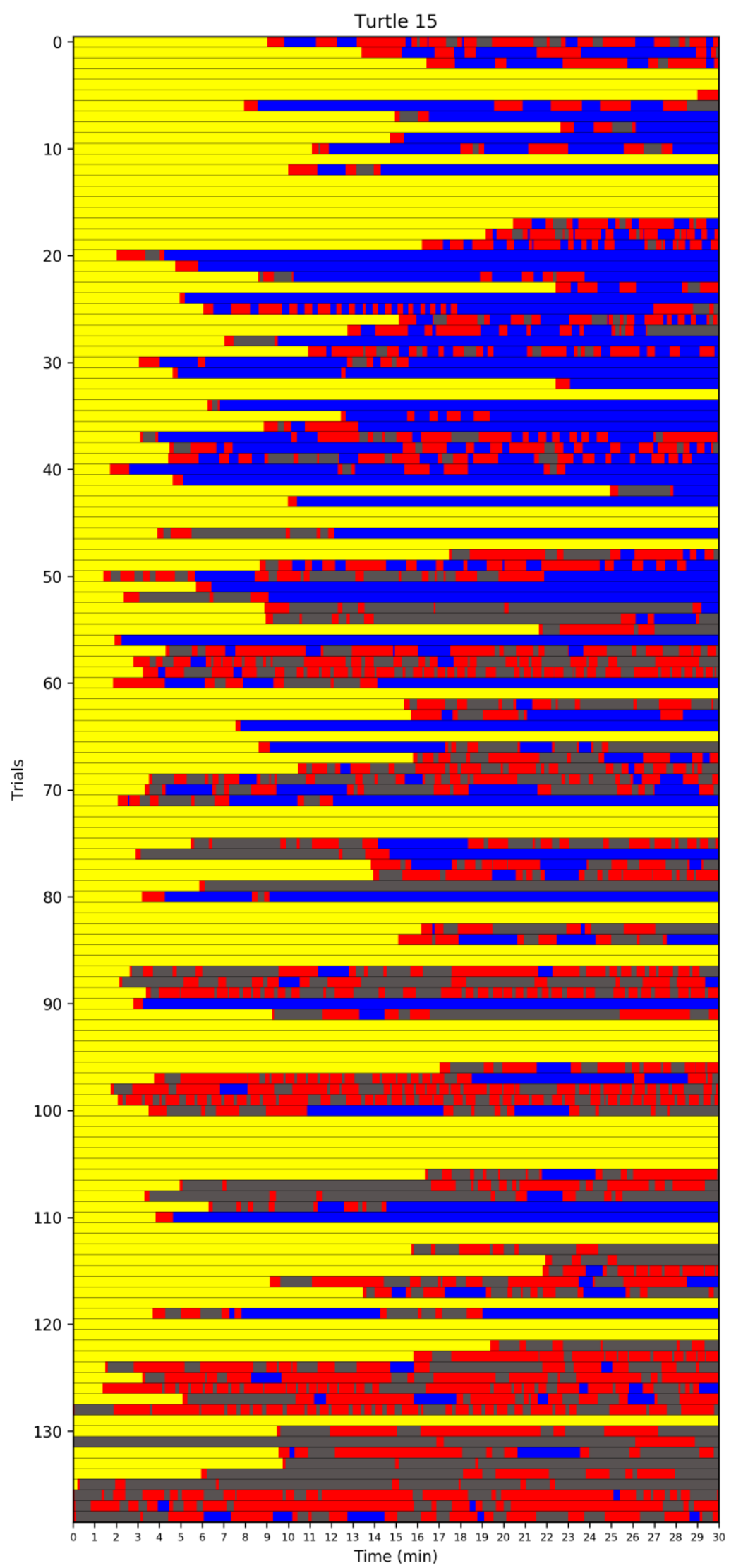


Turtle 16

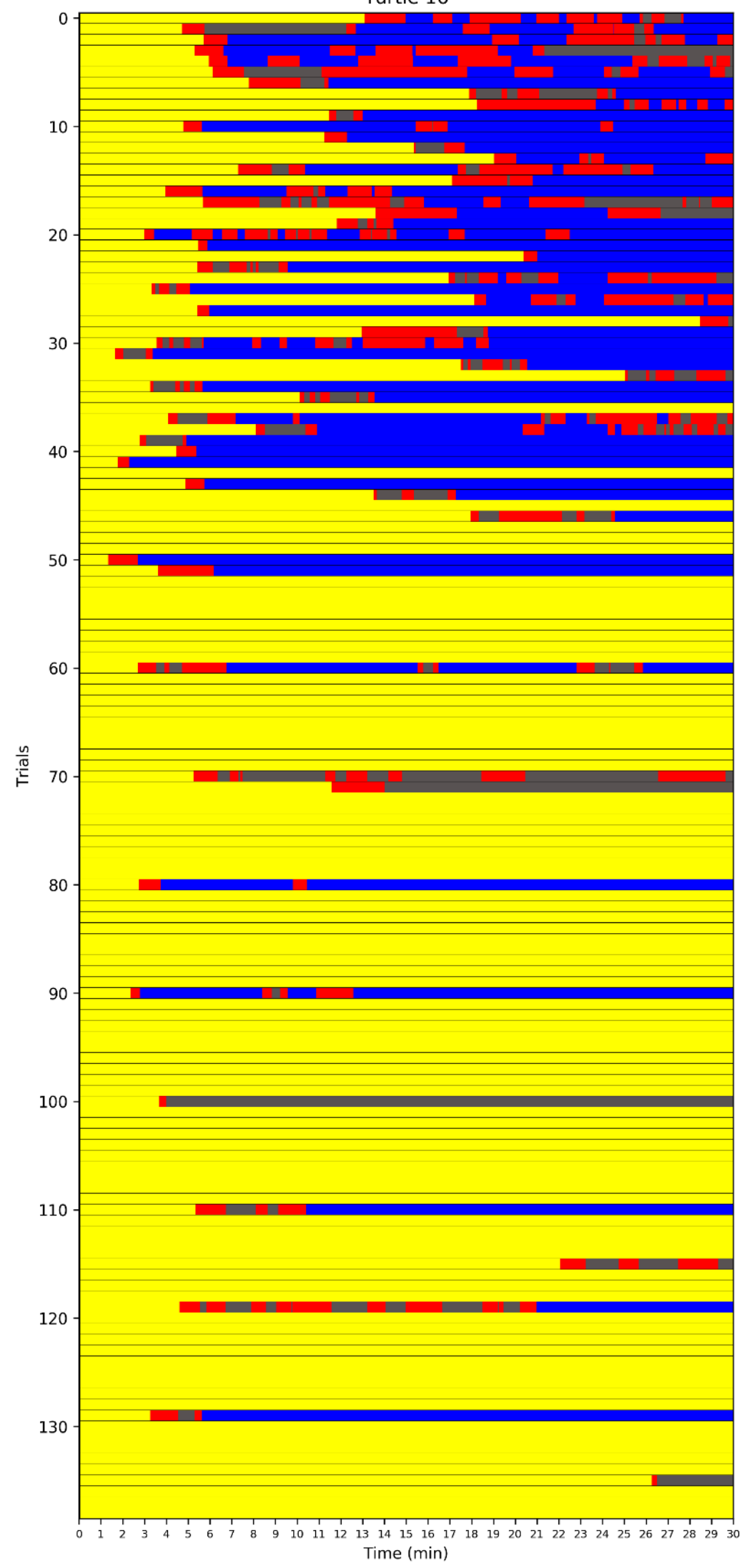


Turtle 17

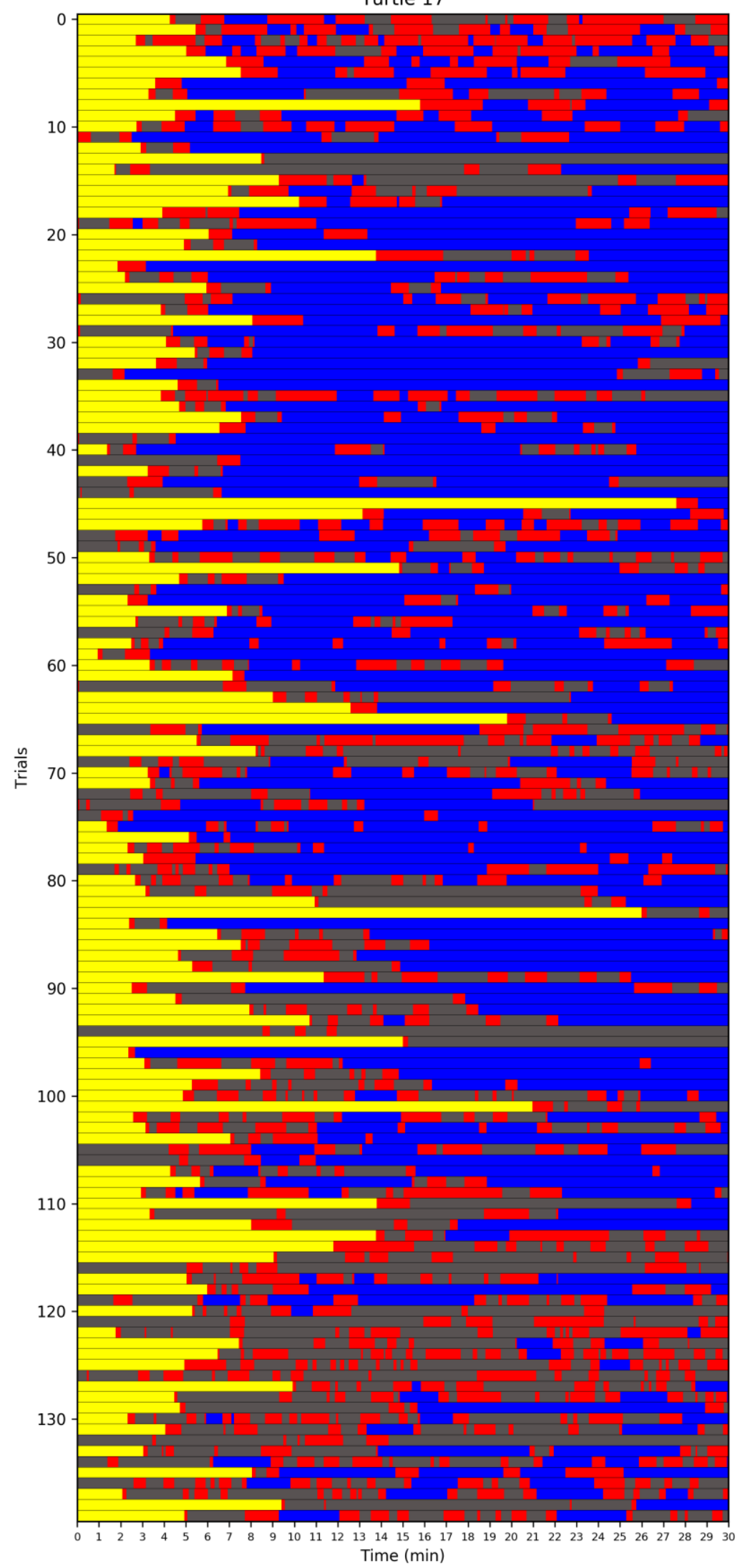


Turtle 18

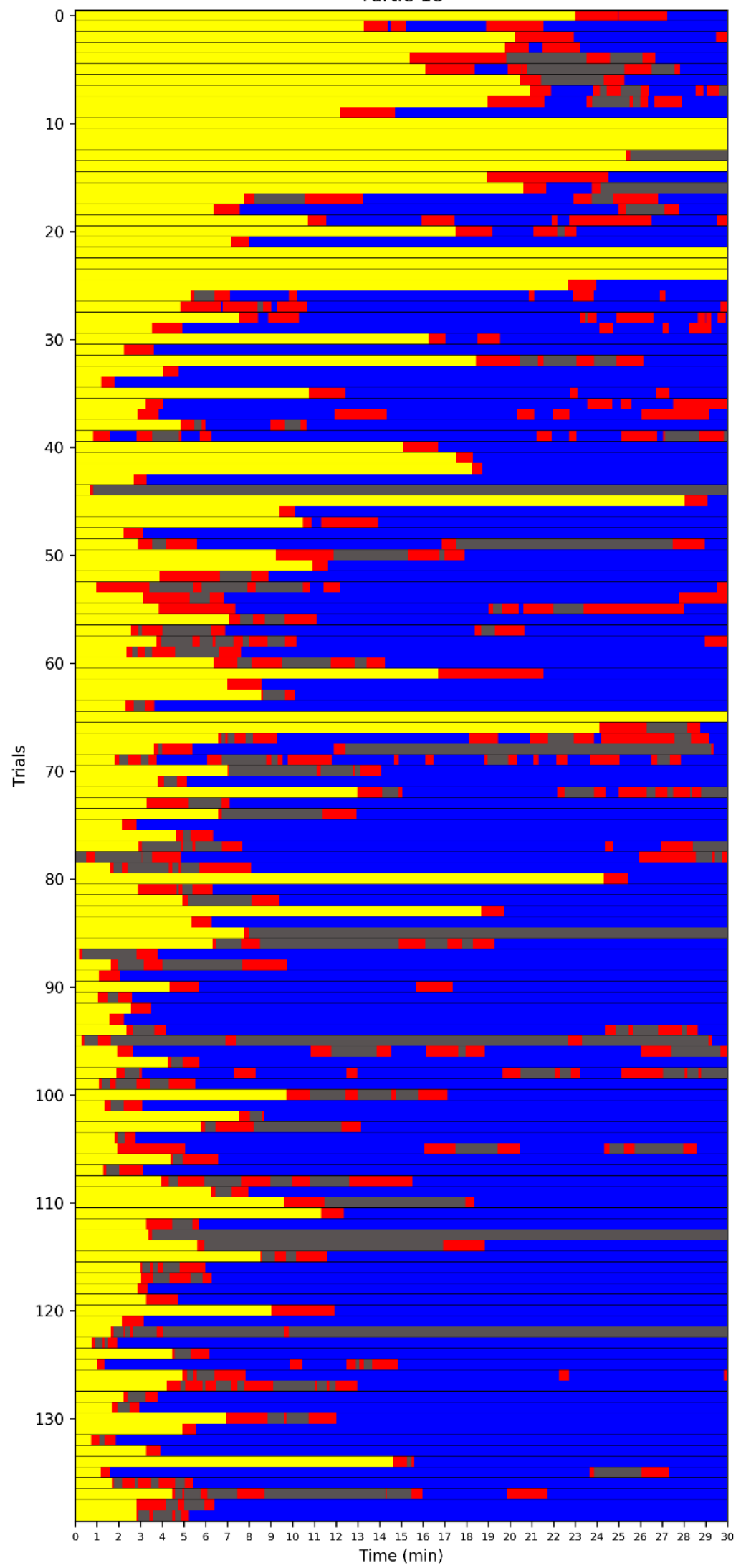


Turtle 19

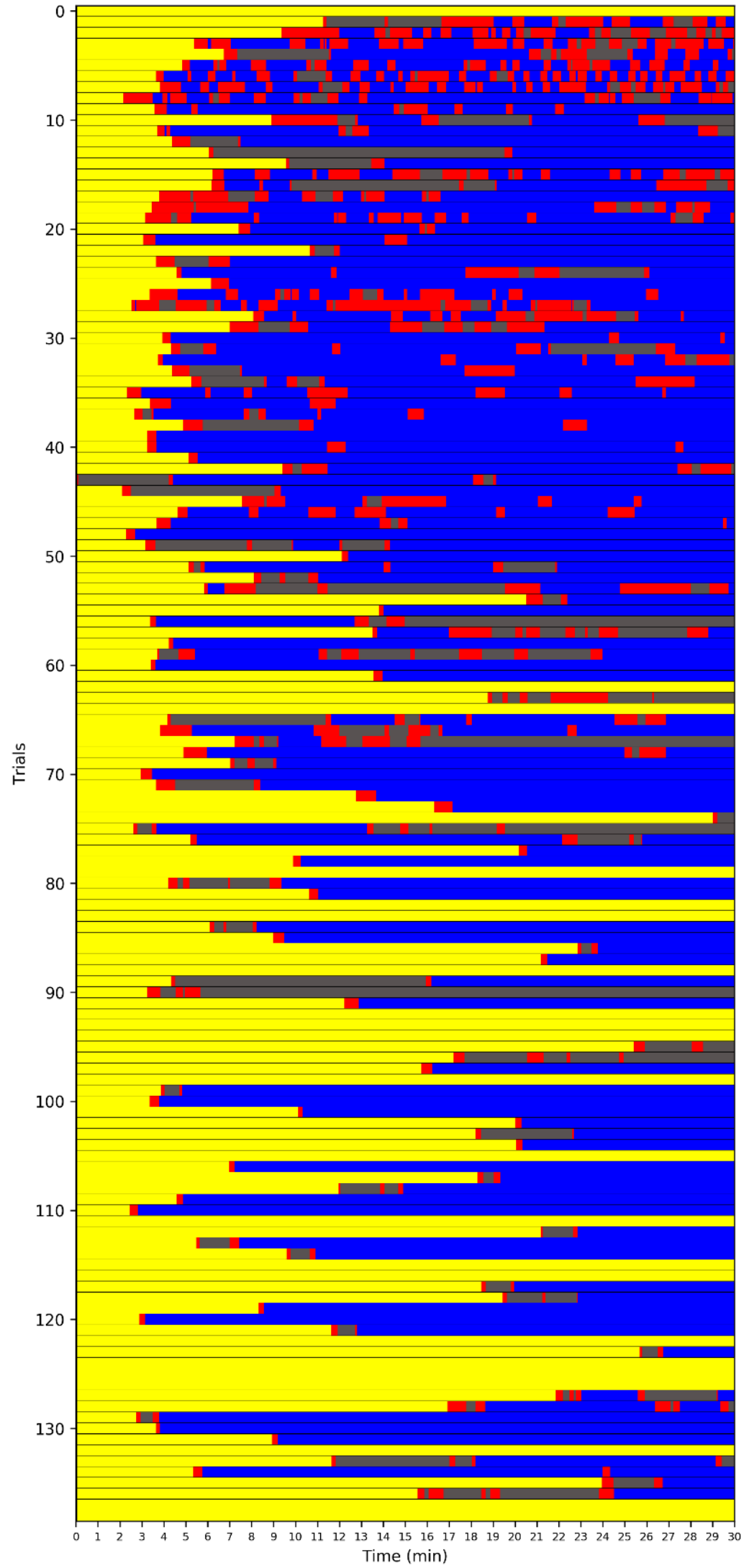


Turtle 20

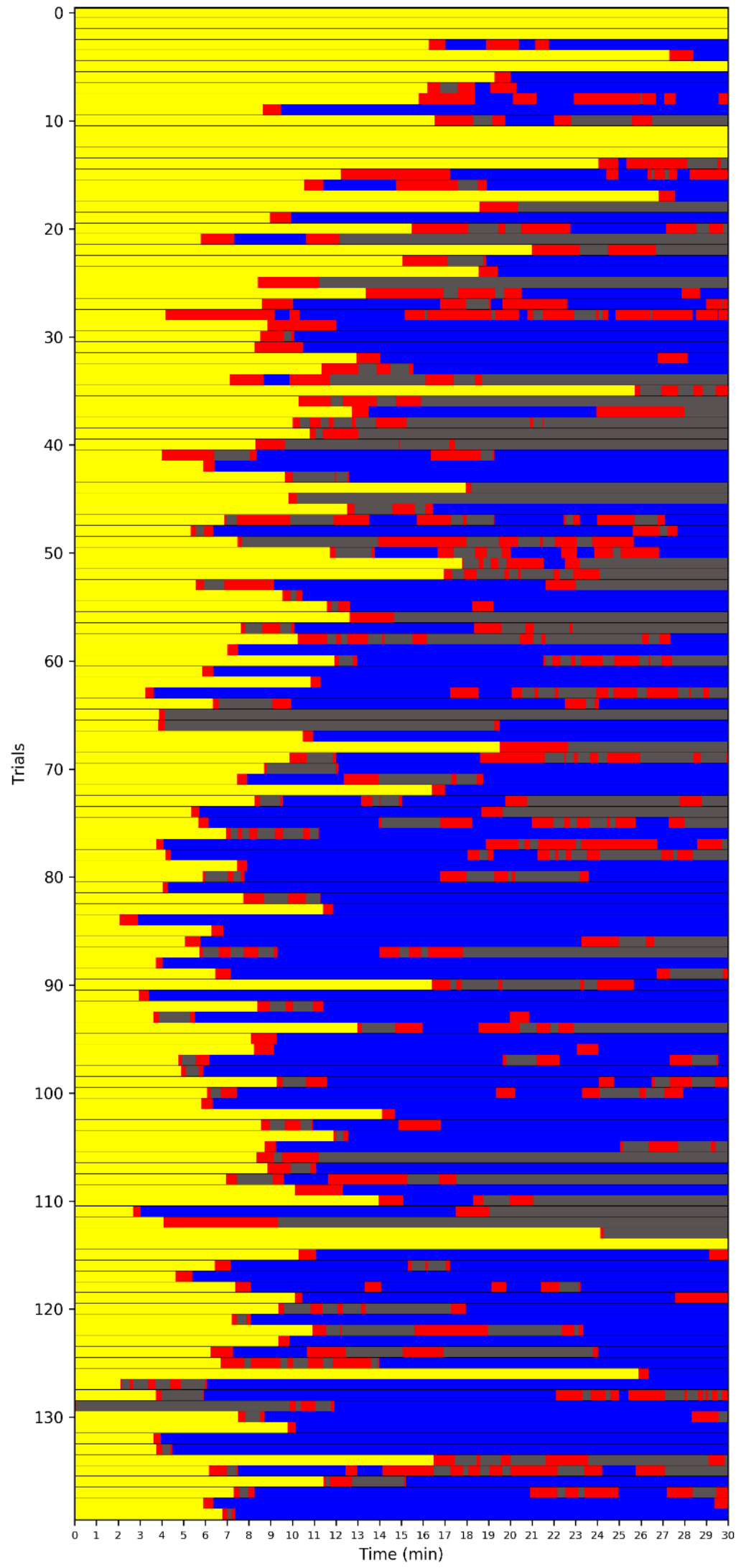


Turtle 21

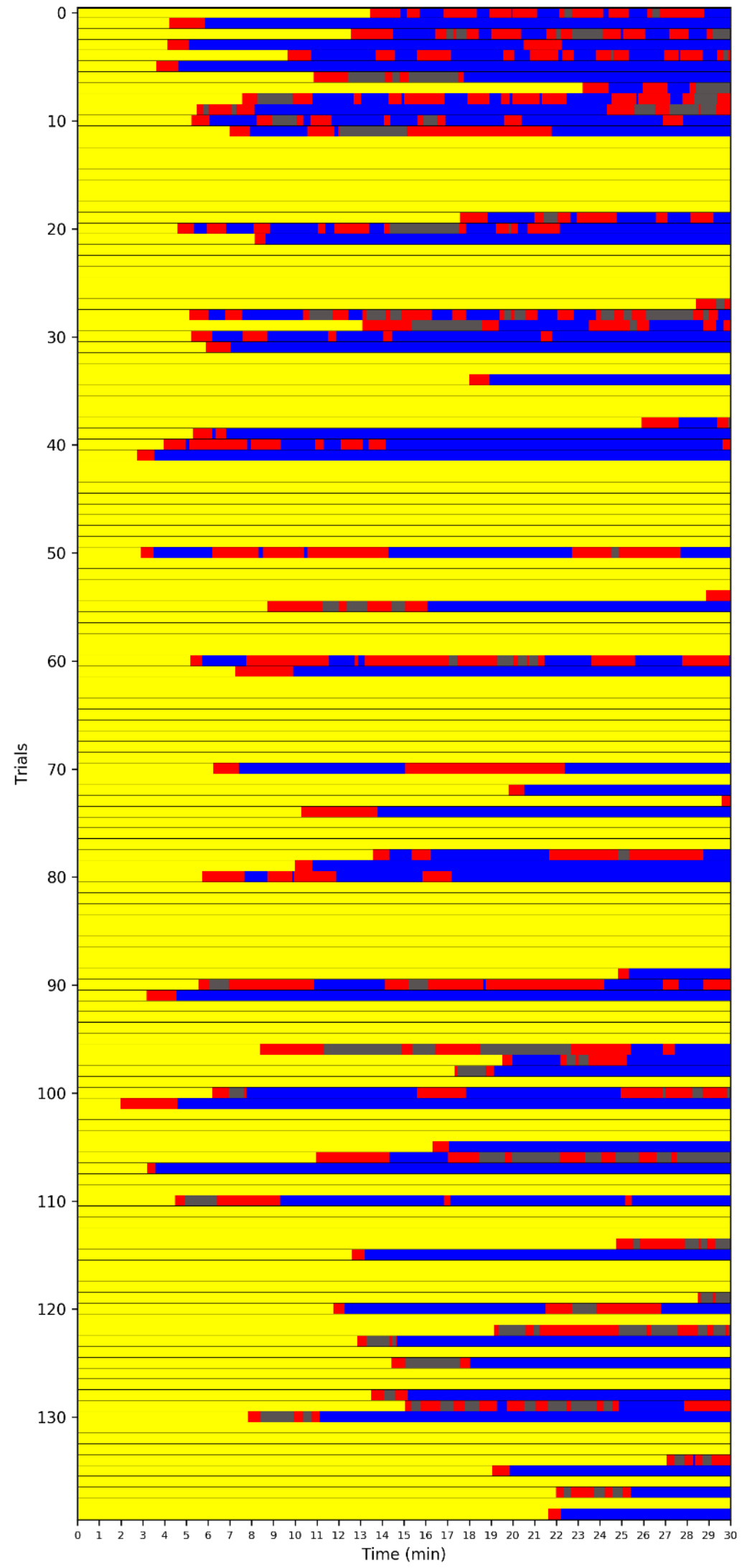


Turtle 22

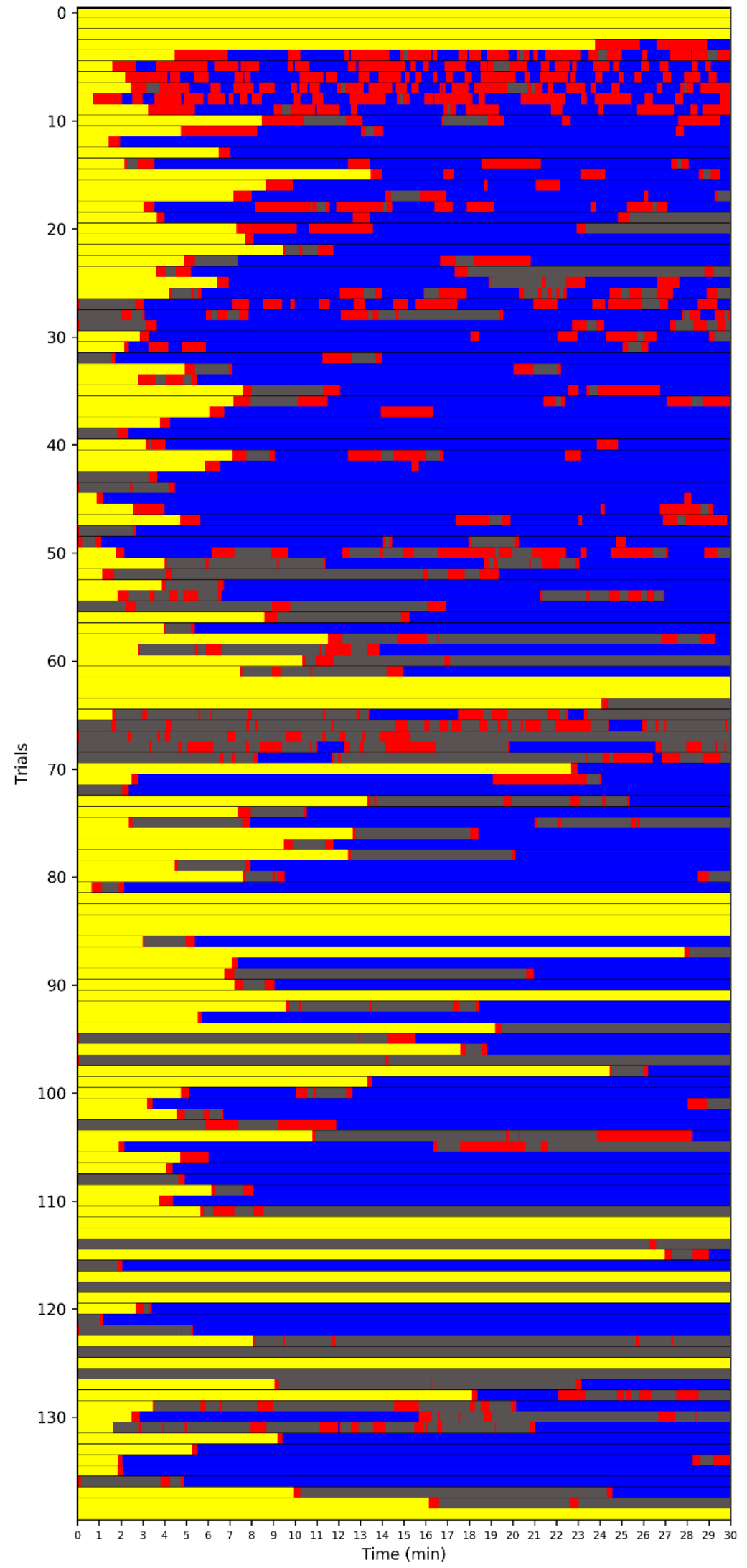


Turtle 23

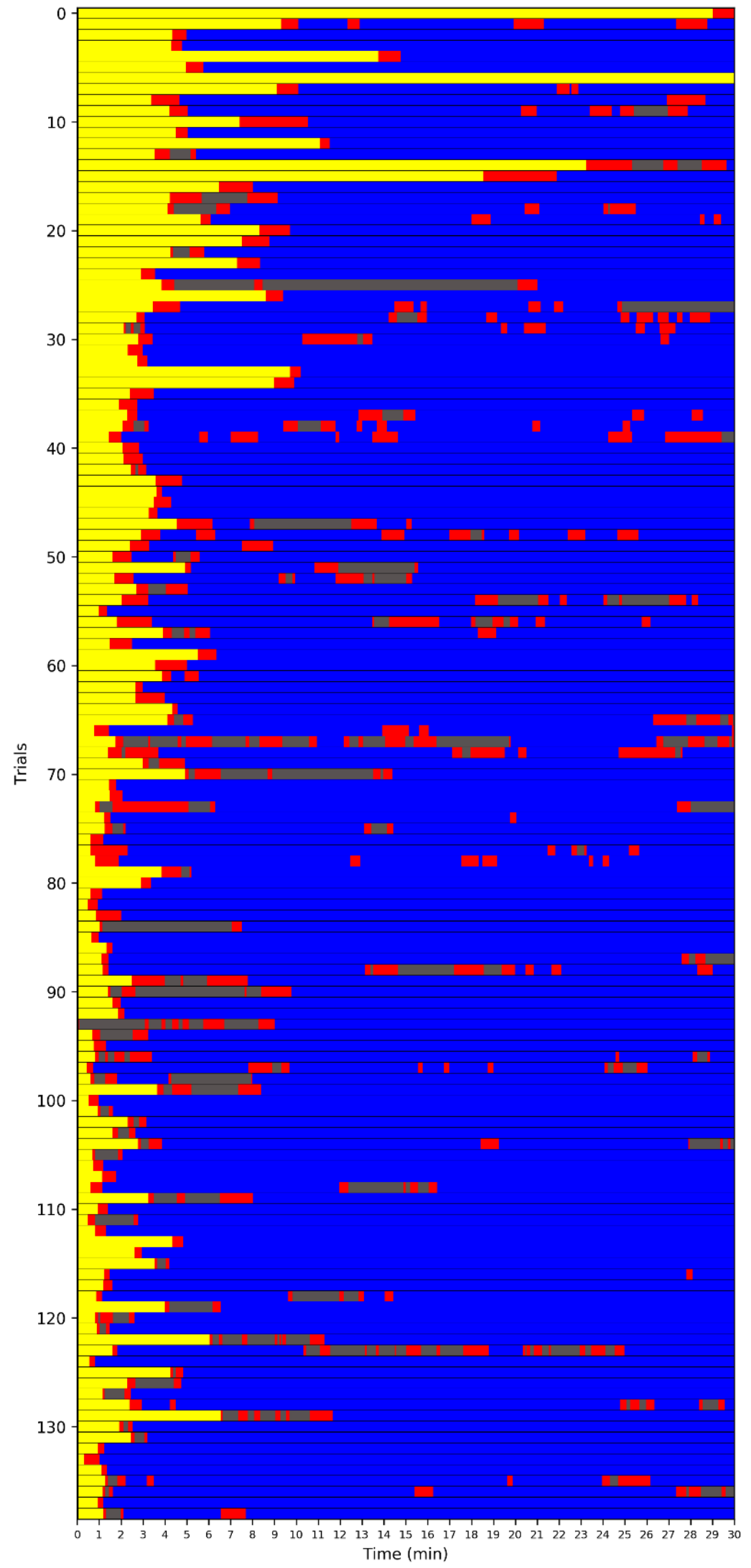


Turtle 24

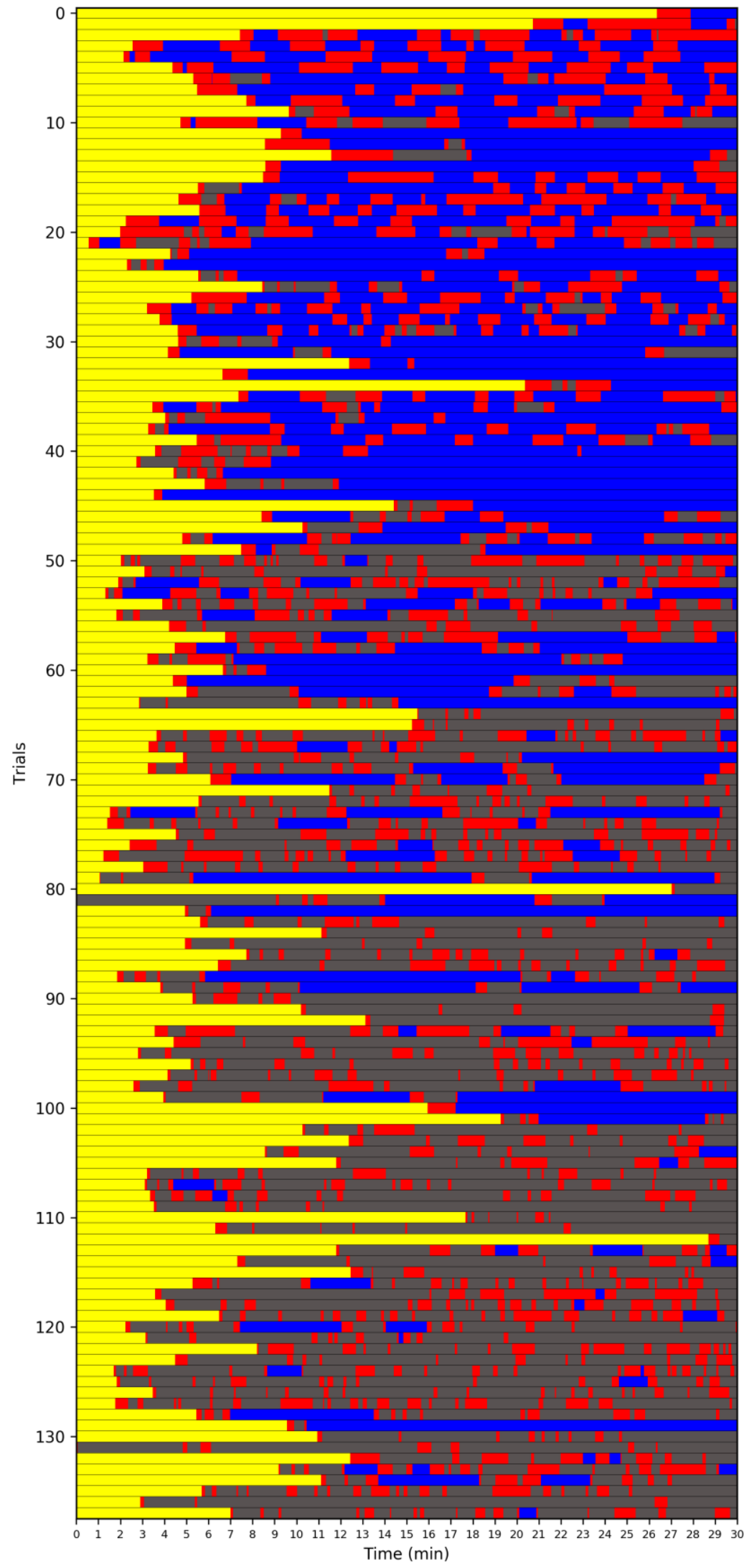


Turtle 25

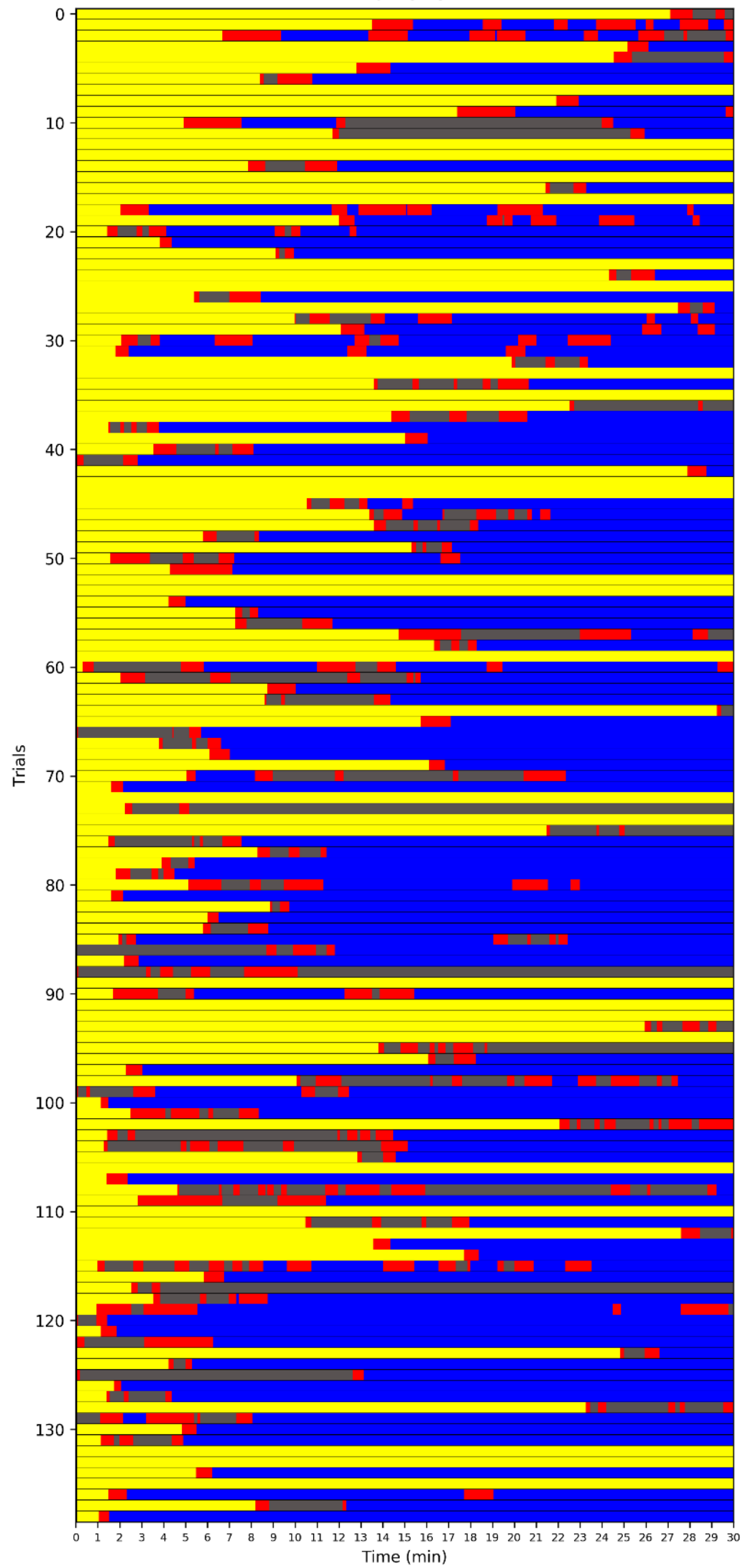

Time (min) 
Turtle 26

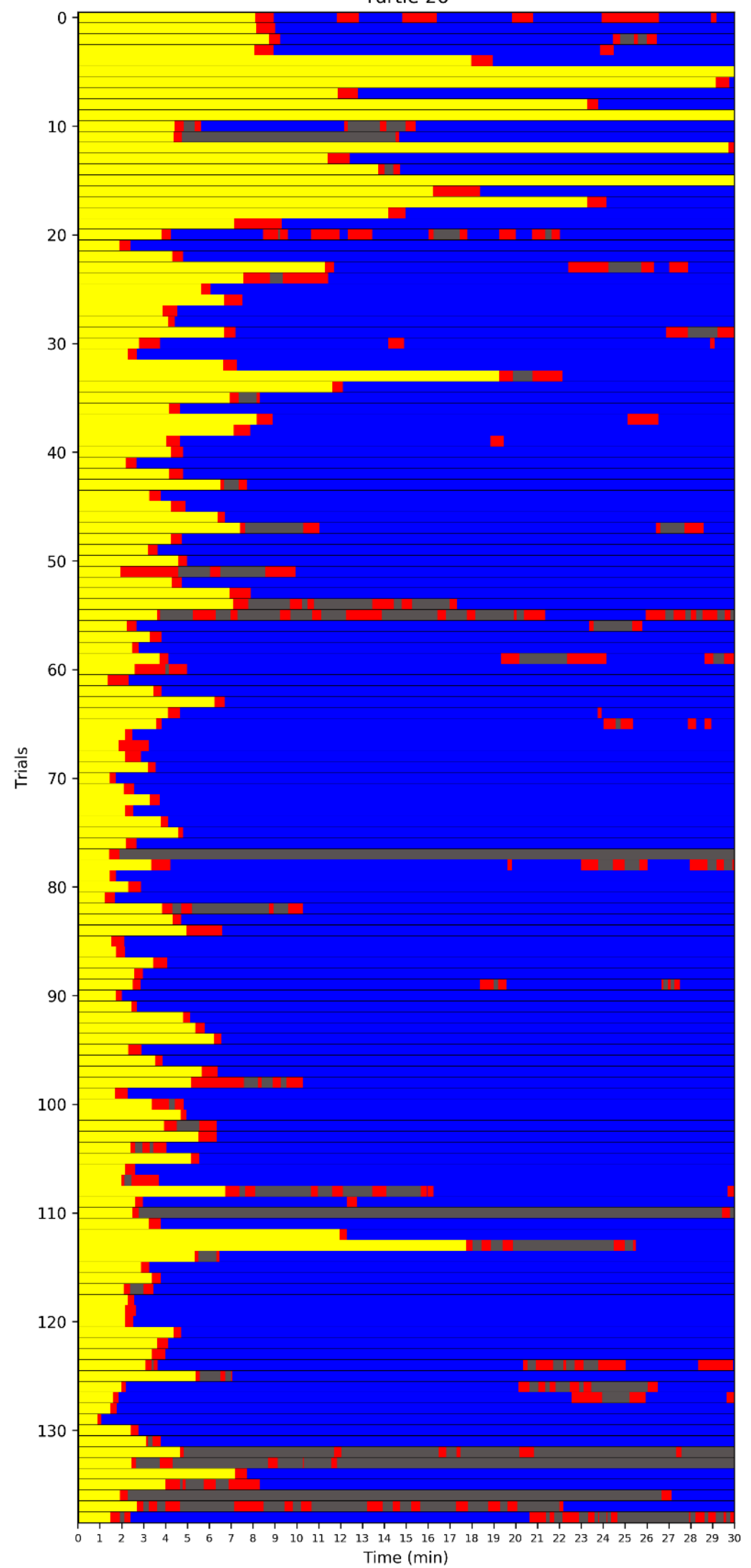


Turtle 27

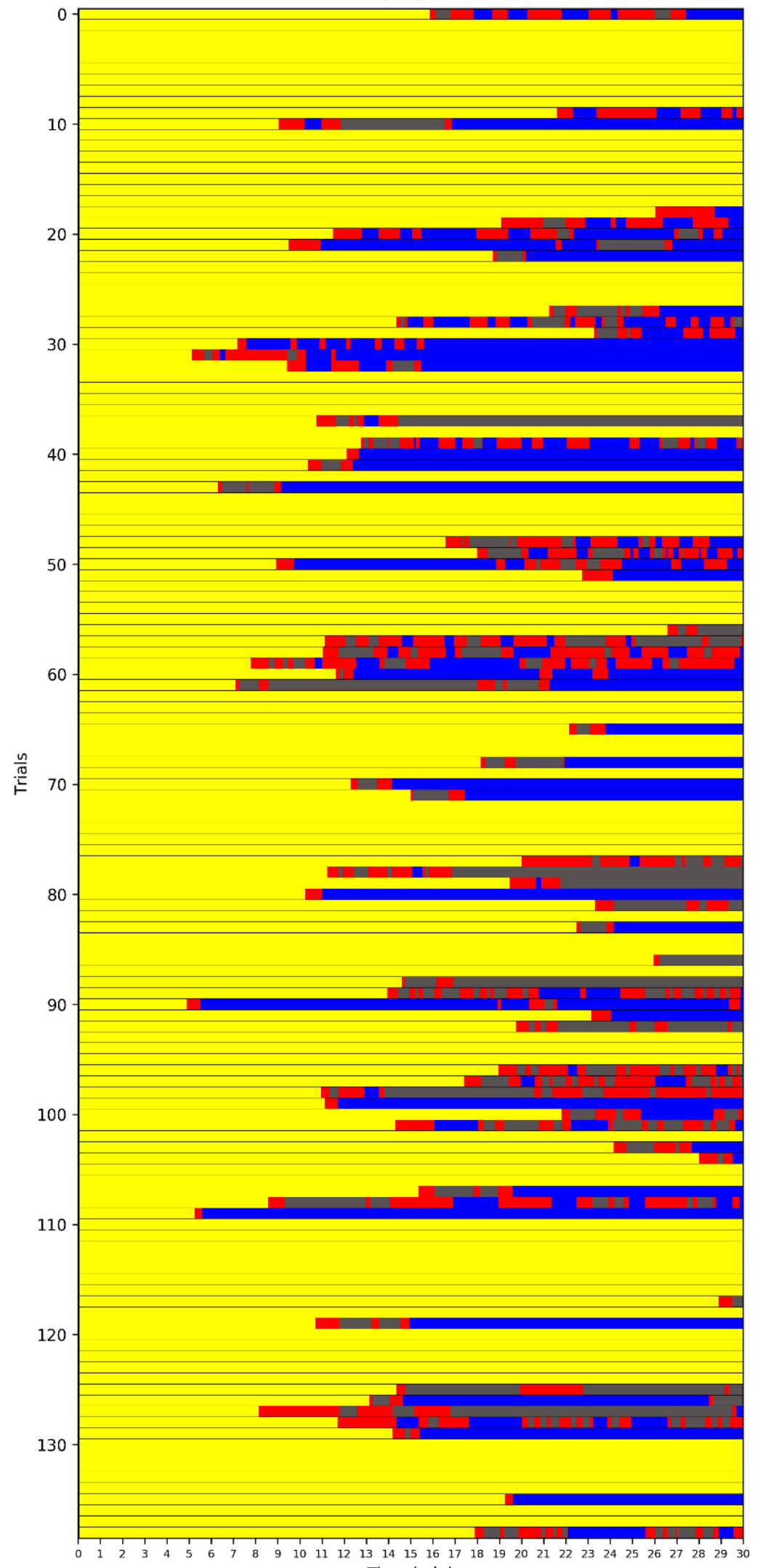

Time (min) 
Turtle 28

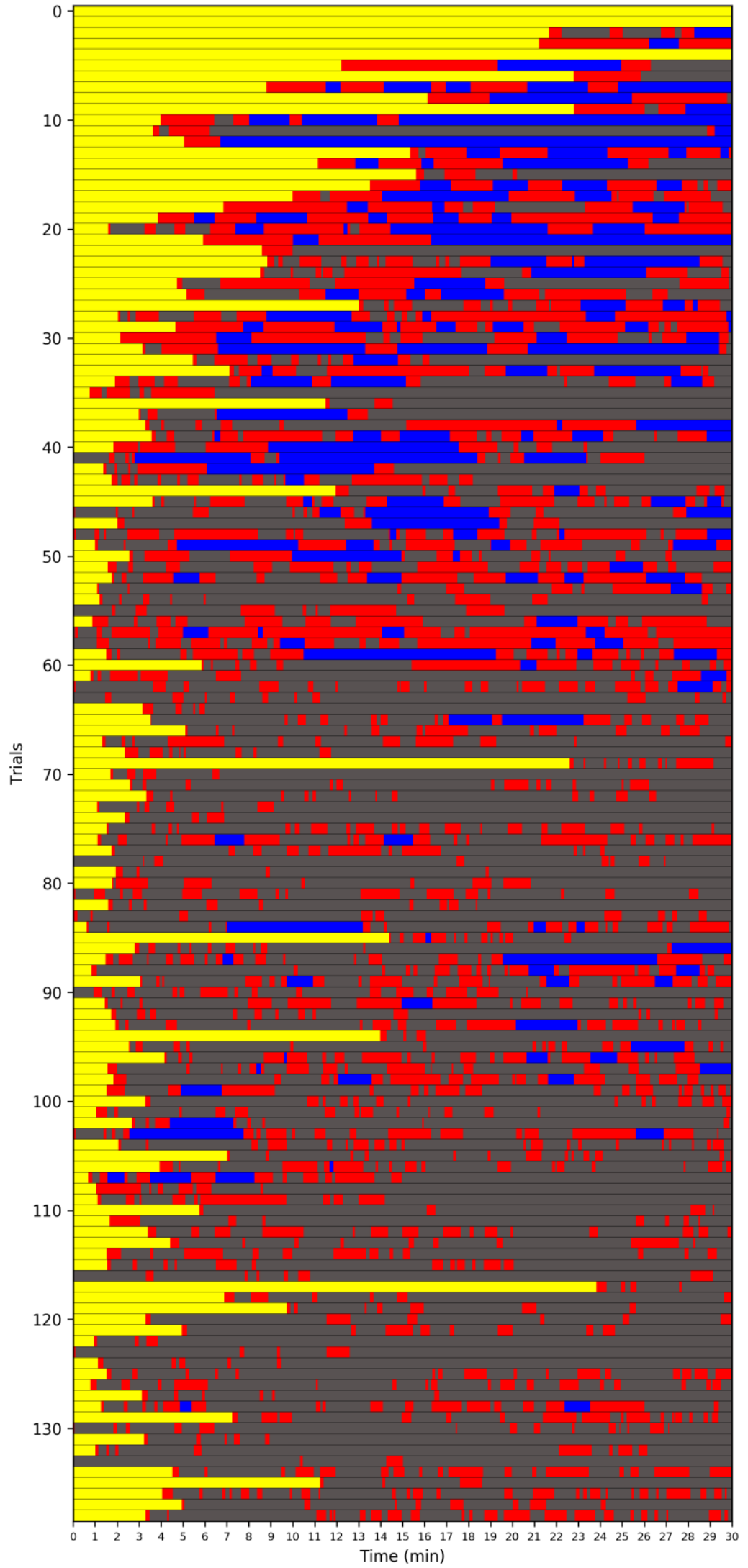


Turtle 29

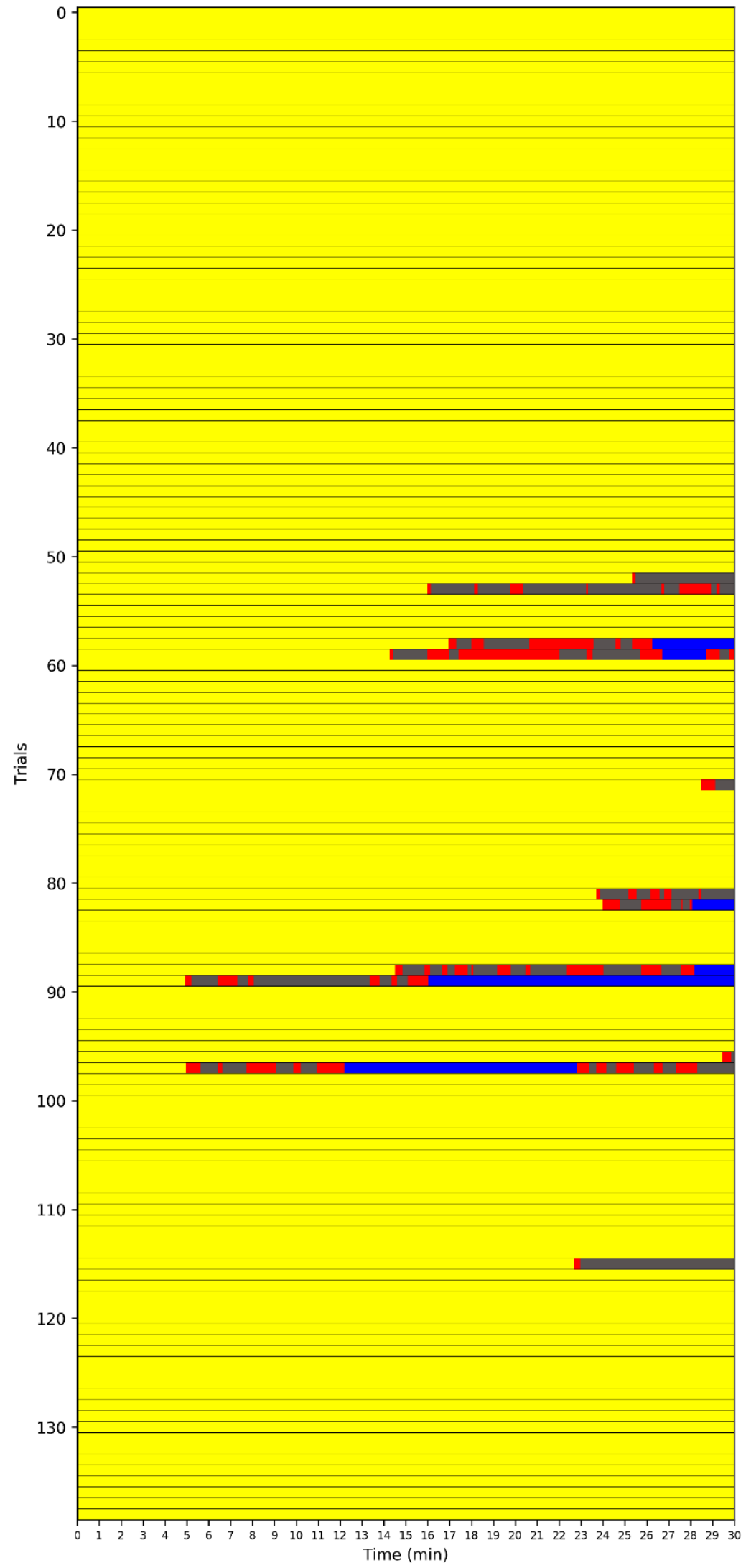




\section{APPENDIX B: PILOT STUDY OF REWARD STIMULII}

After hatching, we conducted a pilot study with a subset of hatchlings from the same clutches and treatments as our focus animals to compare reward stimuli. Pilot hatchlings were not included in the final study. We originally sought to use food as our reward stimulus within maze arms, as is common in navigational learning studies. We tested hatchling interest in various foods, including live and frozen chironimid larvae ("bloodworms"), dried Pyralidae larvae (“waxworms"), and Tetra ${ }^{\circledR}$ ReptoMin ${ }^{\circledR}$ floating aquatic turtle food sticks. We tested all foods individually, where we offered each hatchling one of the food options for 24 hours in their individual cups. Feeding was rare, and no hatchling ate a food item for more than 2 consecutive days, suggesting that food would not serve as a reward stimulus for all hatchlings for the duration of the experiment. This is not necessarily surprising, as T. scripta hatchlings from our field site overwinter in the nest while persisting off of yolk reserves. We observed similar lack of feeding when food was offered within the T-mazes. Once we decided to omit food as a reward stimulus, we offered a frozen bloodworm daily to all experimental hatchlings for the duration of the experiment.

We next assessed the possibility of using a shelter reward stimulus, by monitoring hatchling response to a conspicuous shelter covering one entire arm of the T-maze. We video monitored non-experimental hatchlings in T-mazes with the conspicuous cardboard shelter in either arm of the maze (to correct for potential direction bias) and found that hatchlings spent more time under the shelters and more frequently chose the shelter over the empty arm (data not shown). During this period of our pilot observations, we also found that 30 -minute trials were sufficient time for a majority of hatchlings to make an arm decision, and that 5 consecutive days 
of trials were sufficient to promote trial participation (i.e. movement) in a majority of the pilot hatchlings.

Based on our pilot data, we decided to move forward with overhead shelter as our reward stimulus to offer to our experimental hatchlings. Importantly, we constructed reduced size overhead shelters so that the shelter covered only the portion of the maze arm that was not visible until that arm was chosen (Fig 2). At the conclusion of the pilot study, we had 29 naïve hatchlings remaining (i.e. experimental hatchlings). 